\title{
Nanomole-scale assignment and one-use kits for determining the absolute configuration of secondary alcohols
}

\author{
Alexander J. Wagner, Shawn M. Miller, Ryan P. King, and Scott D. Rychnovsky* \\ Department of Chemistry, 1102 Natural Sciences II, University of California, \\ Irvine, California 92697-2025 \\ srychnov@uci.edu
}

\section{SUPPORTING INFORMATION}

\section{TABLE OF CONTENTS}



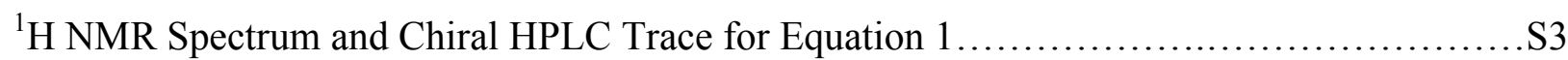

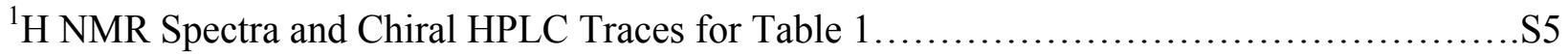

Experimental Data for Kinetic Resolution of $\mathbf{3}$ with other Salts.......................... 9

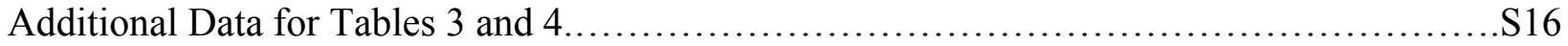

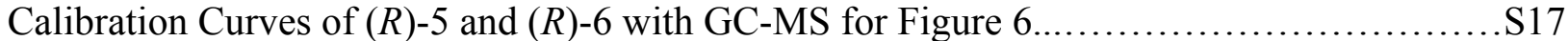

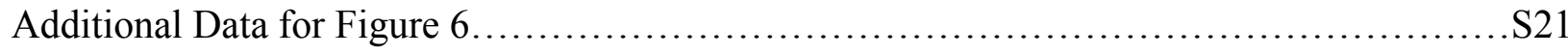

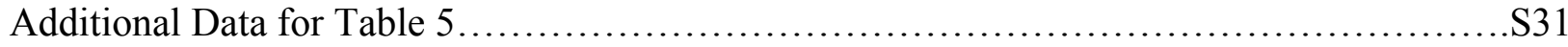



Additional Manipulations of Microscale Systems and Data for Figure 10...................S85

\section{Kinetic Resolution of 3 via salt 2}

Salt $2 b{ }^{1} \mathrm{H}$ and ${ }^{13} \mathrm{C}$ Spectral Data 



${ }^{1} \mathrm{H}$ NMR spectra were collected for the reaction mixtures in Table 1 as well as for both the $R$ HBTM and $S$-HBTM reactions in Figure 6, Table 5, Table 6, Table 7, and Figure 9. The percent conversion for a reaction was measured according to the integrals of a peak corresponding to the 
starting material and to the product after phase correction and baseline correction of the ${ }^{1} \mathrm{H}$ NMR spectrum (Formula 1).

Formula 1.

$$
\text { Percent Conversion }=\frac{{ }^{1} \mathrm{H} \text { NMR integral }{ }_{\text {ESTER }}}{{ }^{1} \mathrm{H} \text { NMR integral }{ }_{\text {ESTER }}+{ }^{1} \mathrm{H} \text { NMR integral }{ }_{\mathrm{ALCOHOL}}} \times 100
$$

\section{${ }^{1}$ H NMR Spectrum and Chiral HPLC Trace for Equation 1}<smiles>CCC(=O)N1c2sc3ccccc3[n+]2CC[C@H]1c1ccccc1</smiles>

$2 a$






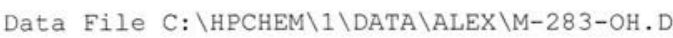

Chiralcel OD with OD guard $5 \% \mathrm{iPrOH} / \mathrm{n}-\mathrm{Hexane} 1.0 \mathrm{~mL} / \mathrm{min}$ 23 bar 254 NM UV



\section{${ }^{1}$ H NMR Spectra and Chiral HPLC Traces for Table 1}

\section{Entry 1}
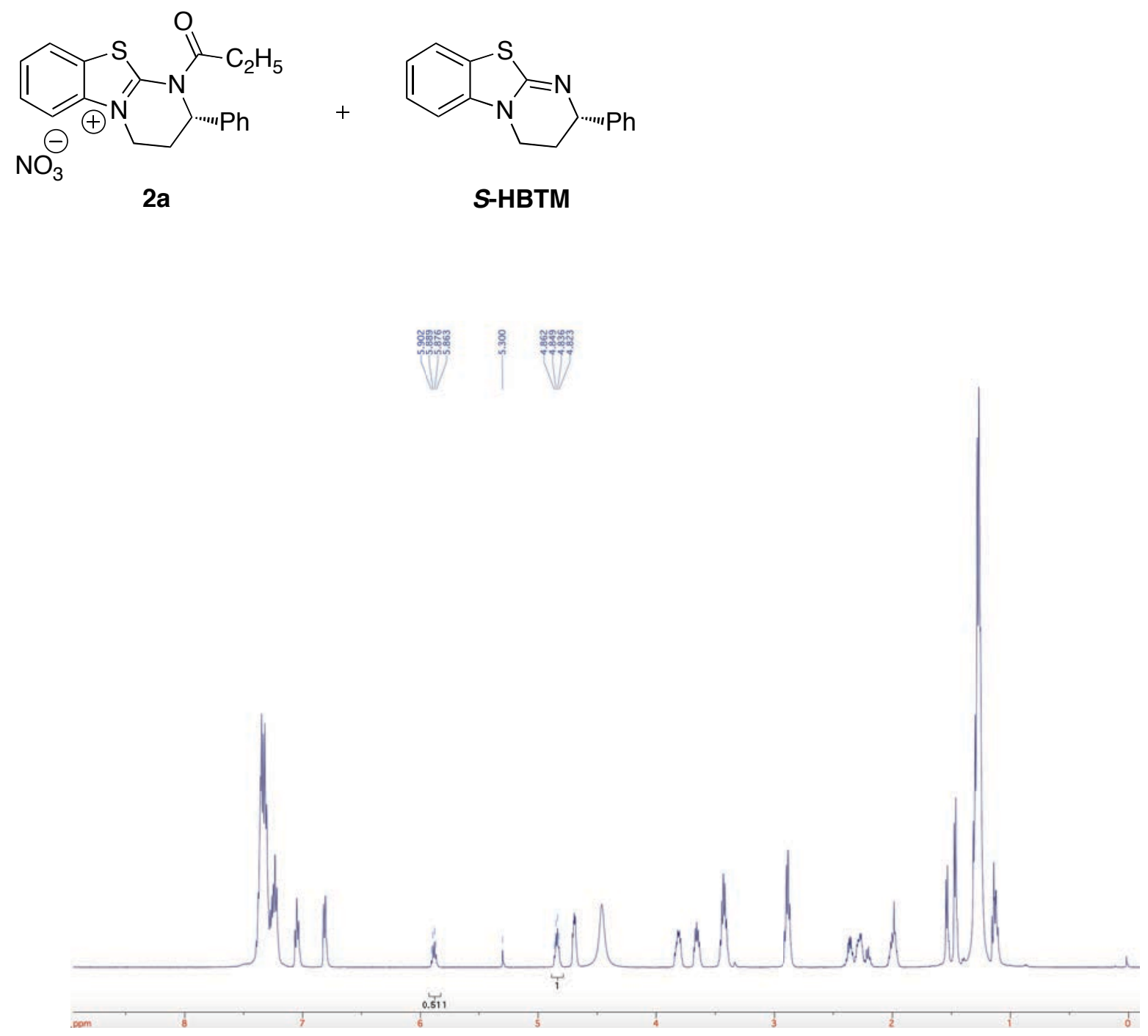


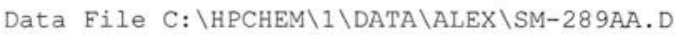

Chiralcel OD with OD guard $5 \% \mathrm{iPrOH} / \mathrm{n}-\mathrm{Hexane} 1.0 \mathrm{~mL} / \mathrm{min}$

23 bar 254 NM UV


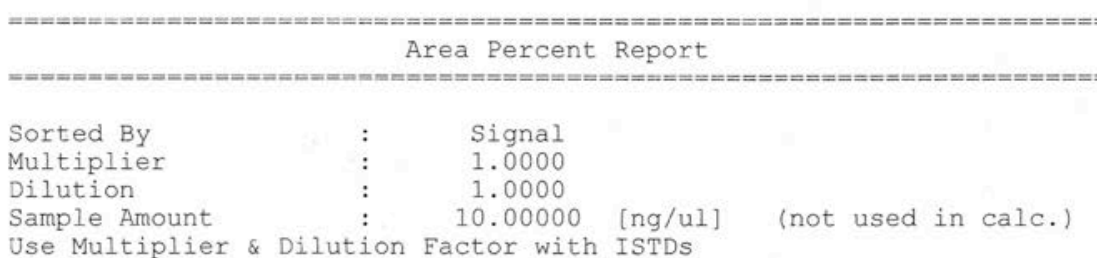

Signal 1: ADC1 A, ADC1 CHANNEL A

Signal 2: VWD1 A, Wavelength=254 nm

\begin{tabular}{|c|c|c|c|c|c|c|}
\hline \multirow{2}{*}{$\begin{array}{c}\text { Peak } \\
\#\end{array}$} & \multirow{2}{*}{$\begin{array}{c}\text { RetTime } \\
\text { [min] }\end{array}$} & \multirow[t]{2}{*}{ Type } & \multirow{2}{*}{$\begin{array}{l}\text { Width } \\
\text { [min] }\end{array}$} & Area & Height & \multirow{2}{*}{$\begin{array}{c}\text { Area } \\
\frac{8}{8}\end{array}$} \\
\hline & & & & $\mathrm{mAU}$ & {$[\mathrm{mAU}]$} & \\
\hline & ------- & & & --- & ---- & --- \\
\hline $\begin{array}{l}1 \\
2\end{array}$ & $\begin{array}{l}10.417 \\
12.543\end{array}$ & $\begin{array}{l}\text { VB } \\
\text { PB }\end{array}$ & $\begin{array}{l}0.5332 \\
0.6197\end{array}$ & $\begin{array}{l}2591.86816 \\
6403.20410\end{array}$ & $\begin{array}{r}76.29269 \\
161.55348\end{array}$ & $\begin{array}{l}28.8143 \\
71.1857\end{array}$ \\
\hline a. & & & & 0722 & & \\
\hline
\end{tabular}

Results obtained with enhanced integrator!

$$
\star \star \star \text { End of Report } * \star \star *
$$




\section{Entry 2}
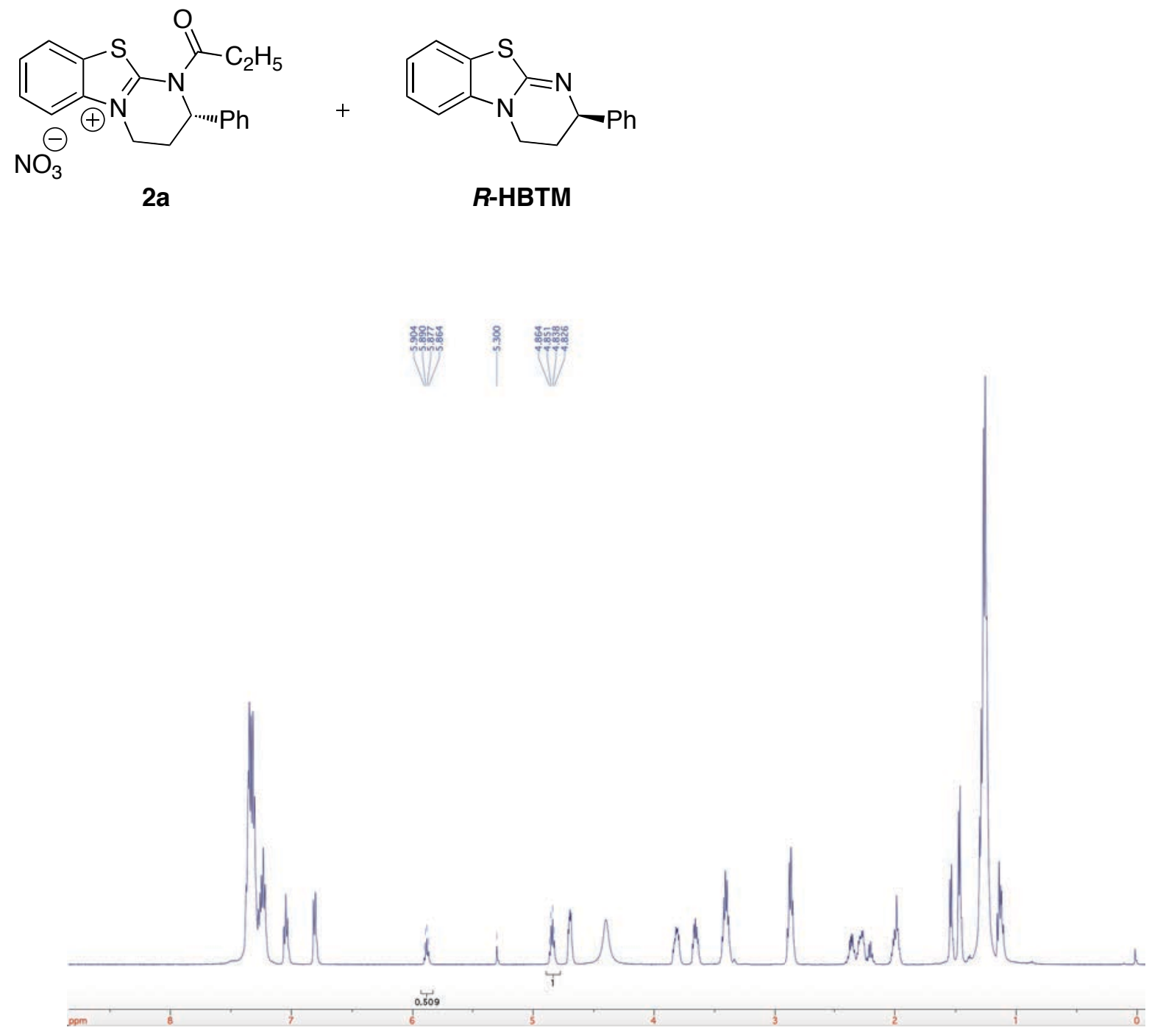


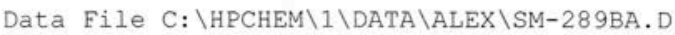

Chiralcel OD with OD guard 58 iPrOH/n-Hexane $1.0 \mathrm{~mL} / \mathrm{min}$
23 bar $254 \mathrm{NM}$ UV
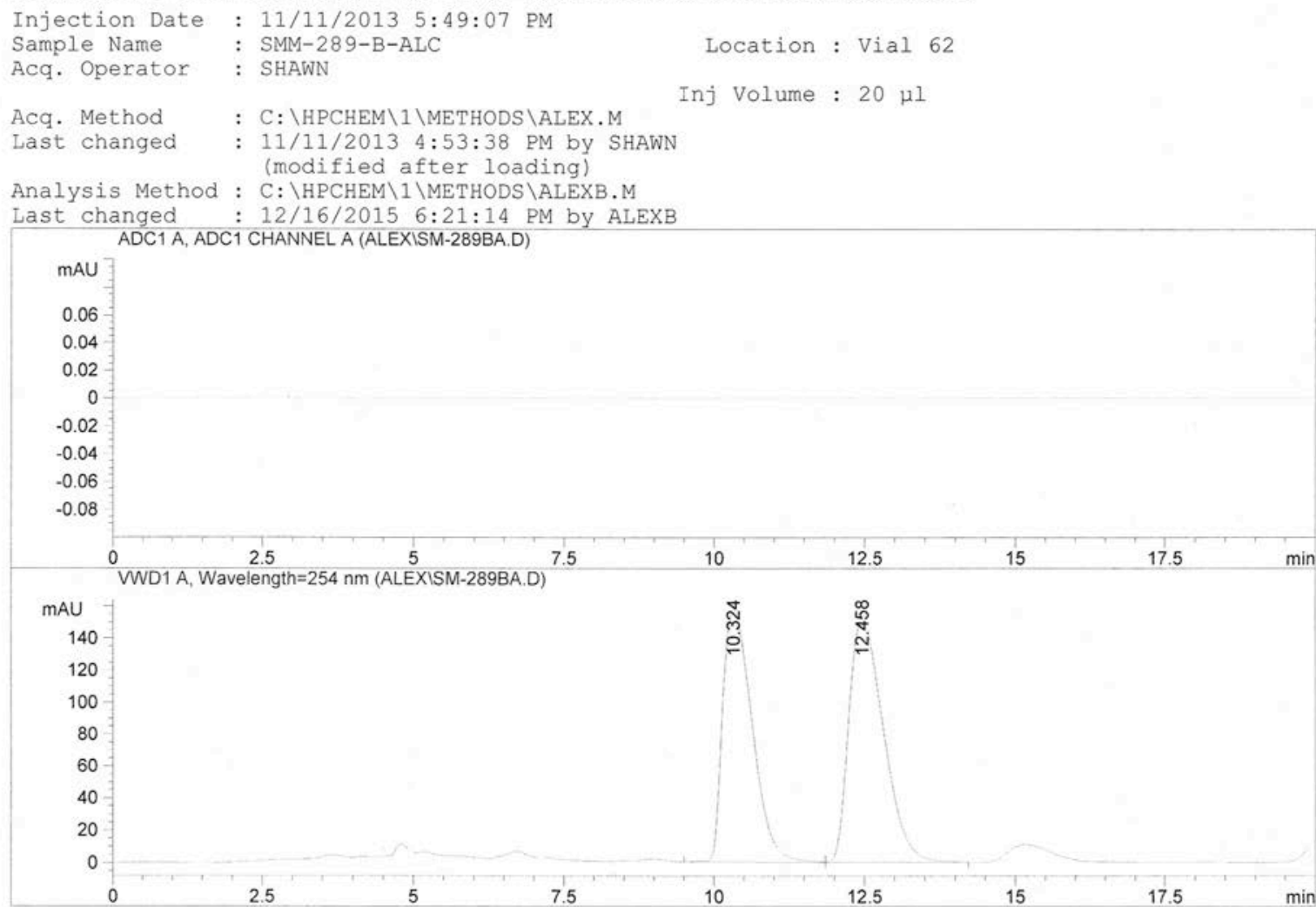

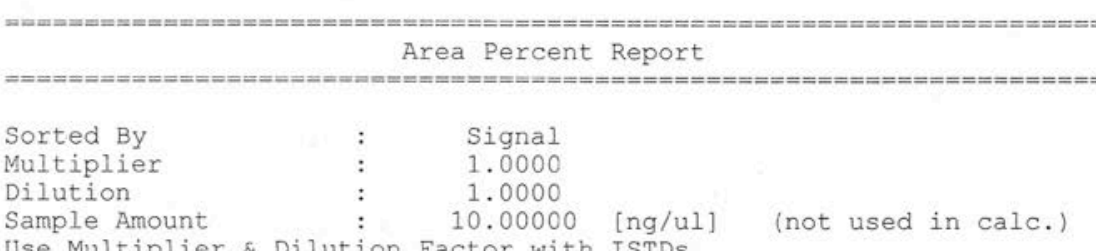

Use Multiplier \& Dilution Factor with ISTDS

Signal 1: ADC1 A, ADC1 CHANNEL A

Signal 2: VWD1 A, Wavelength=254 nm

\begin{tabular}{|c|c|c|c|c|c|c|}
\hline Peak & RetTime & Type & Width & Area & Height & Area \\
\hline \# & [min] & & [min] & $\mathrm{mAU}$ & {$[\mathrm{mAU}$} & 0 \\
\hline $\begin{array}{l}1 \\
2\end{array}$ & $\begin{array}{l}10.324 \\
12.458\end{array}$ & $\begin{array}{l}\text { VV } \\
\text { VB }\end{array}$ & $\begin{array}{l}0.5396 \\
0.6280\end{array}$ & $\begin{array}{l}5358.06152 \\
6065.95459\end{array}$ & $\begin{array}{l}155.79208 \\
151.26903\end{array}$ & $\begin{array}{l}46.9017 \\
53.0983\end{array}$ \\
\hline
\end{tabular}

Totals : $\quad 1.14240$ e4 $\quad 307.06111$

Results obtained with enhanced integrator!

$* \star \star$ End of Report $* \star *$ 


\section{Experimental Data for Kinetic Resolution of 3 with other Salts}

$\mathbf{B F}_{4}$ counterion. 1-phenylethanol $(25.8 \mathrm{mg}, 0.211 \mathrm{mmol})$ was added to a $20 \mathrm{~mL}$ scintillation vial with a stirbar. $\mathrm{CDCl}_{3}(600 . \mu \mathrm{L})$ and $N, N$-diisopropylethylamine $(36.4 \mu \mathrm{L}, 0.209 \mathrm{mmol})$ were added and the reaction mixture was stirred at $0{ }^{\circ} \mathrm{C}$ (ice bath). $\mathrm{BF}_{4}$ salt $(52.0 \mathrm{mg}, 0.127 \mathrm{mmol})$ was added and the reaction was stirred for $1 \mathrm{~h}$ at $0{ }^{\circ} \mathrm{C}$. The reaction was halted with the addition of methanol $(85.9 \mu \mathrm{L}) .{ }^{1} \mathrm{H}$ NMR spectral data of the crude reaction mixture revealed a reaction conversion to ester of $42.6 \%$. The unreacted alcohol was recovered by column chromatography (9:1 hexanes/ethyl acetate) and analyzed by chiral HPLC (Chiralcel OD with OD guard, 10\% $i$ $\mathrm{PrOH}$ in n-hexane, $25 \mathrm{bar}, 1.0 \mathrm{~mL} / \mathrm{min}$, $\mathrm{UV}$ detection at $254 \mathrm{~nm}, \mathrm{t}_{\mathrm{R}}=6.90 \mathrm{~min}, \mathrm{t}_{\mathrm{s}}=8.01 \mathrm{~min}$ ) $61.4 \%$ e.e.

PF 6 counterion. 1-phenylethanol (19.3 $\mathrm{mg}, 0.158 \mathrm{mmol})$ was added to a $20 \mathrm{~mL}$ scintillation vial with a stirbar. $\mathrm{CD}_{3} \mathrm{CN}(600 . \mu \mathrm{L})$ and $N, N$-diisopropylethylamine $(27.5 \mu \mathrm{L}, 0.158 \mathrm{mmol})$ were added and the reaction mixture was stirred at $25{ }^{\circ} \mathrm{C} . \mathrm{PF}_{6}$ salt $(50.8 \mathrm{mg}, 0.108 \mathrm{mmol})$ was added and the reaction was stirred for $14 \mathrm{~h}$. The reaction was halted with the addition of methanol (63.9 $\mu \mathrm{L}) .{ }^{1} \mathrm{H}$ NMR spectral data of the crude reaction mixture revealed a reaction conversion to ester of $26.0 \%$. The unreacted alcohol was recovered by column chromatography $(9: 1$ hexanes/ethyl acetate) and analyzed by chiral HPLC (Chiralcel OD with OD guard, 5\% $i$-PrOH in n-hexane, 23 bar, $1.0 \mathrm{~mL} / \mathrm{min}, \mathrm{UV}$ detection at $\left.254 \mathrm{~nm}, \mathrm{t}_{\mathrm{R}}=10.36 \mathrm{~min}, \mathrm{t}_{\mathrm{S}}=12.40 \mathrm{~min}\right) 15.2 \%$ e.e.

SbF $_{6}$ counterion. 1-phenylethanol $(26.2 \mathrm{mg}, 0.214 \mathrm{mmol})$ was added to a $20 \mathrm{~mL}$ scintillation vial with a stirbar. $\mathrm{CDCl}_{3}(600 . \mu \mathrm{L})$ and $N, N$-diisopropylethylamine $(37.5 \mu \mathrm{L}, 0.215 \mathrm{mmol})$ were 
added and the reaction mixture was stirred at $25^{\circ} \mathrm{C}$. Salt $\mathbf{2 b}(60.4 \mathrm{mg}, 0.108 \mathrm{mmol})$ was added and the reaction was stirred for $14 \mathrm{~h}$. The reaction was halted with the addition of methanol (87.0 $\mu \mathrm{L}) .{ }^{1} \mathrm{H}$ NMR spectral data of the crude reaction mixture revealed a reaction conversion to ester of $30.8 \%$. The unreacted alcohol was recovered by column chromatography $(9: 1$ hexanes/ethyl acetate) and analyzed by chiral HPLC (Chiralcel OD with OD guard, 5\% $i$-PrOH in n-hexane, 23 bar, $1.0 \mathrm{~mL} / \mathrm{min}, \mathrm{UV}$ detection at $254 \mathrm{~nm}, \mathrm{t}_{\mathrm{R}}=10.34 \mathrm{~min}, \mathrm{t}_{\mathrm{S}}=12.61 \mathrm{~min}$ ) $28.8 \%$ e.e.

\section{$\mathrm{BF}_{4}$ Salt}<smiles></smiles>








Chiralcel OD with OD guard $108 \mathrm{iPrOH} / \mathrm{n}-\mathrm{Hexane} 1.0 \mathrm{~mL} / \mathrm{mi}$

n 25 bar 254 NM UV



Use Multiplier \& Dilution Factor with ISTDS

Signal 1: ADC1 A, ADC1 CHANNEL A

Signal 2: VWD1 A, Wavelength $=254 \mathrm{~nm}$

\begin{tabular}{|c|c|c|c|c|c|c|}
\hline Peak & RetTime & Type & Width & Area & Height & Area \\
\hline \# & [min] & & [min] & $\mathrm{mAU}$ & {$[\mathrm{mAU}$} & 8 \\
\hline $\begin{array}{l}1 \\
2\end{array}$ & $\begin{array}{l}6.901 \\
8.015\end{array}$ & $\begin{array}{l}\text { MM } \\
\text { MM. }\end{array}$ & $\begin{array}{l}0.3216 \\
0.3824\end{array}$ & $\begin{array}{l}1017.73035 \\
4249.45020\end{array}$ & $\begin{array}{r}52.74073 \\
185.19360\end{array}$ & $\begin{array}{l}19.3221 \\
80.6779\end{array}$ \\
\hline otal & & & & 18054 & 33 & \\
\hline
\end{tabular}

Results obtained with enhanced integrator!

$\star \star \star$ End of Report $\star \star \star$

\section{$\mathrm{PF}_{6}$ Salt}



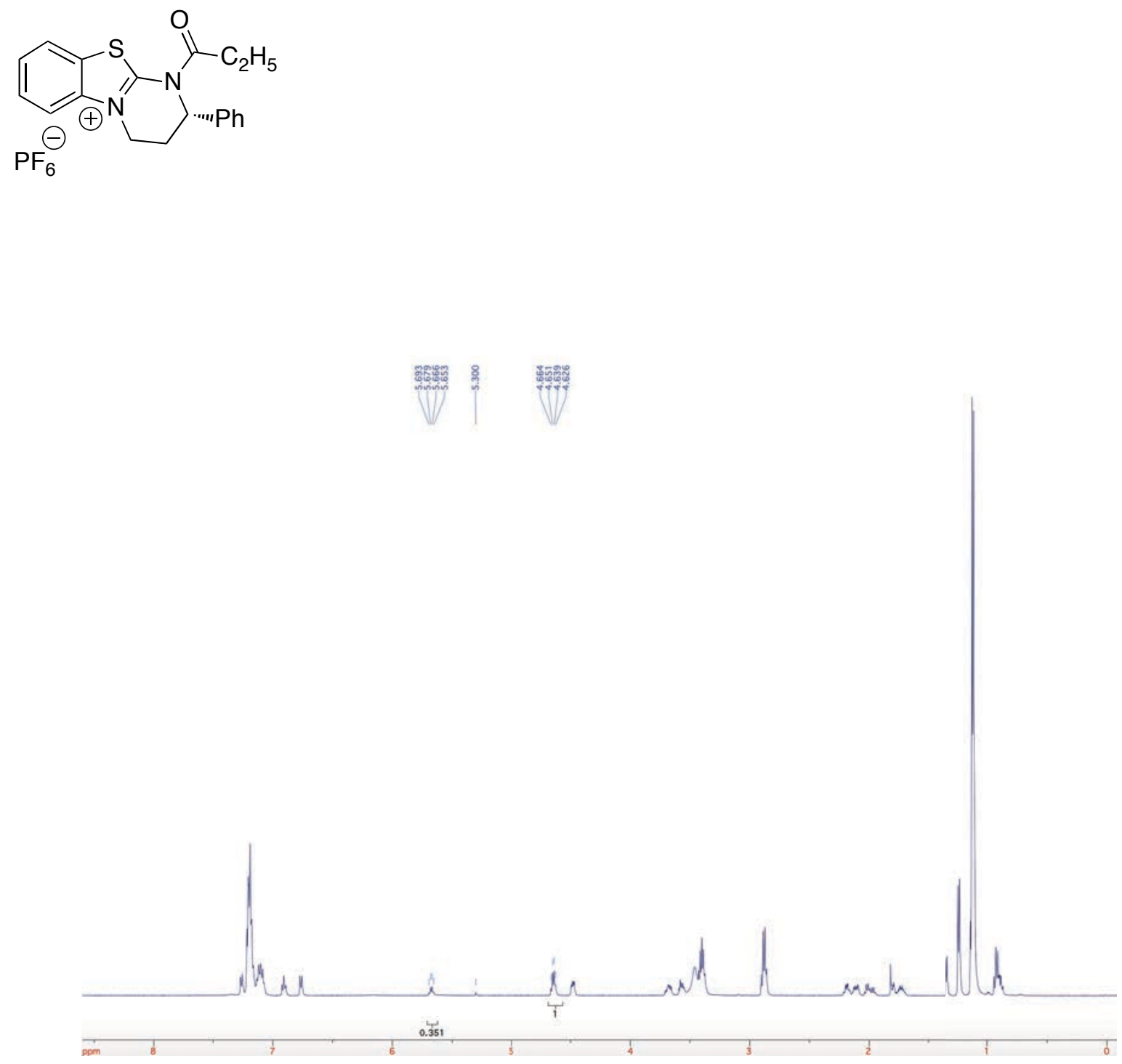


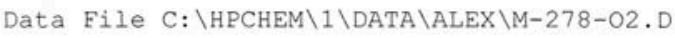

Chiralcel OD with OD guard $5 \%$ iPrOH/n-Hexane $1.0 \mathrm{~mL} / \mathrm{min}$ 23 bar 254 NM UV
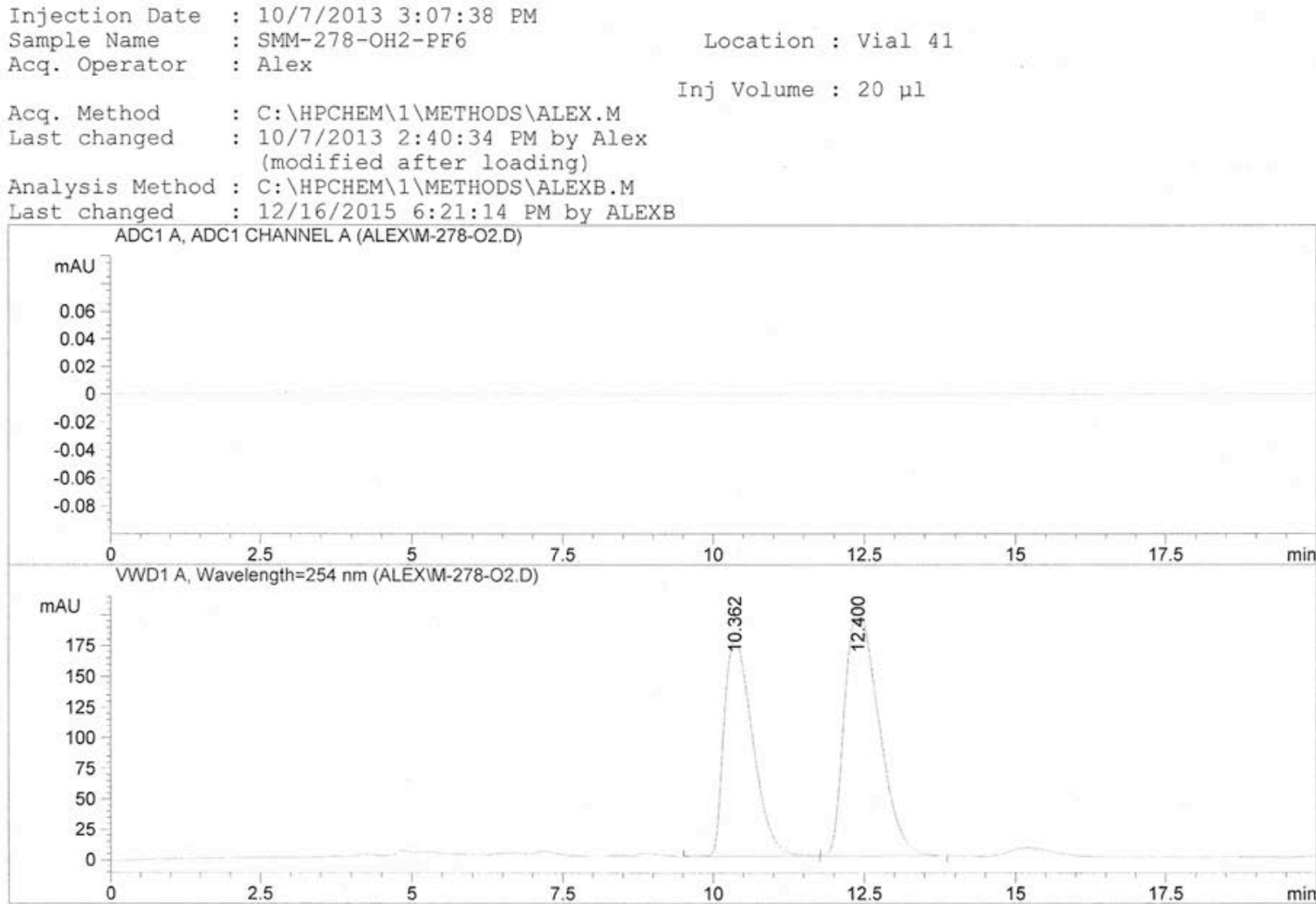

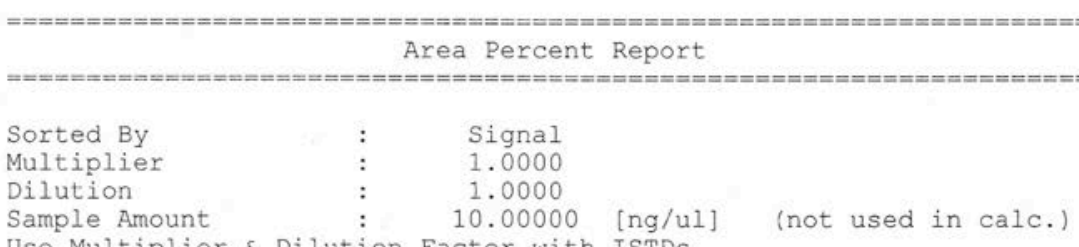

Use Multiplier \& Dilution Eactor with ISTDS

Signal 1: ADC1 A, ADC1 CHANNEL A

Signal 2: VWD1 A, Wavelength=254 nm

\begin{tabular}{|c|c|c|c|c|c|c|}
\hline Peak & RetTime & Type & Width & Area & Height & Area \\
\hline \# & [min] & & [min] & $\mathrm{mAU}$ & {$[\mathrm{mAU}$} & $\%$ \\
\hline-- &  & & ---- & $1--0-1--$ & ------- & --------1 \\
\hline $\begin{array}{l}1 \\
2\end{array}$ & $\begin{array}{l}10.362 \\
12.400\end{array}$ & $\begin{array}{l}\text { VB } \\
\text { BB }\end{array}$ & $\begin{array}{l}0.5300 \\
0.6042\end{array}$ & $\begin{array}{l}5851.21777 \\
7935.34326\end{array}$ & $\begin{array}{l}176.25667 \\
201.88766\end{array}$ & $\begin{array}{l}42.4415 \\
57.5585\end{array}$ \\
\hline
\end{tabular}

Totals: $\quad 1.37866 \mathrm{e} 4 \quad 378.14433$

Results obtained with enhanced integrator!

$$
* * * \text { End of Report *** }
$$




\section{$\mathrm{SbF}_{6}$ Salt}<smiles>CCC(=O)N1c2sc3ccccc3[n+]2CC[C@H]1c1ccccc1</smiles>

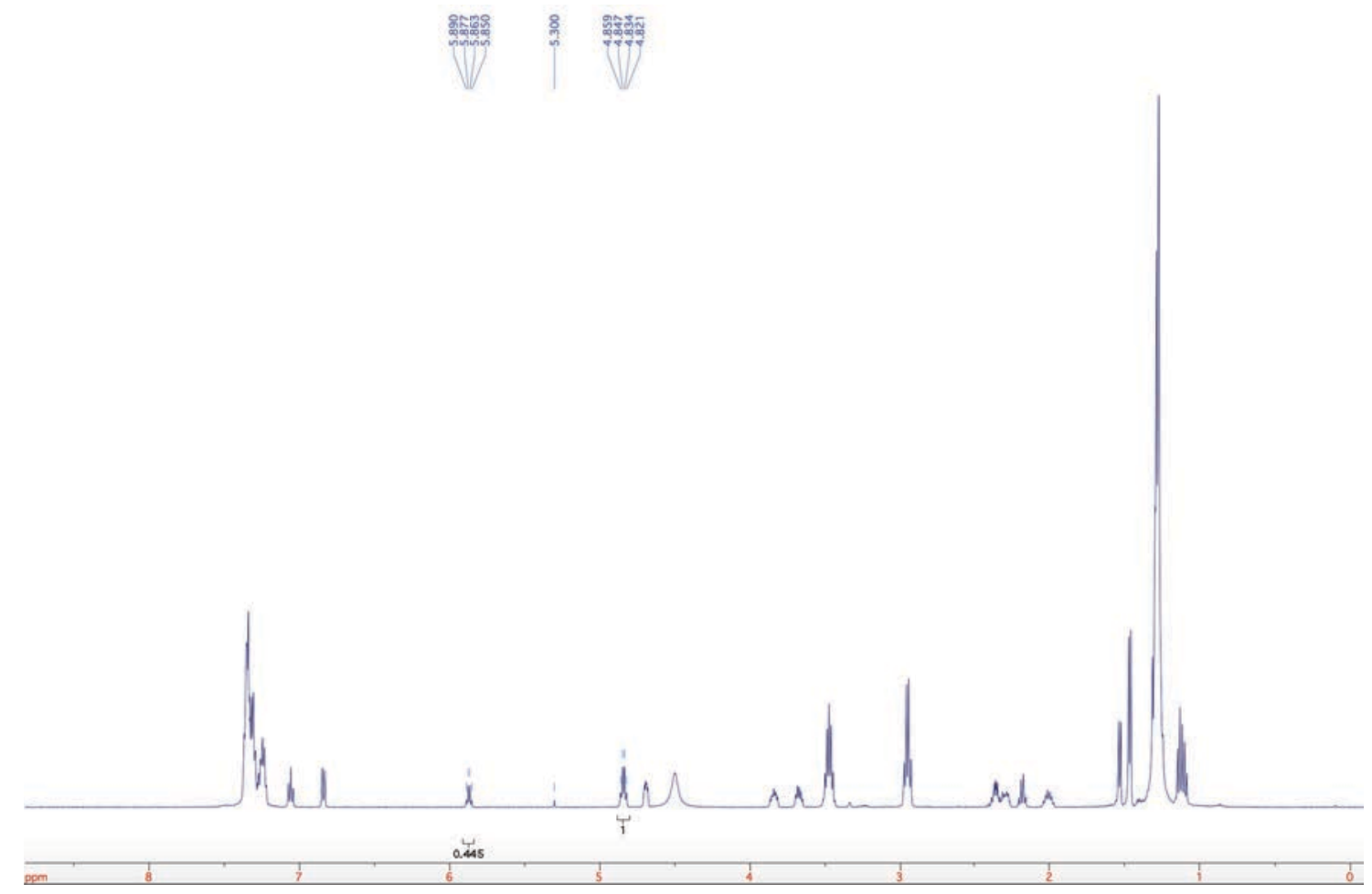




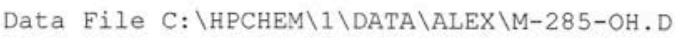

Chiralcel OD with OD guard $5 \% \mathrm{iPrOH} / \mathrm{n}$-Hexane $1.0 \mathrm{~mL} / \mathrm{min}$

23 bar 254 NM UV

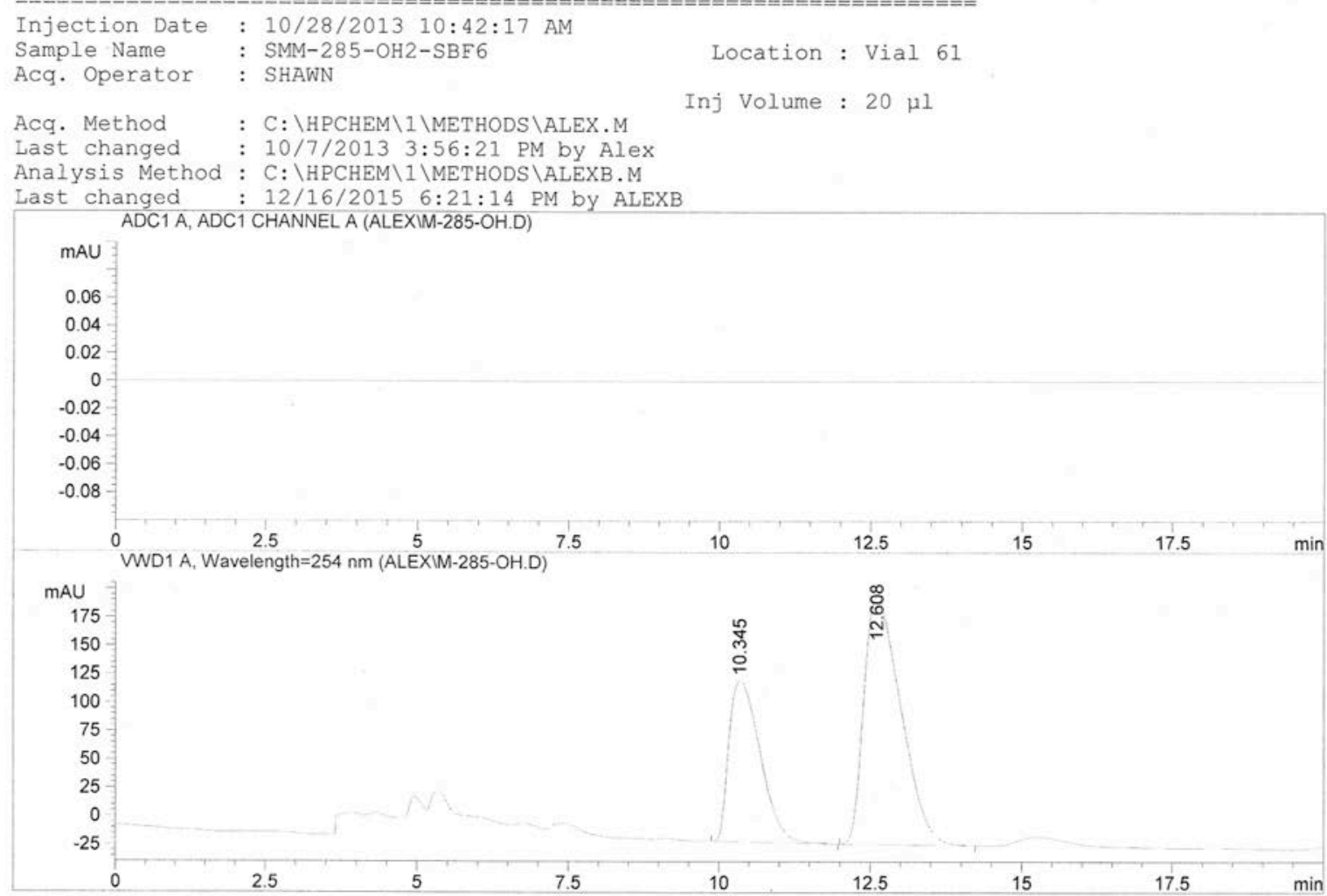

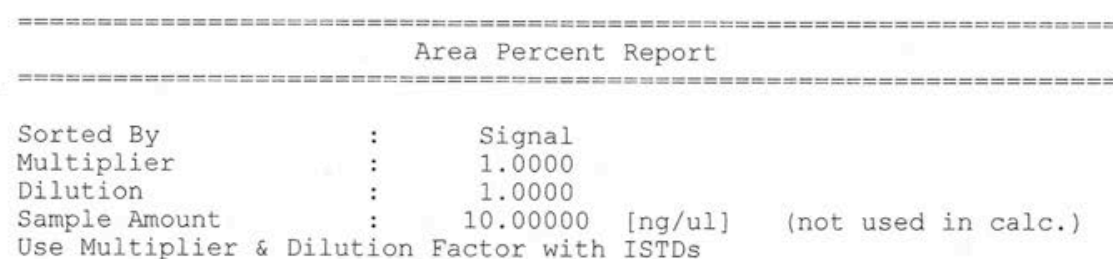

Use Multiplier \& Dilution Factor with ISTDs

Signal 1: ADC1 A, ADC1 CHANNEL A

Signal 2: VWD1 A, Wavelength=254 nm

\begin{tabular}{|c|c|c|c|c|c|c|}
\hline Peak & RetTime & Type & Width & Area & Height & Area \\
\hline \# & [min] & & [min] & $\mathrm{mAU}$ & {$[\mathrm{mAU}$} & 8 \\
\hline 1 & 10.345 & VP & 0.5539 & 5129.94238 & 142.03905 & 35.5690 \\
\hline 2 & 12.608 & BP & 0.6479 & 9292.57813 & 218.35796 & 64.4310 \\
\hline
\end{tabular}

Totals : $\quad 1.44225 \mathrm{e} \quad 360.39700$

Results obtained with enhanced integrator!

$* * *$ End of Report $* * *$ 


\section{Additional Data for Tables 3 and 4}

Table SI.1. Masses, TLC solvent systems, and TLC plate staining solutions used for compounds in Tables 3 and 4 with the CEC microscale protocol

\begin{tabular}{ccccc} 
table & entry & $\begin{array}{c}\text { mass in } \mathbf{~ m L} \\
\text { volumetric flask } \\
\text { (mg) }\end{array}$ & TLC solvent conditions & TLC stain \\
\hline 3 & 1 & 2.5 & $7: 3$ hexanes/ethyl acetate & PMA \\
3 & 2 & 2.5 & $7: 3$ hexanes/ethyl acetate & PMA \\
3 & 3 & 2.9 & $3: 1$ hexanes/ethyl acetate & PMA \\
3 & 4 & 2.9 & $3: 1$ hexanes/ethyl acetate & PMA \\
3 & 5 & 2.2 & $3: 1$ hexanes/ethyl acetate & PMA \\
3 & 6 & 3.0 & $6: 1$ hexanes/ethyl acetate & Dragendorf-Munier ${ }^{\mathrm{a}}$ \\
3 & 7 & 2.6 & $6: 1$ hexanes/ethyl acetate & PMA \\
3 & 8 & 2.0 & $6: 1$ hexanes/ethyl acetate & PMA \\
4 & 1 & 5.9 & $6: 1$ hexanes/ethyl acetate & KMnO4 \\
4 & 2 & 4.3 & $6: 1$ hexanes/ethyl acetate & PMA \\
4 & 3 & 4.3 & $6: 1$ hexanes/ethyl acetate & PMA \\
4 & 4 & 3.0 & ethyl acetate & Dragendorf-Munier ${ }^{\mathrm{a}}$ \\
4 & 5 & 4.5 & $6: 1$ hexanes/ethyl acetate & KMnO4 \\
4 & 6 & 4.0 & $6: 1$ hexanes/ethyl acetate & PMA \\
4 & 7 & 3.4 & $3: 1$ hexanes/ethyl acetate & PMA \\
4 & 8 & 3.6 & $6: 1$ hexanes/ethyl acetate & PMA
\end{tabular}

(a) plate was allowed to dry at room temperature over a period of 3-5 min before a photograph of the image was captured 


\section{Calibration Curves of (R)-5 and (R)-6 with GC-MS for Figure 6}

\section{Stock Solutions}

(R)-5. To a $10 \mathrm{~mL}$ volumetric flask was added $(\boldsymbol{R})-5(5.0 \mathrm{mg}, 0.029 \mathrm{mmol})$ and the flask was filled to the line with dichloromethane, preparing a solution of $(\boldsymbol{R})-5(2.9 \mathrm{mM})$.

(R)-6. To a $10 \mathrm{~mL}$ volumetric flask was added $(\boldsymbol{R})-6(6.6 \mathrm{mg}, 0.029 \mathrm{mmol})$ and the flask was filled to the line with dichloromethane, preparing a solution of $(\boldsymbol{R})-6(2.9 \mathrm{mM})$.

\section{Calibration Solutions}

All solutions are summarized in Table SI.2.

Solution 1. To a GC-MS vial was added stock solutions of $(\boldsymbol{R})-5(909 \mu \mathrm{L})$ and $(\boldsymbol{R})-\mathbf{6}(91.0 \mu \mathrm{L})$, preparing a solution ratio for $(\boldsymbol{R})-\mathbf{5}:(\boldsymbol{R})-\mathbf{6}$ of $10: 1$ at $2.6 \mathrm{mM}$ and $0.26 \mathrm{mM}$.

Solution 2. To a GC-MS vial was added stock solutions of $(\boldsymbol{R})-5(833 \mu \mathrm{L})$ and $(\boldsymbol{R})-\mathbf{6}(167 \mu \mathrm{L})$, preparing a solution ratio for $(\boldsymbol{R})-\mathbf{5 :}(\boldsymbol{R})-\mathbf{6}$ of $5: 1$ at $2.4 \mathrm{mM}$ and $0.48 \mathrm{mM}$.

Solution 3. To a GC-MS vial was added stock solutions of $(\boldsymbol{R})-5(667 \mu \mathrm{L})$ and $(\boldsymbol{R})-6(333 \mu \mathrm{L})$, preparing a solution ratio for $(\boldsymbol{R})-\mathbf{5 :}(\boldsymbol{R})-\mathbf{6}$ of $2: 1$ at $1.9 \mathrm{mM}$ and $0.97 \mathrm{mM}$.

Solution 4. To a GC-MS vial was added stock solutions of $(\boldsymbol{R})-5(500 . \mu \mathrm{L})$ and $(\boldsymbol{R})-6(500 . \mu \mathrm{L})$, preparing a solution ratio for $(\boldsymbol{R})-\mathbf{5}:(\boldsymbol{R})-\mathbf{6}$ of $1: 1$ at $1.5 \mathrm{mM}$ and $1.5 \mathrm{mM}$. 
Solution 5. To a GC-MS vial was added stock solutions of $(\boldsymbol{R})-5(333 \mu \mathrm{L})$ and $(\boldsymbol{R})-6(667 \mu \mathrm{L})$, preparing a solution ratio for $(\boldsymbol{R})-\mathbf{5 :}(\boldsymbol{R})-\mathbf{6}$ of $1: 2$ at $0.97 \mathrm{mM}$ and $1.9 \mathrm{mM}$.

Solution 6. To a GC-MS vial was added stock solutions of $(\boldsymbol{R})-5(167 \mu \mathrm{L})$ and $(\boldsymbol{R})-6(833 \mu \mathrm{L})$, preparing a solution ratio for $(\boldsymbol{R}) \mathbf{- 5 : ( R ) - 6}$ of $1: 5$ at $0.48 \mathrm{mM}$ and $2.4 \mathrm{mM}$.

Solution 7. To a GC-MS vial was added stock solutions of $(\boldsymbol{R})-5(91.0 \mu \mathrm{L})$ and $(\boldsymbol{R})-\mathbf{6}(909 \mu \mathrm{L})$, preparing a solution ratio for $(\boldsymbol{R})-\mathbf{5}:(\boldsymbol{R})-\mathbf{6}$ of $1: 10$ at $0.26 \mathrm{mM}$ and $2.6 \mathrm{mM}$.

Table SI.2. Mixed ratios of $(\boldsymbol{R})-5$ and $(\boldsymbol{R})-6$ in solutions used for GC-MS calibration curves

\begin{tabular}{c|cc|cc|c}
\multicolumn{3}{c}{ concentration $(\mathbf{m M})$} & \multicolumn{2}{c}{ ratio } & $\begin{array}{c}\text { simulated } \\
\text { conversion }\end{array}$ \\
\hline solution & $(\boldsymbol{R})-5$ & $(\boldsymbol{R})-\mathbf{6}$ & $(\boldsymbol{R})-\mathbf{5}$ & $(\boldsymbol{R})-\mathbf{6}$ & $\mathbf{( \% )}$ \\
\hline 1 & 2.6 & 0.26 & 10 & 1 & 9.1 \\
2 & 2.4 & 0.48 & 5 & 1 & 17 \\
3 & 1.9 & 0.97 & 2 & 1 & 33 \\
4 & 1.5 & 1.5 & 1 & 1 & 50 \\
5 & 0.97 & 1.9 & 1 & 2 & 67 \\
6 & 0.48 & 2.4 & 1 & 5 & 83 \\
7 & 0.26 & 2.6 & 1 & 10 & 91
\end{tabular}

Vials of solutions 1-7 were capped and subsequently analyzed via GC-MS with a programmed method increasing from $50{ }^{\circ} \mathrm{C}$ to $290{ }^{\circ} \mathrm{C}$ at a rate of $5{ }^{\circ} \mathrm{C}$ per min. Solutions $1-7$ were compared to pure samples of $(\boldsymbol{R})-\mathbf{5}$ and $(\boldsymbol{R})-\mathbf{6}$ at concentrations of $2.9 \mathrm{mM}$ to match retention times.

Integration of peak intensities in solutions 1-7 was collected and compared to the concentrations of $(\boldsymbol{R})-5$ and $(\boldsymbol{R})-\mathbf{6}$ within each solution to develop calibration curves (Table SI.3). GC-MS peak 
intensities were divided by $100,000,000$ to simply the resulting graphs for $(\boldsymbol{R})-\mathbf{5}$ (Figure SI.1) and (R)-6 (Figure SI.2).

Table SI.3. GC-MS integration of peak intensities of $(\boldsymbol{R})-\mathbf{5}$ and $(\boldsymbol{R})-\mathbf{6}$ for solutions 1-7.

\begin{tabular}{c|cc|cc} 
& \multicolumn{2}{|c|}{ GC-MS integration } & \multicolumn{2}{c}{$\begin{array}{c}\text { GC-MS integration } \\
(\mathbf{1 0 0 0 0 0 0 0 0 )}\end{array}$} \\
\hline Solution & $\mathbf{( R ) - 5}$ & $\mathbf{( R ) - 6}$ & $\mathbf{( R ) - 5}$ & $(\boldsymbol{R})-\mathbf{6}$ \\
\hline 1 & 1669713607 & 474853025 & 16.69713607 & 4.74853025 \\
2 & 1392970981 & 706776467 & 13.92970981 & 7.06776467 \\
3 & 1014542369 & 1308193746 & 10.14542369 & 13.08193746 \\
4 & 642913949 & 1819330621 & 6.42913949 & 18.19330621 \\
5 & 397478401 & 2730191225 & 3.97478401 & 27.30191225 \\
6 & 122986457 & 3572101899 & 1.22986457 & 35.72101899 \\
7 & 45344897 & 4272364606 & 0.45344897 & 42.72364606
\end{tabular}

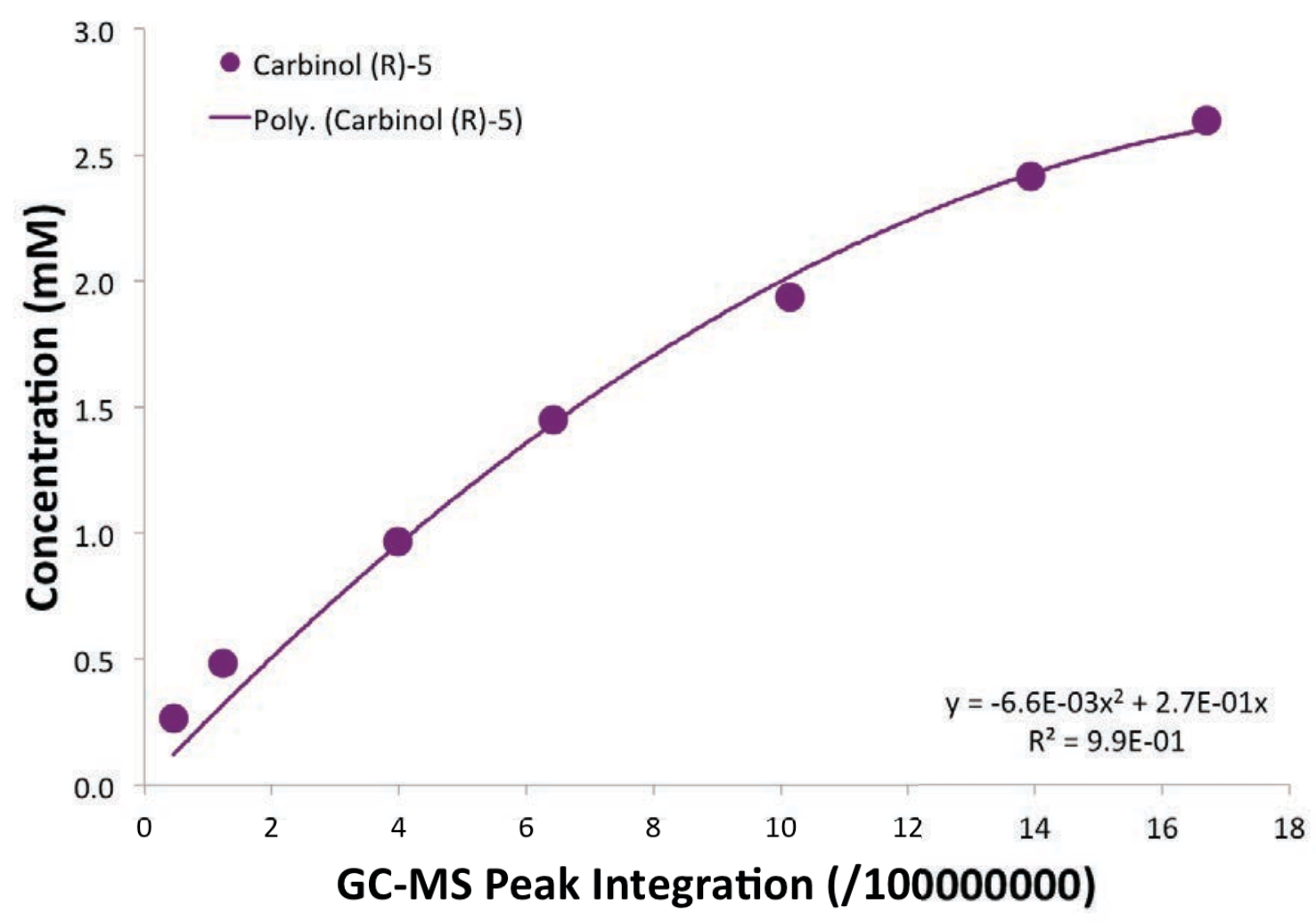

Figure SI.1. Calibration curve for concentration of $(\boldsymbol{R})-\mathbf{5}$ relative to GC-MS peak intensity 


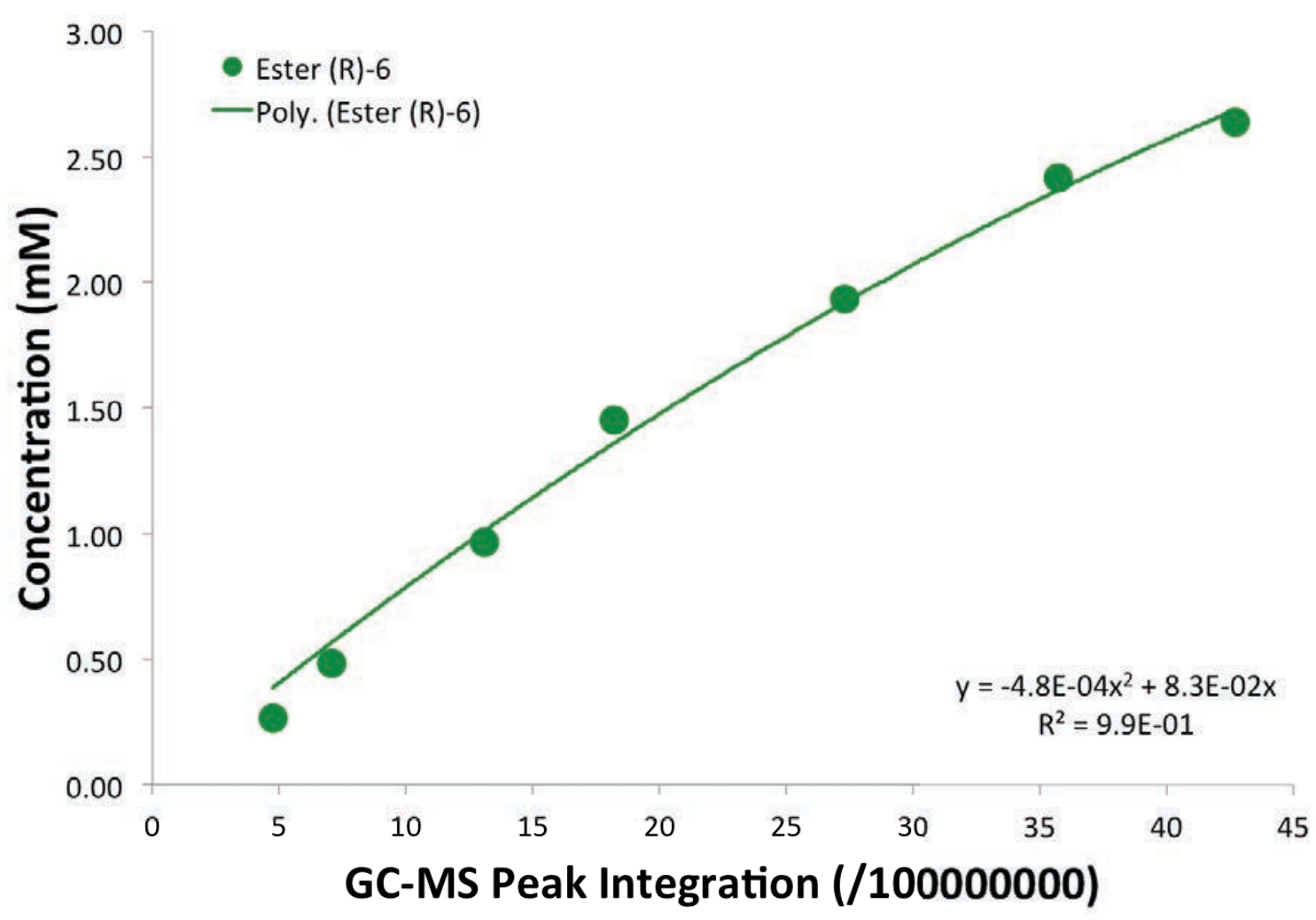

Figure SI.2. Calibration curve for concentration of $(\boldsymbol{R})-\mathbf{6}$ relative to GC-MS peak intensity 


\section{Additional Data for Figure 6 \\ Testing Reaction Conversion by Varied Initial Concentrations of $(R)-5$ with the CEC Kit conditions}

\section{CEC Protocol}

Substrate $(\boldsymbol{R})-\mathbf{5}$ was solvated in $\mathrm{CDCl}_{3}$ in a 1 dram vial. Masses and the volume of $\mathrm{CDCl}_{3}$ added are included in Table SI.4. The resulting alcohol solution $(100 . \mu \mathrm{L})$ was dispensed to both the $R$ HBTM and $S$-HBTM CEC kit vials via microsyringe with a one-minute gap between additions. A needle was inserted to the CEC kit vial to equalize the pressure before addition of the alcohol solution. The solutions were agitated to ensure homogeneity and let sit for $30 \mathrm{~min}$. Methanol- $d_{4}$ $(50 . \mu \mathrm{L})$ was added via microsyringe and the solution was again agitated to ensure homogeneity, halting reaction progress.

\section{TLC Analysis}

To a TLC plate with 2 lanes was spotted the $R$-HBTM reaction $(4.0 \mu \mathrm{L})$, and the $S$-HBTM reaction $(4.0 \mu \mathrm{L})$ via micropipette. The plate was run $(30 \%$ ethyl acetate in hexanes), dried, stained (PMA), heated by oven $\left(160^{\circ} \mathrm{C}, \sim 1 \mathrm{~min}\right)$, and photographed. Images are included in Figure SI.3.

\section{${ }^{1}$ H NMR Analysis}

The quenched solution was then analyzed by ${ }^{1} \mathrm{H}$ NMR spectroscopy to assess reaction conversion via measurement of peak integration of the proton germinal to the alcohol and ester 
functional groups on the substrate and product respectively. Spectra from entries 1-6 are included starting on page SI.31.

\section{GC-MS Analysis}

The $R$-HBTM and $S$-HBTM CEC kit solutions were concentrated under reduced pressure. The mixture was then resolvated in methylene chloride $(2 \mathrm{~mL})$, washed with saturated aqueous $\mathrm{NaHCO}_{3}(2 \times 2 \mathrm{~mL})$ and brine $(1 \times 2 \mathrm{~mL})$. The organic layer was dried $\left(\mathrm{MgSO}_{4}\right)$, filtered, and concentrated under reduced pressure to afford the crude reaction mixtures for each entry. Each crude mixture was then solvated with methylene chloride in order to give an assumed additive concentration between $(\boldsymbol{R})-\mathbf{5}$ and $(\boldsymbol{R})-\mathbf{6}$ of $2.5 \mathrm{mM}$ based on the initial amount of substrate added to the reaction kit. If the total solution was in excess of $1.0 \mathrm{~mL}$, then a portion of the solution $(1.0$ $\mathrm{mL}$ ) was transferred to a GC-MS vial and capped under air for subsequent analysis via GC-MS with a programmed method increasing from $50{ }^{\circ} \mathrm{C}$ to $290{ }^{\circ} \mathrm{C}$ at a rate of $5{ }^{\circ} \mathrm{C}$ per min. Volumes and the resulting GC-MS integration data are included below. The GC-MS integration data for $(R)-5$ and $(R)-6$ was utilized with previously developed calibration curves to calculate concentrations in each reaction mixture and the reaction conversion for each entry. Data are summarized for $R$-HBTM and $S$-HBTM reactions with entries 1-6 in Table SI.5 and Table SI.6. 
Table SI.4. CEC Kit substrate loadings analyzed for $(\boldsymbol{R})-\mathbf{5}$ in Figure 6

\begin{tabular}{ccccccccccc} 
& \multicolumn{2}{c}{ substrate } & \multicolumn{2}{c}{$\begin{array}{c}\mathbf{C D C l}_{3} \text { added } \\
\text { to substrate }\end{array}$} & \multicolumn{2}{c}{$\begin{array}{c}\text { substrate added } \\
\text { to each reaction }\end{array}$} & $\begin{array}{c}\text { substrate } \\
\text { stock } \\
\text { solution }\end{array}$ & \multicolumn{3}{c}{$\begin{array}{c}\text { reaction } \\
\text { concentration }\end{array}$} \\
\hline Entry & $(\mathrm{mg})$ & $(\mu \mathrm{mol})$ & $(\mu \mathrm{L})$ & $(\mathrm{mL})$ & $(\mu \mathrm{mol})$ & $(\mathrm{nmol})$ & conc. $(\mathrm{M})$ & $(\mathrm{M})$ & $(\mathrm{mM})$ & {$[\mathrm{KIT}]$} \\
\hline 1 & 6.8 & 40 & 250 & 0.250 & 16 & 16000 & 0.16 & 0.029 & 29 & $2 \mathrm{x}$ \\
2 & 3.4 & 20 & 250 & 0.250 & 8.0 & 8000 & 0.079 & 0.014 & 14 & same \\
3 & 3.4 & 20 & 500 & 0.500 & 4.0 & 4000 & 0.039 & 0.0072 & 7.2 & $1 / 2$ \\
4 & 3.4 & 20 & 750 & 0.750 & 2.7 & 2700 & 0.027 & 0.0048 & 4.8 & $1 / 3$ \\
5 & 3.4 & 20 & 1250 & 1.250 & 1.6 & 1600 & 0.016 & 0.0029 & 2.9 & $1 / 5$ \\
6 & 3.4 & 20 & 2500 & 2.500 & 0.80 & 800 & 0.0079 & 0.0014 & 1.4 & $1 / 10$
\end{tabular}
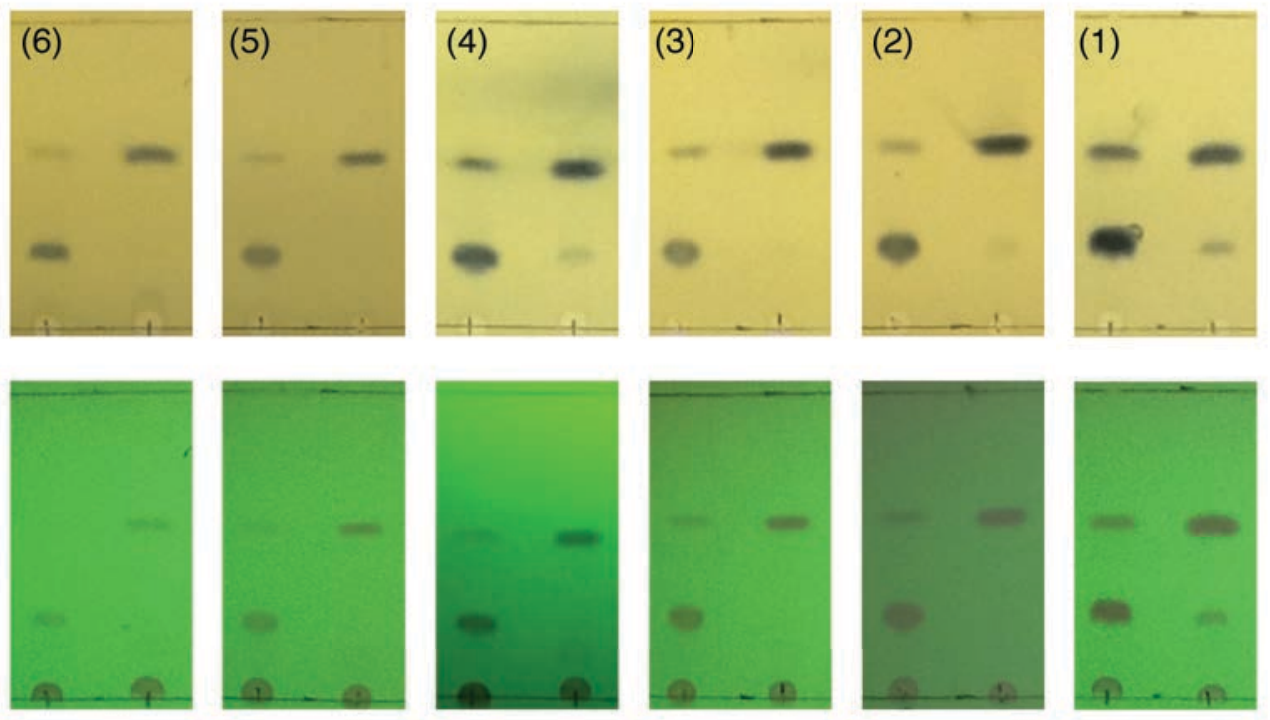

Figure SI.3. TLC plate images of CEC kit conditions for entries 1-6 in Table SI.4, plotted in Figure 6. The left lane of each TLC plate contains $R$-HBTM and the right lane contains $S$ HBTM. Plates were eluted in $30 \%$ ethyl acetate in hexanes. Visualization was achieved by UV lamp (bottom row) and staining with PMA stain (top row). Plate numbers correlate to entry numbers in Table SI.4. 
Table SI.5. $R$-HBTM GC-MS integration data and reaction conversion for entries 1-6 of Table SI.4 plotted in Figure 6

\begin{tabular}{|c|c|c|c|c|c|c|c|c|}
\hline & $\begin{array}{l}\text { lume for } \\
2.5 \mathrm{mM}\end{array}$ & \multicolumn{2}{|c|}{ GC-MS integration } & \multicolumn{2}{|c|}{$\begin{array}{c}\text { GC-MS integration } \\
(/ \mathbf{1 0 0 0 0 0 0 0 0 )}\end{array}$} & \multicolumn{2}{|c|}{$\begin{array}{l}\text { calculated } \\
\text { conc. }(\mathbf{m M})\end{array}$} & $\begin{array}{l}\text { rxn } \\
\text { conv. }\end{array}$ \\
\hline Entry & $(\mathrm{mL})$ & $(R)-5$ & $(R)-6$ & $(R)-5$ & $(R)-6$ & $(R)-5$ & $(R)-6$ & $(\%)$ \\
\hline 1 & 11.49 & 454669679 & 206664466 & 4.54669679 & 2.06664466 & 1.1 & 0.17 & 13 \\
\hline 2 & 5.74 & 454000294 & 231883693 & 4.54000294 & 2.31883693 & 1.1 & 0.19 & 15 \\
\hline 3 & 2.87 & 533763819 & 298020674 & 5.33763819 & 2.98020674 & 1.3 & 0.24 & 16 \\
\hline 5 & 1.15 & 627156689 & 337632800 & 6.27156689 & 3.376328 & 1.4 & 0.27 & 16 \\
\hline 6 & 0.57 & 628174270 & 353906743 & 6.2817427 & 3.53906743 & 1.4 & 0.29 & 17 \\
\hline
\end{tabular}

Table SI.6. S-HBTM GC-MS integration data and reaction conversion for entries 1-6 of Table SI.4 plotted in Figure 6

\begin{tabular}{|c|c|c|c|c|c|c|c|c|}
\hline & $\begin{array}{l}\text { olume for } \\
2.5 \mathrm{mM}\end{array}$ & GC-MS & ntegration & $\begin{array}{r}\text { GC-MS } \\
(/ 100\end{array}$ & $\begin{array}{l}\text { itegration } \\
00000)\end{array}$ & $\begin{array}{l}\text { calc } \\
\text { conc }\end{array}$ & $\begin{array}{l}\text { ed } \\
M)\end{array}$ & $\begin{array}{c}\text { rxn } \\
\text { conv. }\end{array}$ \\
\hline Entry & $(\mathbf{m L})$ & $(R)-5$ & $(R)-6$ & $(R)-5$ & $(R)-6$ & $(R)-5$ & $(R)-6$ & $(\%)$ \\
\hline 1 & 11.49 & 7044090 & 858842838 & 0.0704409 & 8.58842838 & 0.019 & 0.68 & 97 \\
\hline 2 & 5.74 & 2194404 & 1042526810 & 0.02194404 & 10.4252681 & 0.0059 & 0.81 & 99 \\
\hline 3 & 2.87 & 3228511 & 1038670941 & 0.03228511 & 10.38670941 & 0.0087 & 0.81 & 99 \\
\hline 5 & 1.15 & 3530036 & 1351621465 & 0.03530036 & 13.51621465 & 0.0095 & 1.0 & 99 \\
\hline 6 & 0.57 & 3540546 & 1374798635 & 0.03540546 & 13.74798635 & 0.0096 & 1.1 & 99 \\
\hline
\end{tabular}


${ }^{1}$ H NMR Spectra CEC Analysis for entries 1-6 of Table SI.4 plotted in Figure 6

Table SI.4 Entry 1. 29 mM (R)-5 CEC ${ }^{1}$ H NMR spectra




Table SI.4 Entry 2. 14 mM (R)-5 CEC ${ }^{1} \mathrm{H}$ NMR spectra
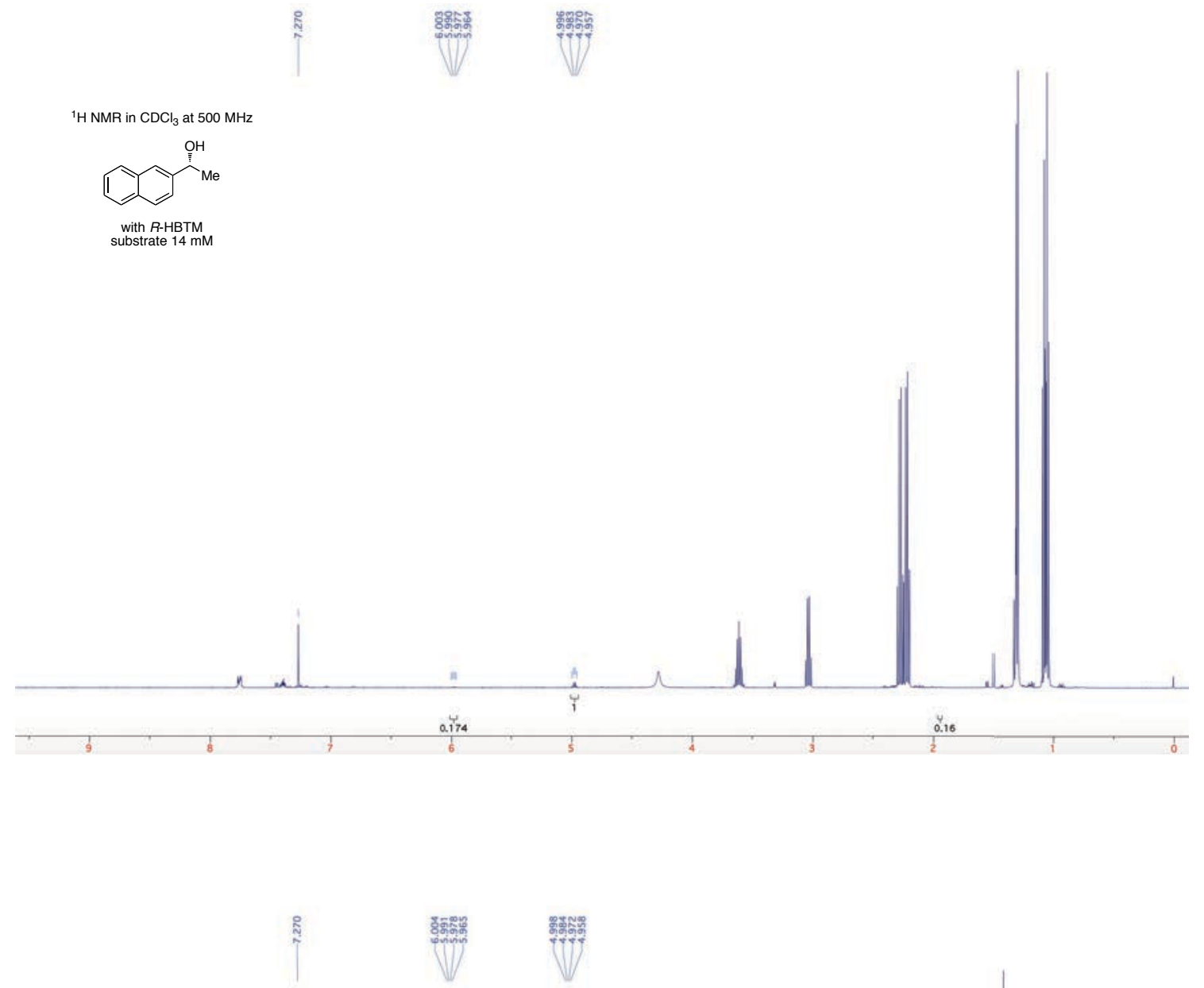

${ }^{1} \mathrm{H} \mathrm{NMR}$ in $\mathrm{CDCl}_{3}$ at $500 \mathrm{MHz}$

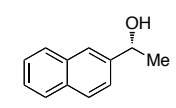

with S-HBTM

substrate $14 \mathrm{mM}$ 
Table SI.4 Entry 3. $7.2 \mathrm{mM}(\boldsymbol{R})-5 \mathrm{CEC}{ }^{1} \mathrm{H}$ NMR spectra
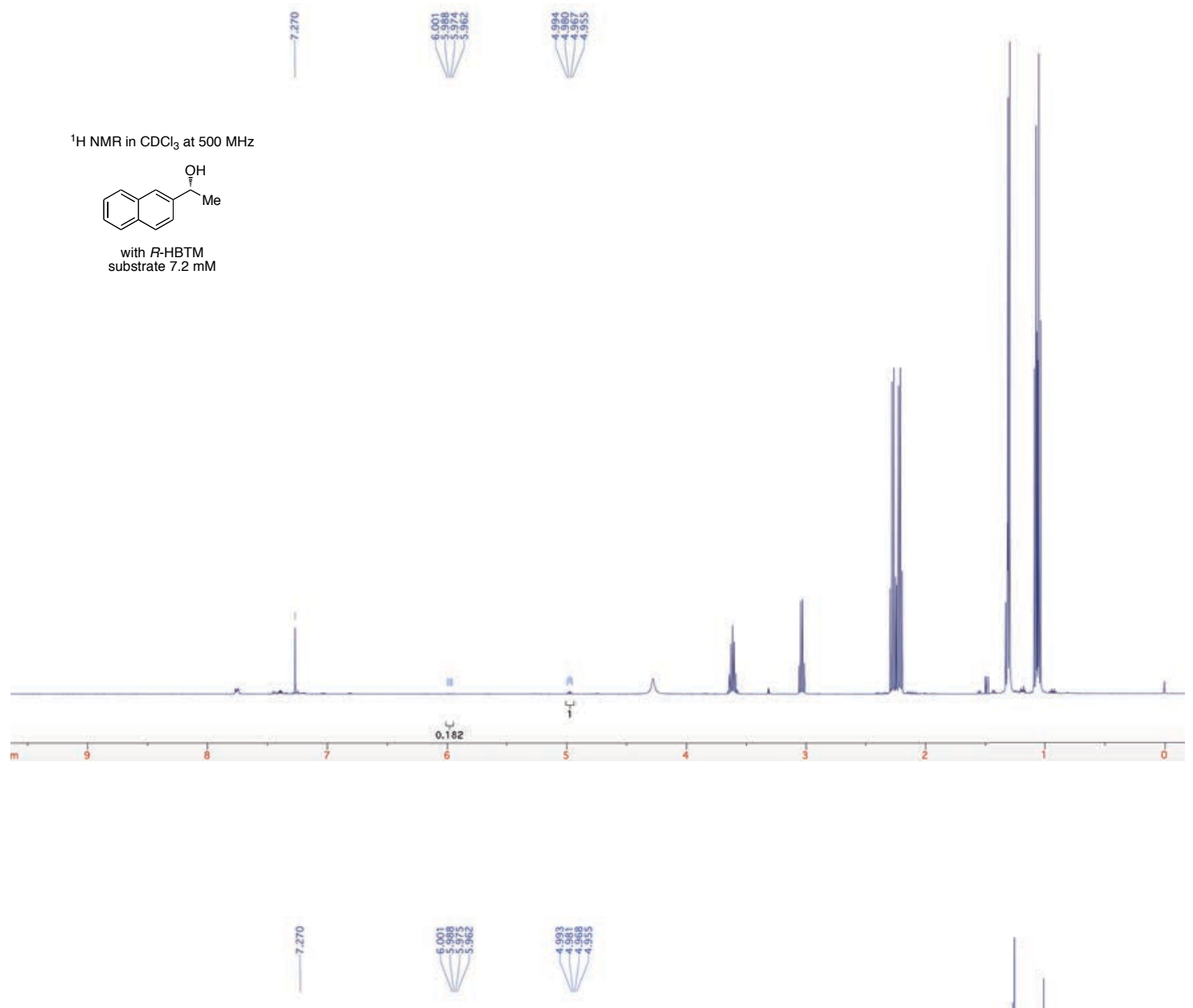

${ }^{1} \mathrm{H} \mathrm{NMR}$ in $\mathrm{CDCl}_{3}$ at $500 \mathrm{MHz}$



substrate $7.2 \mathrm{mM}$ 
Table SI.4 Entry 4. 4.8 mM (R)-5 CEC ${ }^{1} \mathrm{H}$ NMR spectra
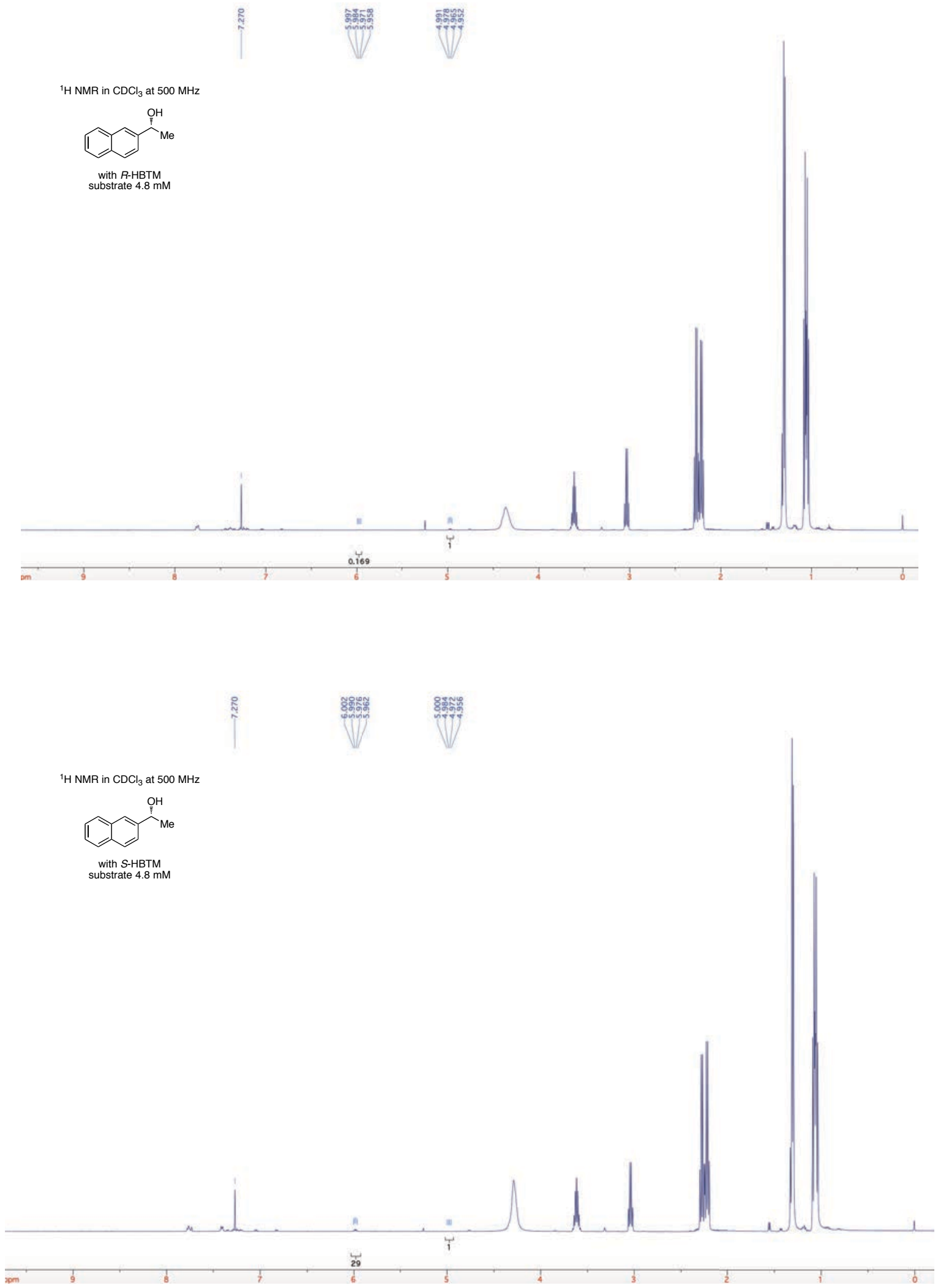
Table SI.4 Entry 5. 2.9 mM (R)-5 CEC ${ }^{1} \mathrm{H}$ NMR spectra
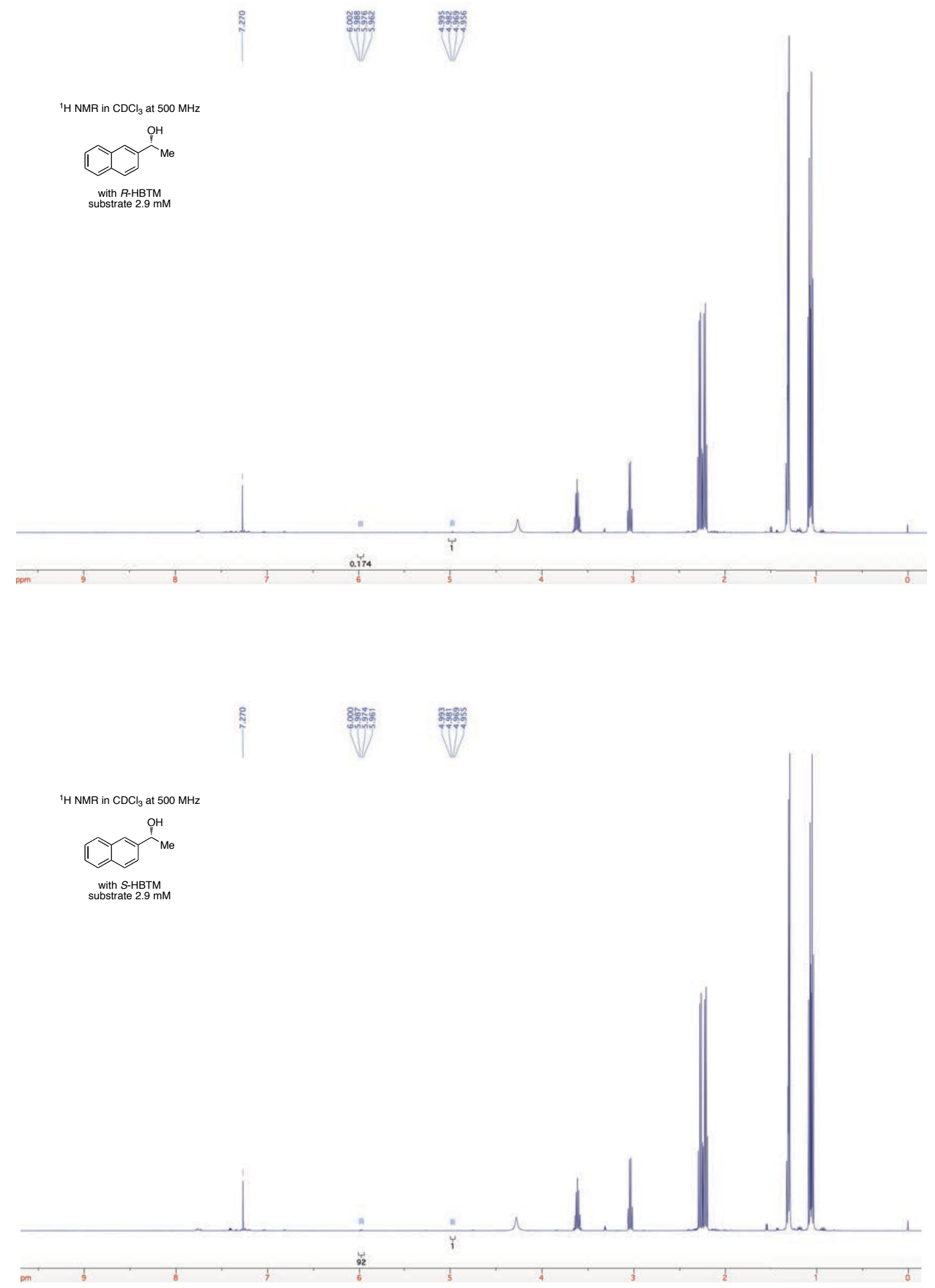
Table SI.4 Entry 6. $1.4 \mathrm{mM}(\boldsymbol{R})-5 \mathrm{CEC}^{1} \mathrm{H}$ NMR spectra
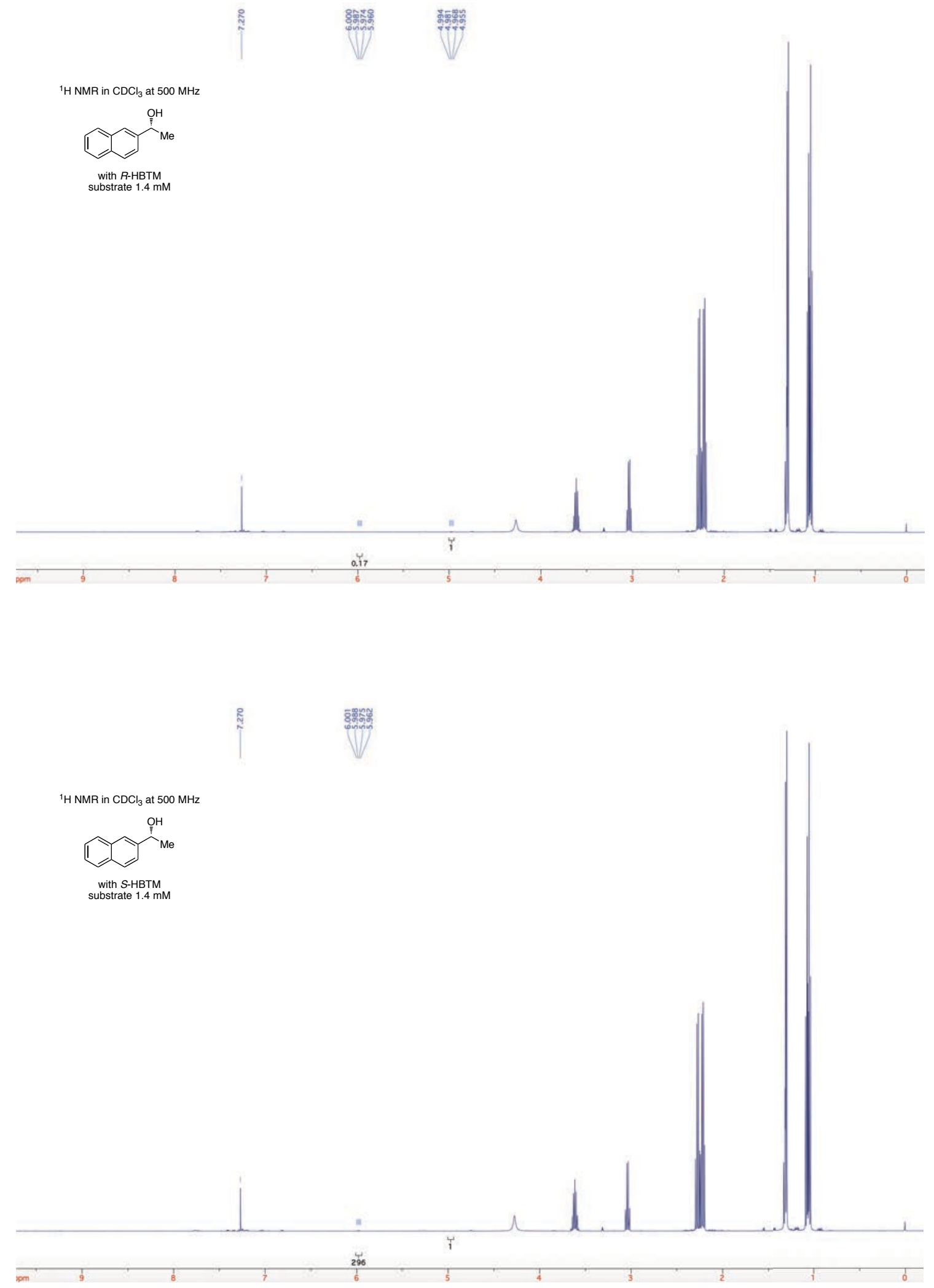


\section{Additional Data for Table 5}

\section{Testing Reaction Conversion by Varied Solvent to Solvate $(R)-5$ with the $\mathrm{CEC} \mathrm{Kit} \mathrm{in} \mathrm{CDCl}_{3}$} Preparation of Solutions

Substrate. Substrate $(\boldsymbol{R})-5(3.4 \mathrm{mg}, 0.020 \mathrm{mmol})$ was solvated in a deuterated solvent varying between entries $1-7$ of Table $5(250, \mu \mathrm{L})$ in a 1 dram vial.

CEC Kit. Prepared as previously described in the Experimental Section.

\section{CEC Protocol}

The resulting alcohol solution $(100 . \mu \mathrm{L})$ was dispensed to both the $R$-HBTM and $S$-HBTM CEC kit vials via microsyringe with a one-minute gap between additions. A needle was inserted to the CEC kit vial to equalize the pressure before addition of the alcohol solution. The solutions were agitated to ensure homogeneity and let sit for $30 \mathrm{~min}$. Methanol- $d_{4}(50 . \mu \mathrm{L})$ was added via microsyringe and the solution was again agitated to ensure homogeneity, halting reaction progress. Deuterated solvents tested are included below in Table SI.7.

\section{TLC Analysis}

To a TLC plate with 2 lanes was spotted the $R$-HBTM reaction $(4.0 \mu \mathrm{L})$, and the $S$-HBTM reaction $(4.0 \mu \mathrm{L})$ via micropipette. The plate was run $(30 \%$ ethyl acetate in hexanes), dried, stained (PMA), heated by oven $\left(160^{\circ} \mathrm{C}, \sim 1 \mathrm{~min}\right)$, and photographed. Images are included in Figure SI.4.

\section{${ }^{1}$ H NMR Analysis}

The quenched solution was then analyzed by ${ }^{1} \mathrm{H}$ NMR spectroscopy to assess reaction conversion via measurement of peak integration of the proton germinal to the alcohol and ester 
functional groups on the substrate and product respectively. Spectra and a graph of dielectric constant compared to reaction conversion for both HBTM reactions for entries 1-7 are included below starting on S39.

Table SI.7. Deuterated solvents used in solvating $(\boldsymbol{R})-5$ for use in the $\mathrm{CEC}$ kit in $\mathrm{CDCl}_{3}$

\begin{tabular}{cc} 
entry & $\begin{array}{c}\text { substrate } \\
\text { loading solvent }\end{array}$ \\
\hline 1 & toluene- $d_{8}$ \\
2 & $\mathrm{CDCl}_{3}$ \\
3 & THF- $d_{8}$ \\
4 & acetone- $d_{6}$ \\
5 & MeCN- $d_{3}$ \\
6 & DMF- $d_{7}$ \\
7 & DMSO- $d_{6}$
\end{tabular}
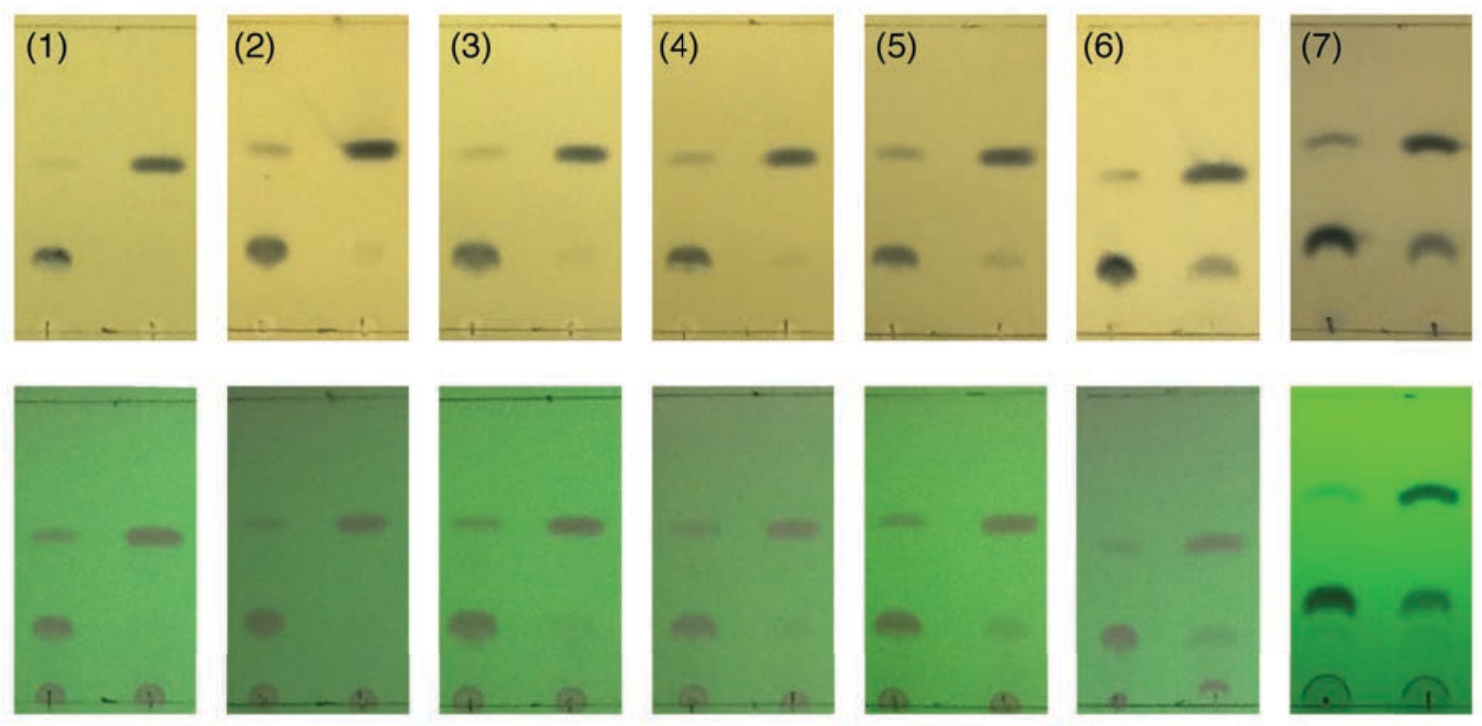

Figure SI.4. TLC plate images of CEC kit conditions for entries 1-7 in Table SI.5. The left lane of each TLC plate contains $R$-HBTM and the right lane contains $S$-HBTM. Plates were eluted in $30 \%$ ethyl acetate in hexanes. Visualization was achieved by UV lamp (bottom row) and staining with PMA stain (top row). Plate numbers correlate to entry numbers in Table SI.5 


\section{${ }^{1}$ H NMR Spectra CEC Analysis of Entries 1-7 from Table 5}

Table 5. Entry 1

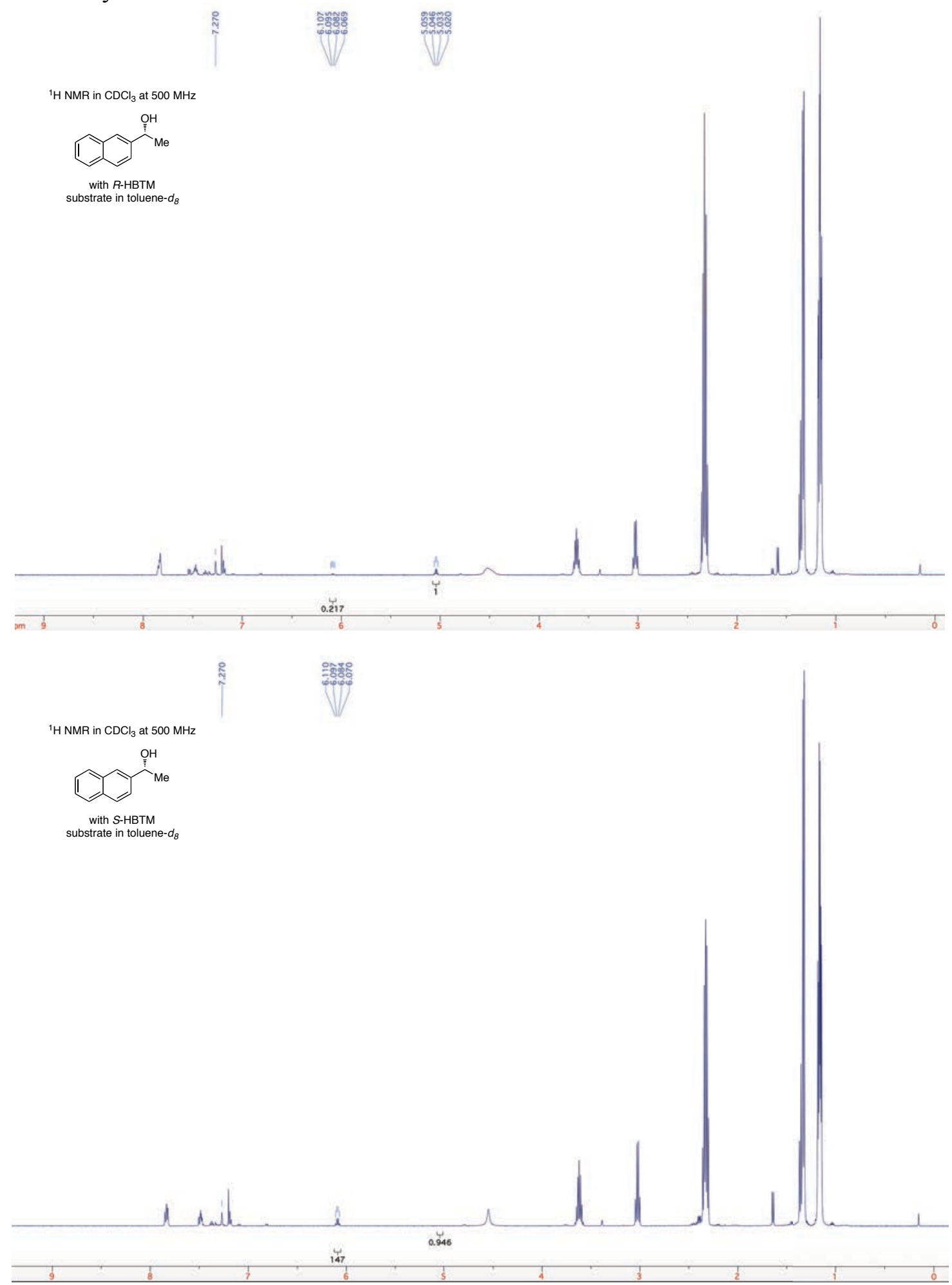


Table 5. Entry 2

Table 5. Entry 3

Table 5. Entry 4



\section{Table 5. Entry 5}

Table 5. Entry 6
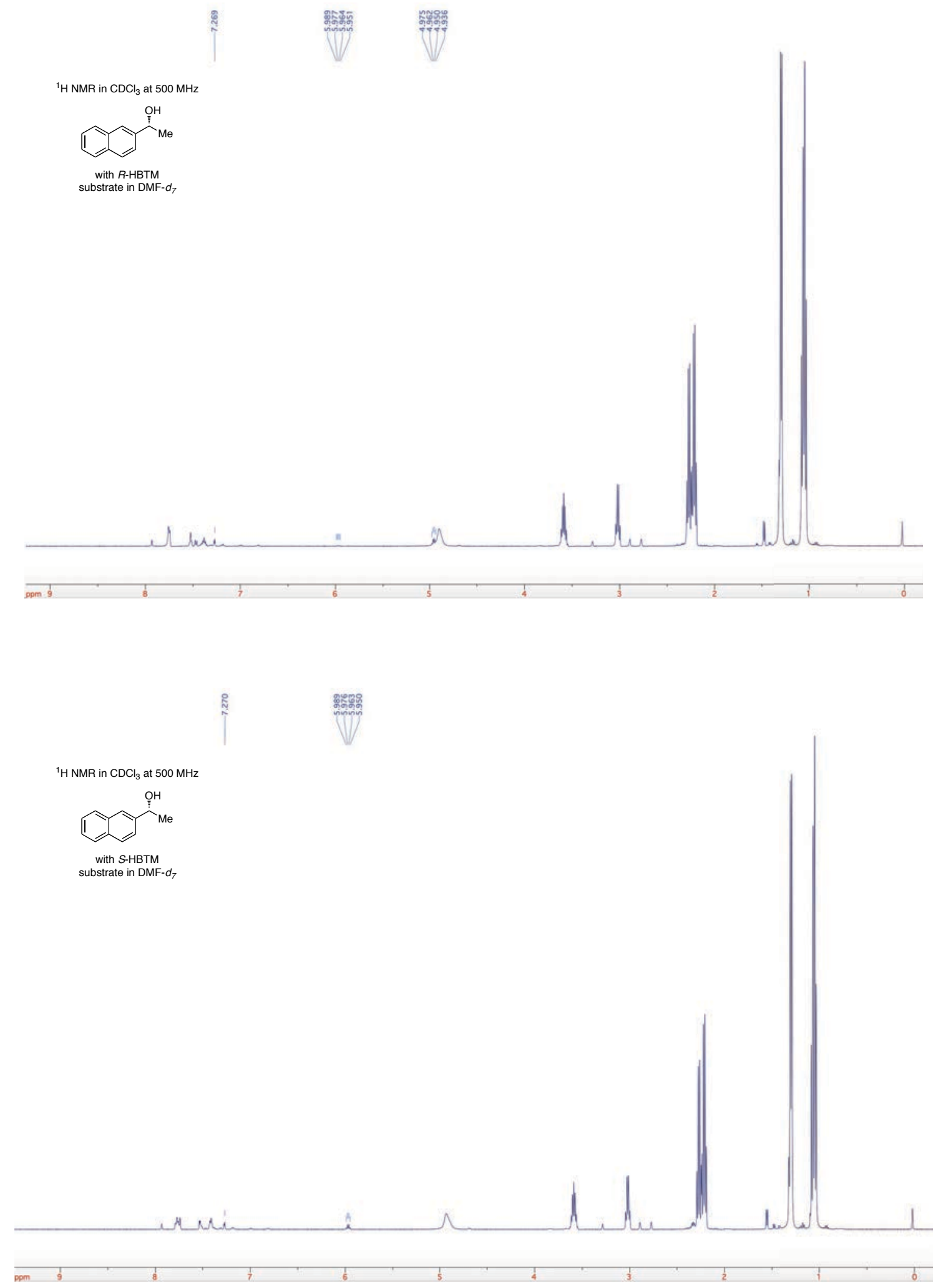
Table 5. Entry 6 - after vacuum removal of solvent and resolvation in $\mathrm{CDCl}_{3}$
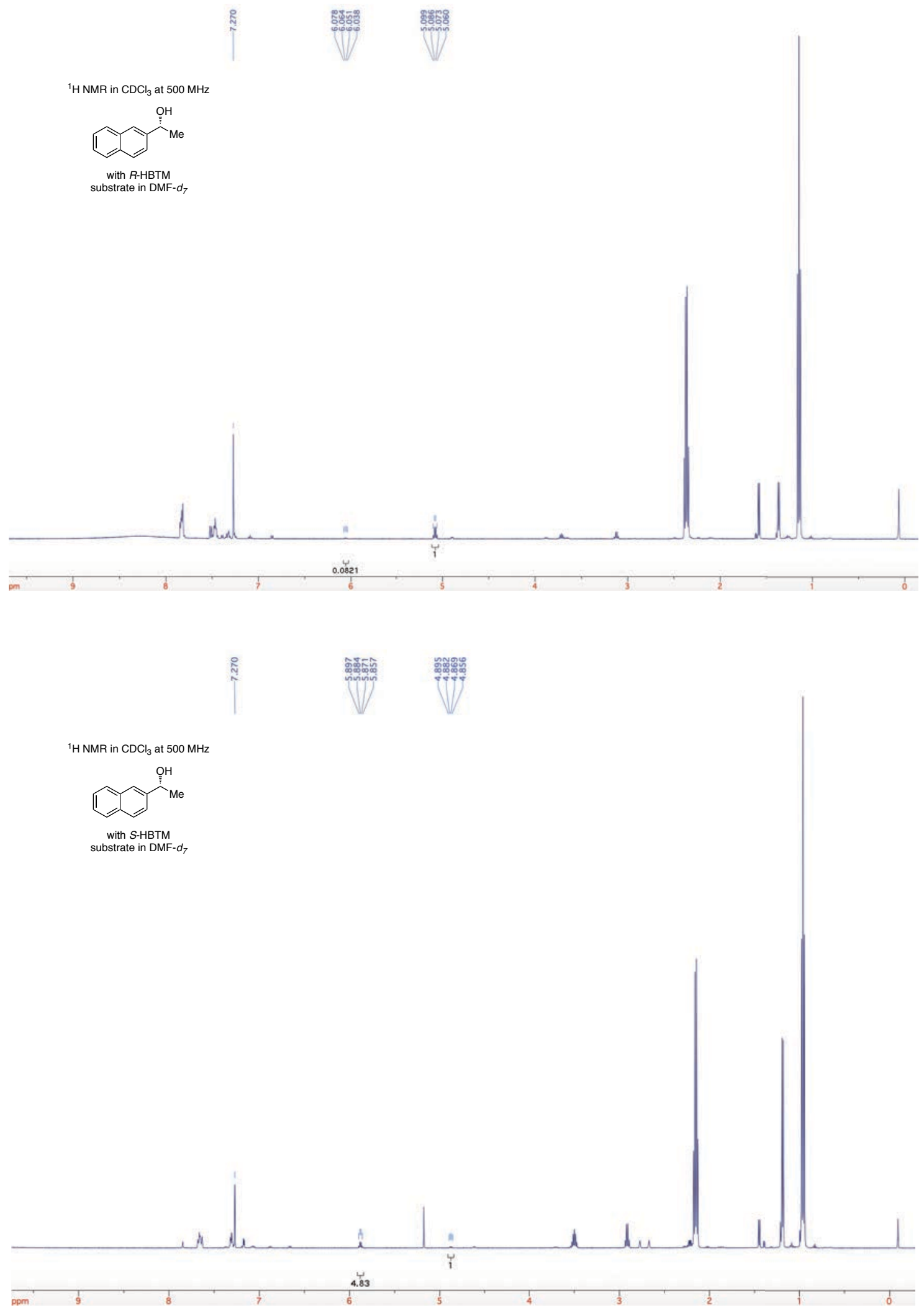
Table 5. Entry 7
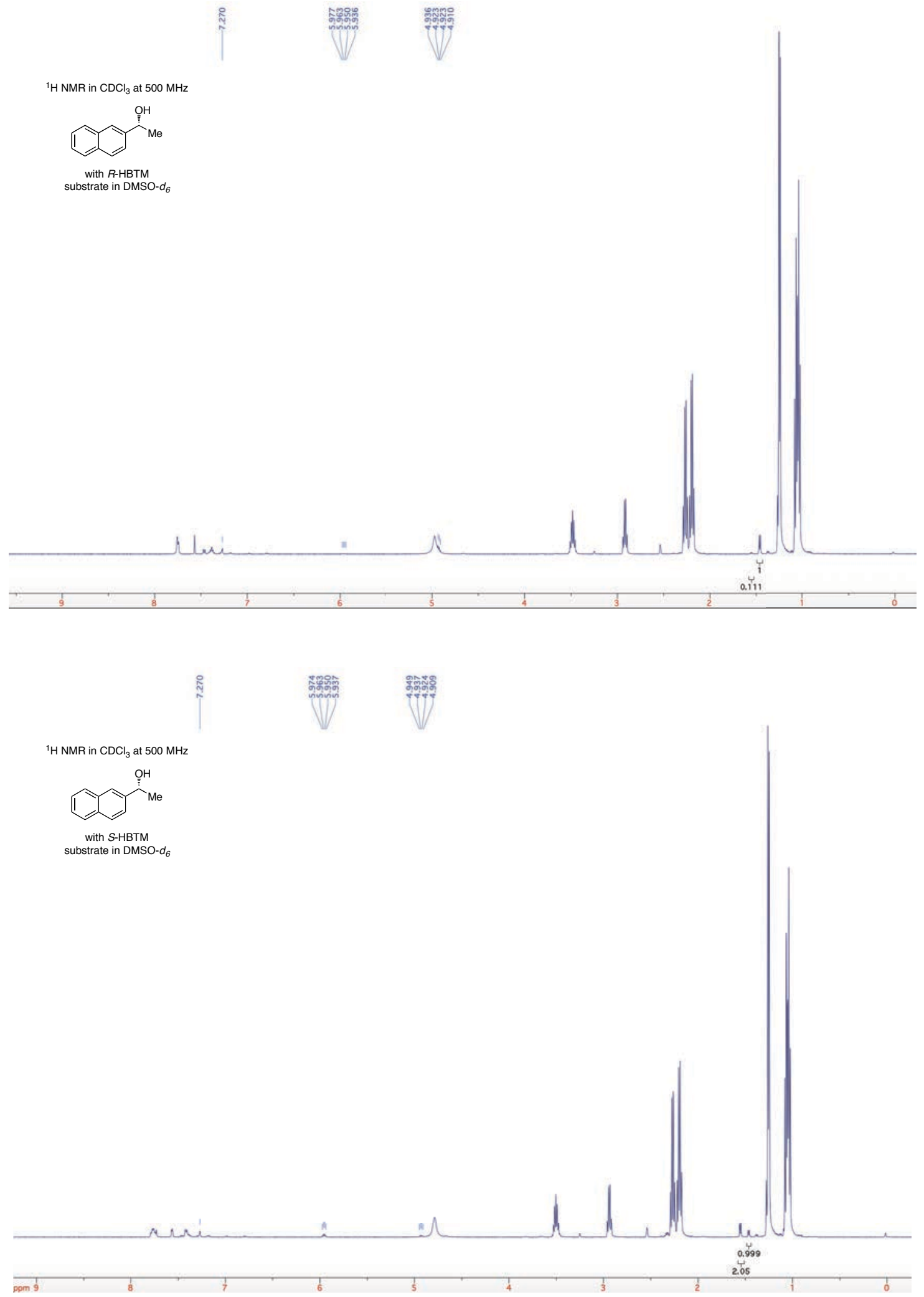
Table 5. Entry 7 - after vacuum removal of solvent and resolvation in $\mathrm{CDCl}_{3}$

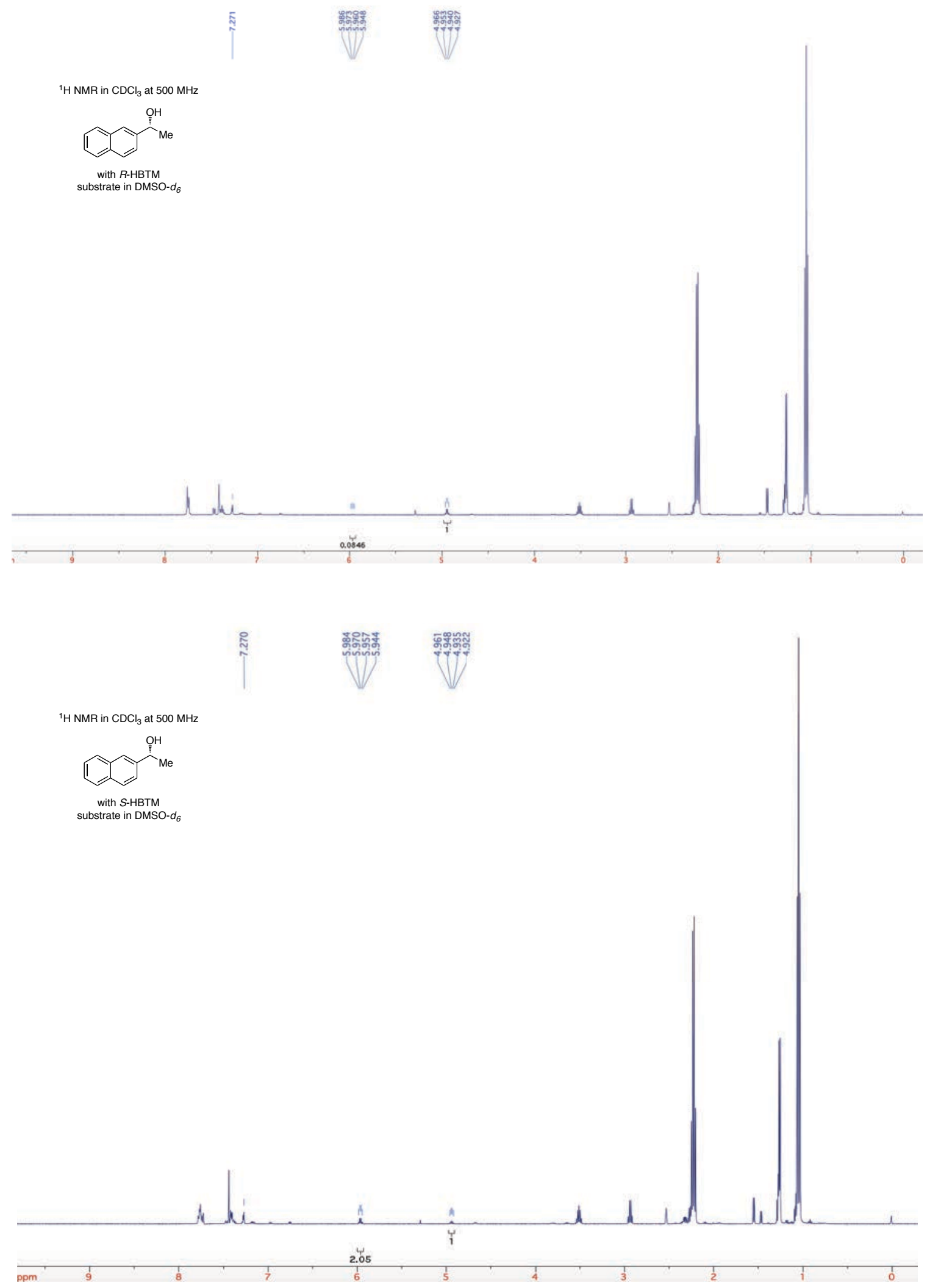




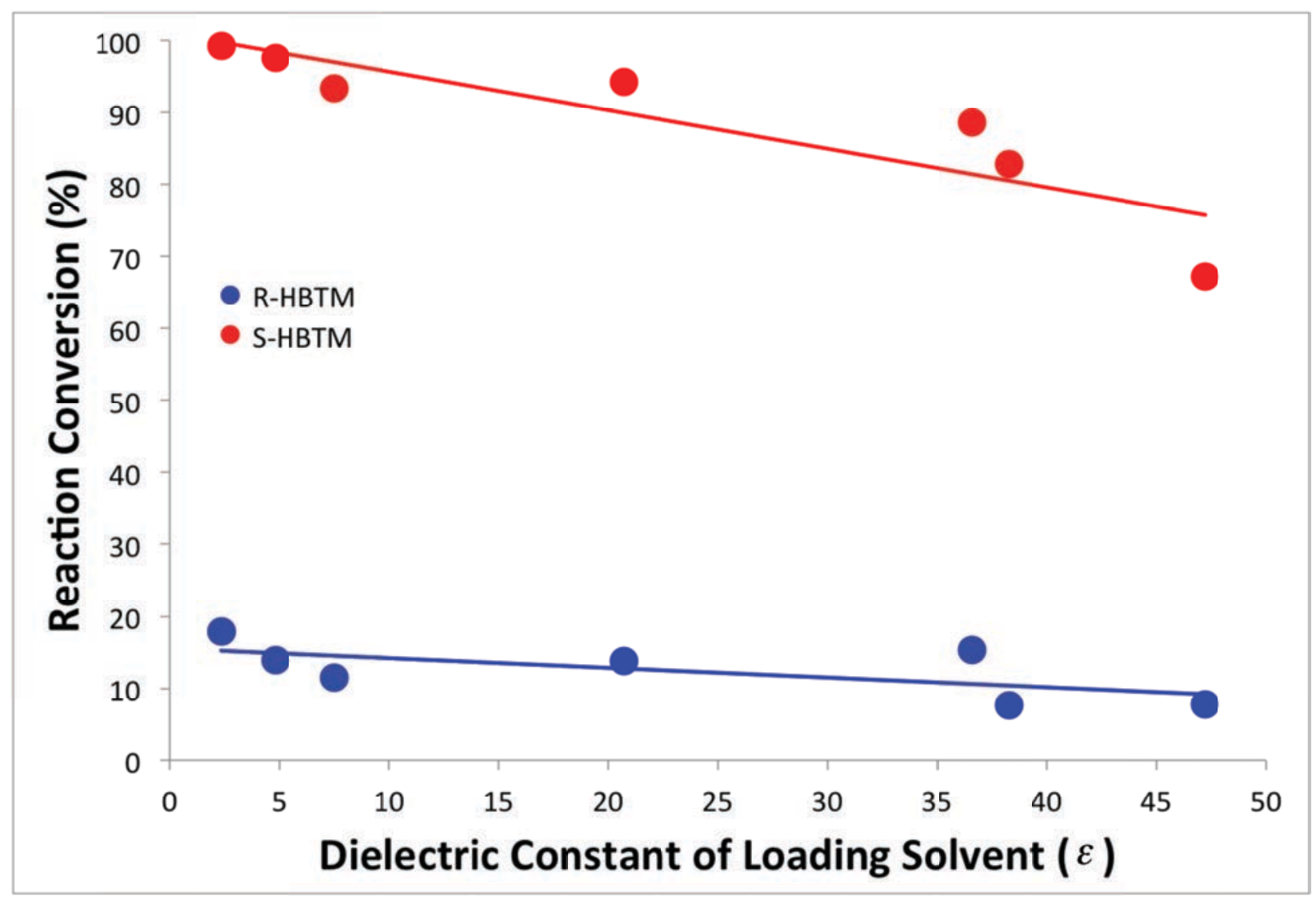

Figure SI.5. Comparison of reaction conversion (\%) after 30 minutes of $(\boldsymbol{R})-\mathbf{5}$ to $(\boldsymbol{R})-\mathbf{6}$ relative to the dielectric constant of the solvent $(\boldsymbol{R})-\mathbf{5}$ was loaded into to the CEC kit that contained $\mathrm{CDCl}_{3}$. 


\section{Additional Data for Tables 6, Table 7, and Figure 9}

Table SI.8. Masses, TLC solvent systems, and TLC plate staining solutions used for compounds in Tables 6 and 7 with the CEC kit protocol

\begin{tabular}{|c|c|c|c|c|}
\hline table & entry & $\begin{array}{c}\text { mass in } 1 \\
\text { dram vial } \\
\text { (mg) }\end{array}$ & TLC solvent conditions & TLC stain \\
\hline 6 & 1 & 3.4 & 3:1 hexanes/ethyl acetate & PMA \\
\hline 6 & 2 & 3.4 & $3: 1$ hexanes/ethyl acetate & PMA \\
\hline 6 & 3 & 4.0 & 3:1 hexanes/ethyl acetate & PMA \\
\hline 6 & 4 & 3.0 & $3: 1$ hexanes/ethyl acetate & PMA \\
\hline 6 & 5 & 4.4 & ethyl acetate & Dragendorf-Munier $^{\mathrm{b}}$ \\
\hline 6 & 6 & 4.2 & $6: 1$ hexanes/ethyl acetate & Dragendorf-Munier $^{\mathrm{b}}$ \\
\hline 6 & 7 & 3.6 & $6: 1$ hexanes/ethyl acetate & PMA \\
\hline 6 & $8^{\mathrm{a}}$ & 2.5 & ethyl acetate & Hannesian \\
\hline 6 & 9 & 2.5 & 1:2 hexanes/ethyl acetate & Dragendorf-Munier $^{\mathrm{b}}$ \\
\hline 6 & $10^{\mathrm{a}}$ & 3.2 & ethyl acetate & Dragendorf-Munier $^{b}$ \\
\hline 6 & $11^{\mathrm{a}}$ & 3.2 & ethyl acetate & Dragendorf-Munier $^{\mathrm{b}}$ \\
\hline 6 & 12 & 8.0 & 1:9 hexanes/ethyl acetate & $\mathrm{KMnO} 4$ \\
\hline 7 & 1 & 2.8 & $6: 1$ hexanes/ethyl acetate & PMA \\
\hline 7 & 2 & 2.8 & $6: 1$ hexanes/ethyl acetate & $\mathrm{KMnO}_{4}{ }^{\mathrm{b}}$ \\
\hline 7 & 3 & 3.4 & 3:1 hexanes/ethyl acetate & $\mathrm{KMnO}_{4}$ \\
\hline 7 & 4 & 2.2 & 1:1 hexanes/ethyl acetate & Hannesian \\
\hline 7 & 5 & 2.4 & 1:1 hexanes/ethyl acetate & Hannesian $^{\mathrm{b}}$ \\
\hline 7 & 6 & 3.6 & 2:1 hexanes/ethyl acetate & PMA \\
\hline 7 & 7 & 2.9 & ethyl acetate & $\mathrm{KMnO}_{4}$ \\
\hline 7 & 8 & 2.9 & ethyl acetate & $\mathrm{KMnO}_{4}$ \\
\hline 7 & 9 & 4.1 & ethyl acetate & Dragendorf-Munier $^{b}$ \\
\hline 7 & 10 & 6.2 & $6: 1$ hexanes/ethyl acetate & $\mathrm{KMnO}_{4}$ \\
\hline 7 & 11 & 5.5 & $6: 1$ hexanes/ethyl acetate & PMA \\
\hline 7 & 12 & 4.7 & 3:1 hexanes/ethyl acetate & PMA \\
\hline
\end{tabular}

(a) substrate solvated in DMSO- $d_{6}$ before injection into CEC kit in $\mathrm{CDCl}_{3}$ (b) plate was allowed to dry at room temperature over a period of 3-5 min before a photograph of the image was captured 

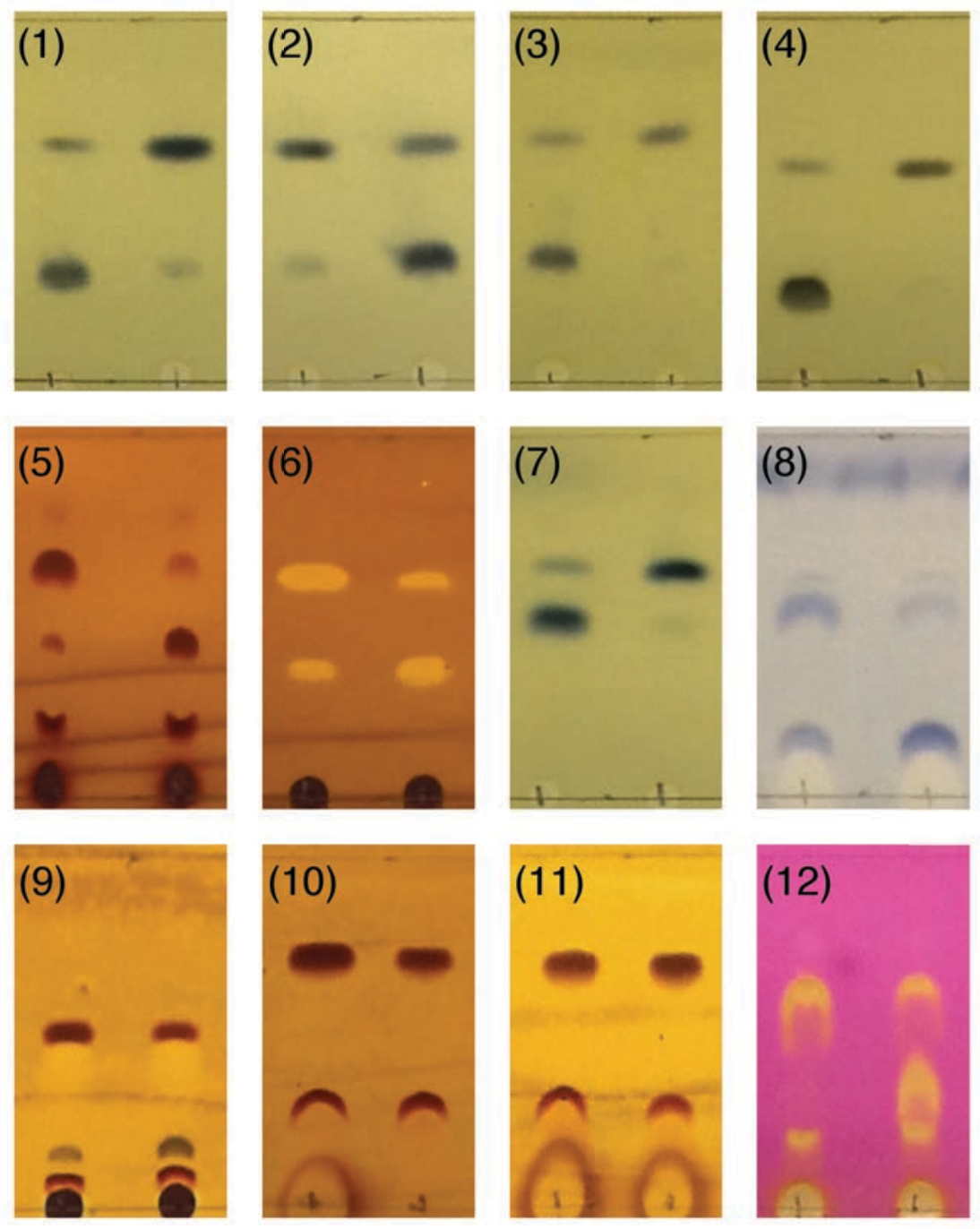

Figure SI.6. TLC images corresponding to each entry tested in Table 6. Left TLC lane: $R$ HBTM; Right TLC lane: S-HBTM. TLC conditions and stains are listed in Table SI.8. 

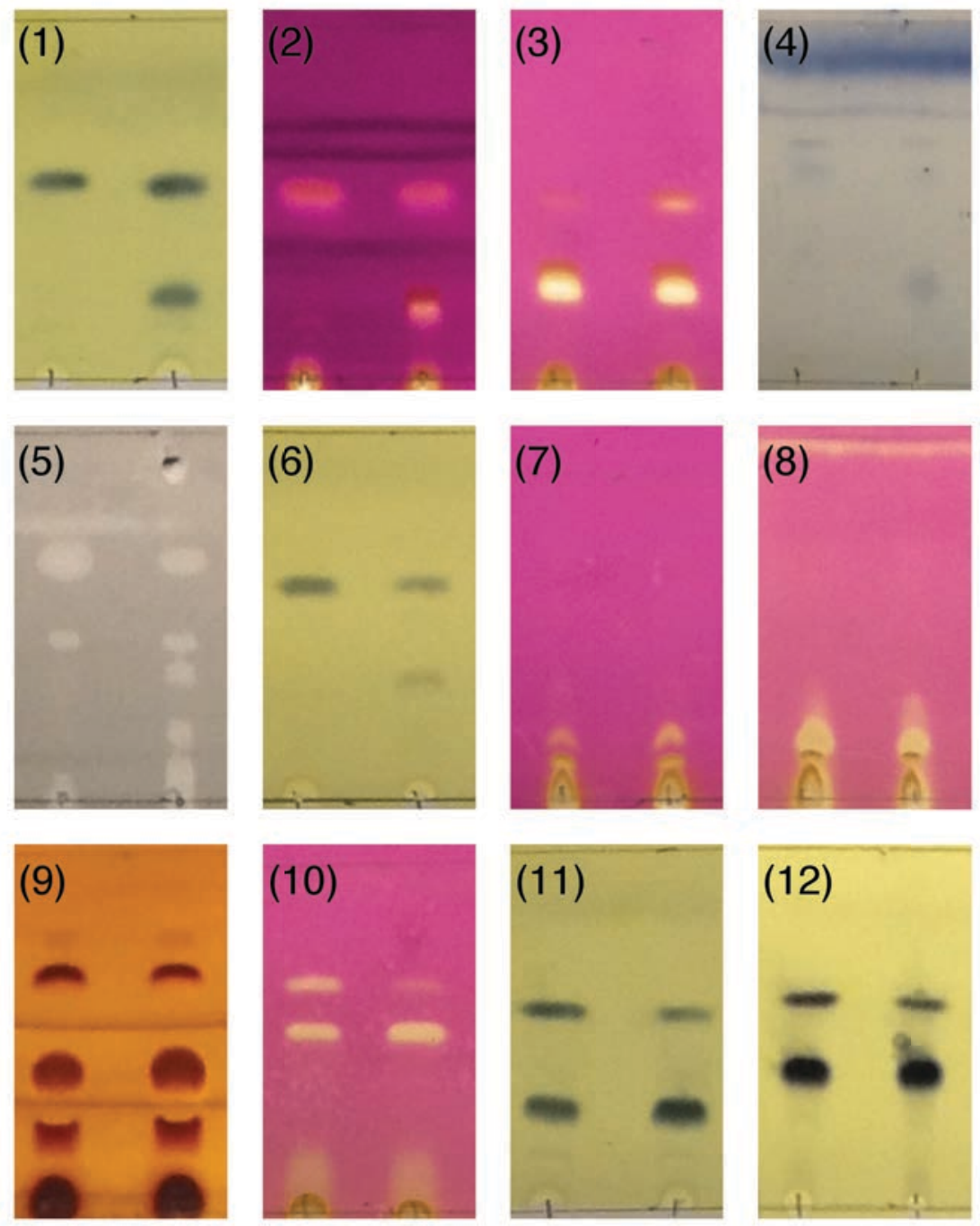

Figure SI.7. TLC images corresponding to each entry tested in Table 7. Left TLC lane: $R$ HBTM; Right TLC lane: $S$-HBTM. TLC conditions and stains are listed in Table SI.8. 


\section{${ }^{1}$ H NMR Spectra CEC Analysis for Tables 6 and 7}

Table 6. Entry 1

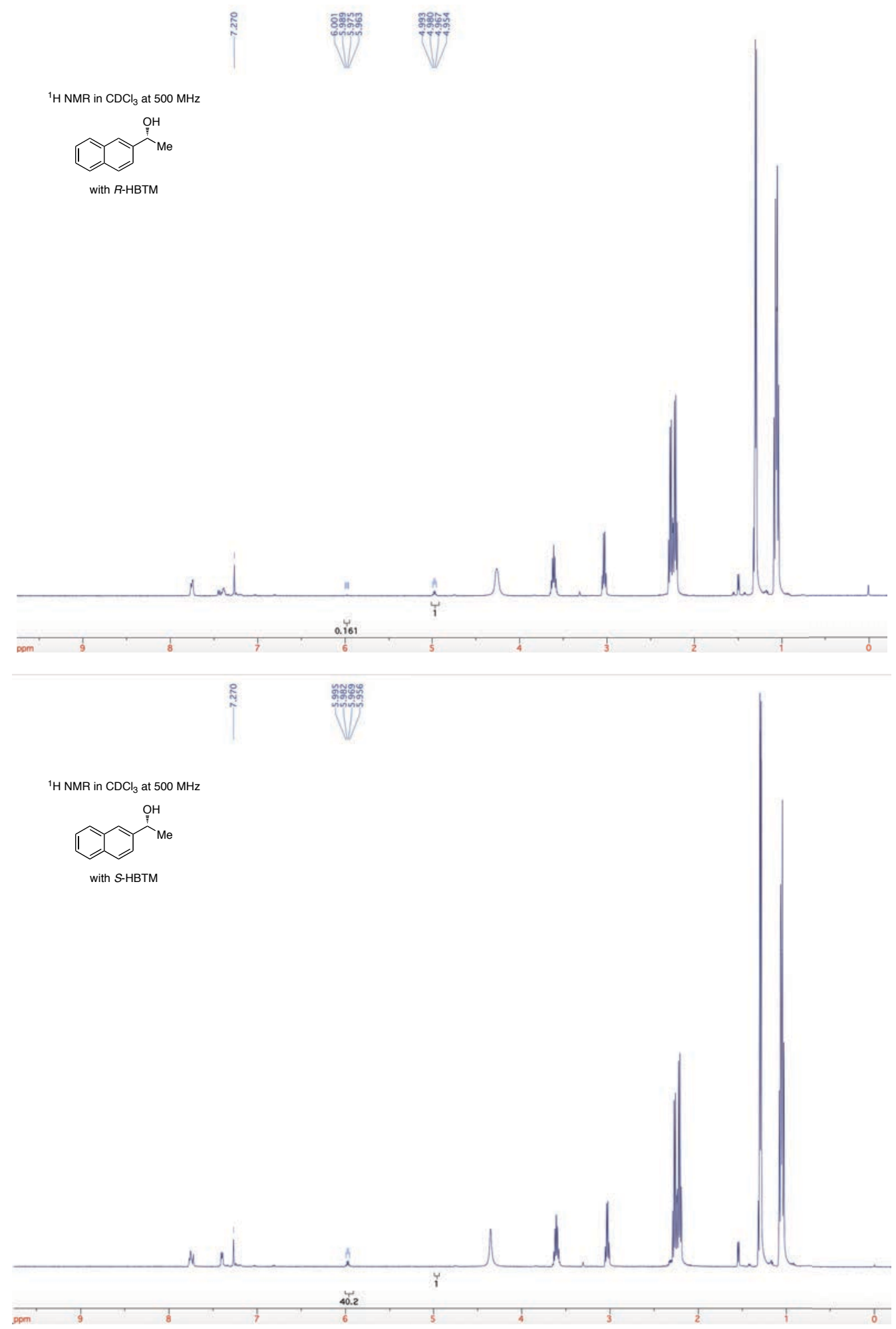


Table 6. Entry 2
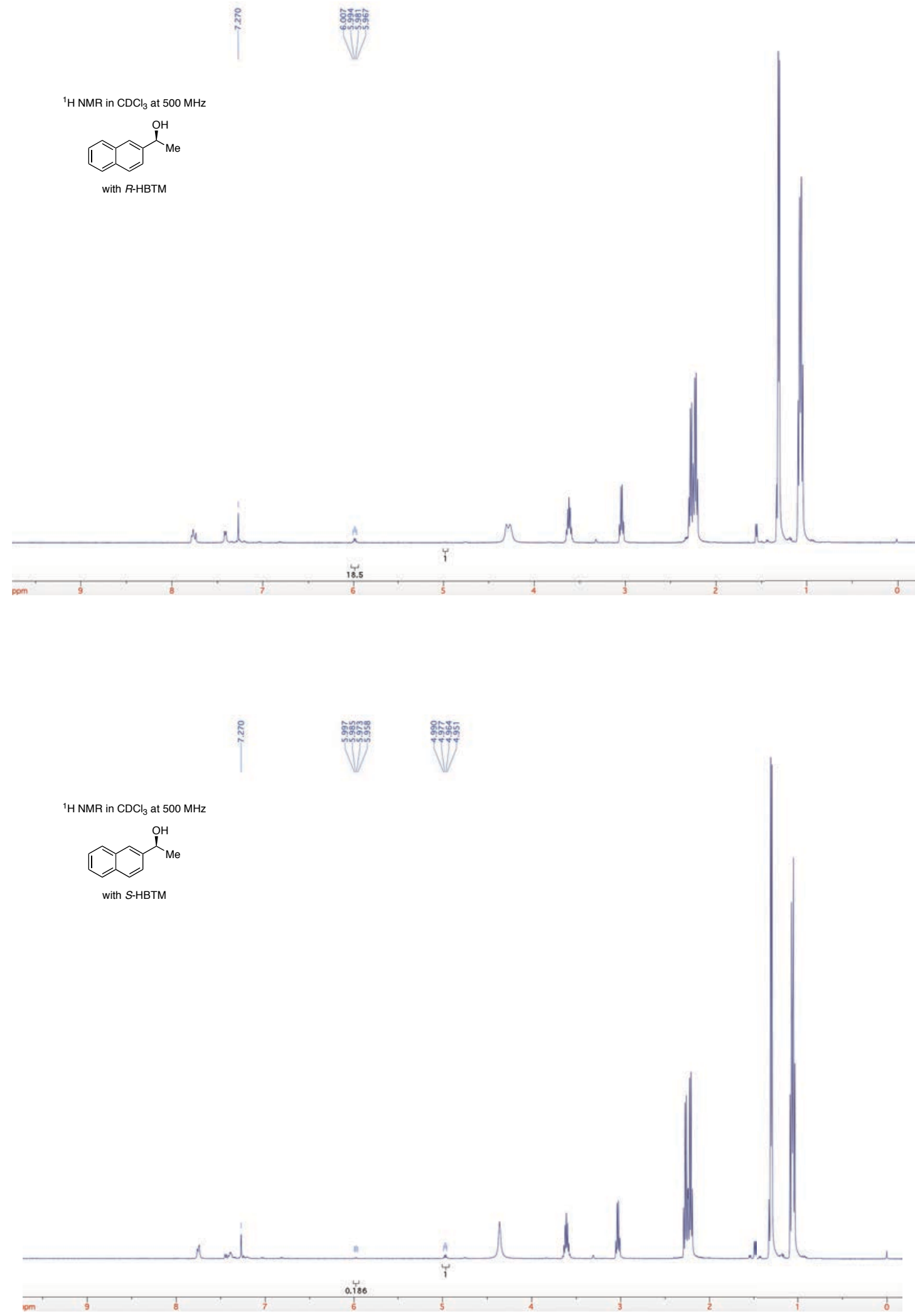
Table 6. Entry 3
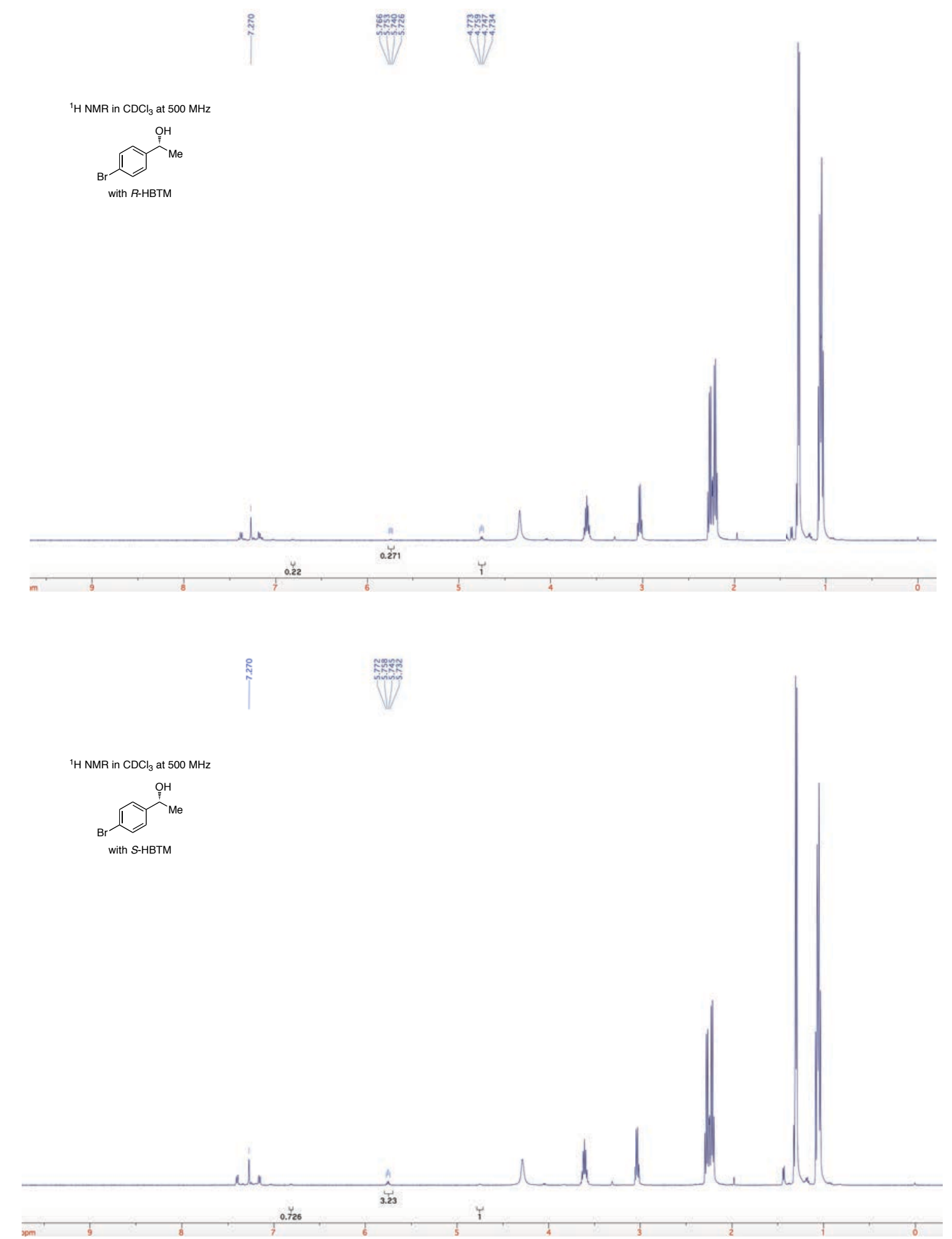

A peak from HBTM $(1 \mathrm{H})$ overlaps with the starting material peak $(1 \mathrm{H})$ at $4.75 \mathrm{ppm}$. The integrated starting material peak in the reaction mixture was calculated by subtracting the integrated catalyst peak $(1 \mathrm{H})$ at $6.81 \mathrm{ppm}$ before calculating percent conversion. 
Table 6. Entry 4


A peak from HBTM $(1 \mathrm{H})$ overlaps with the starting material peak $(1 \mathrm{H})$ at $4.77 \mathrm{ppm}$. The integrated starting material peak in the reaction mixture was calculated by subtracting the integrated catalyst peak $(1 \mathrm{H})$ at $7.03 \mathrm{ppm}$ before calculating percent conversion. 
Table 6. Entry 5
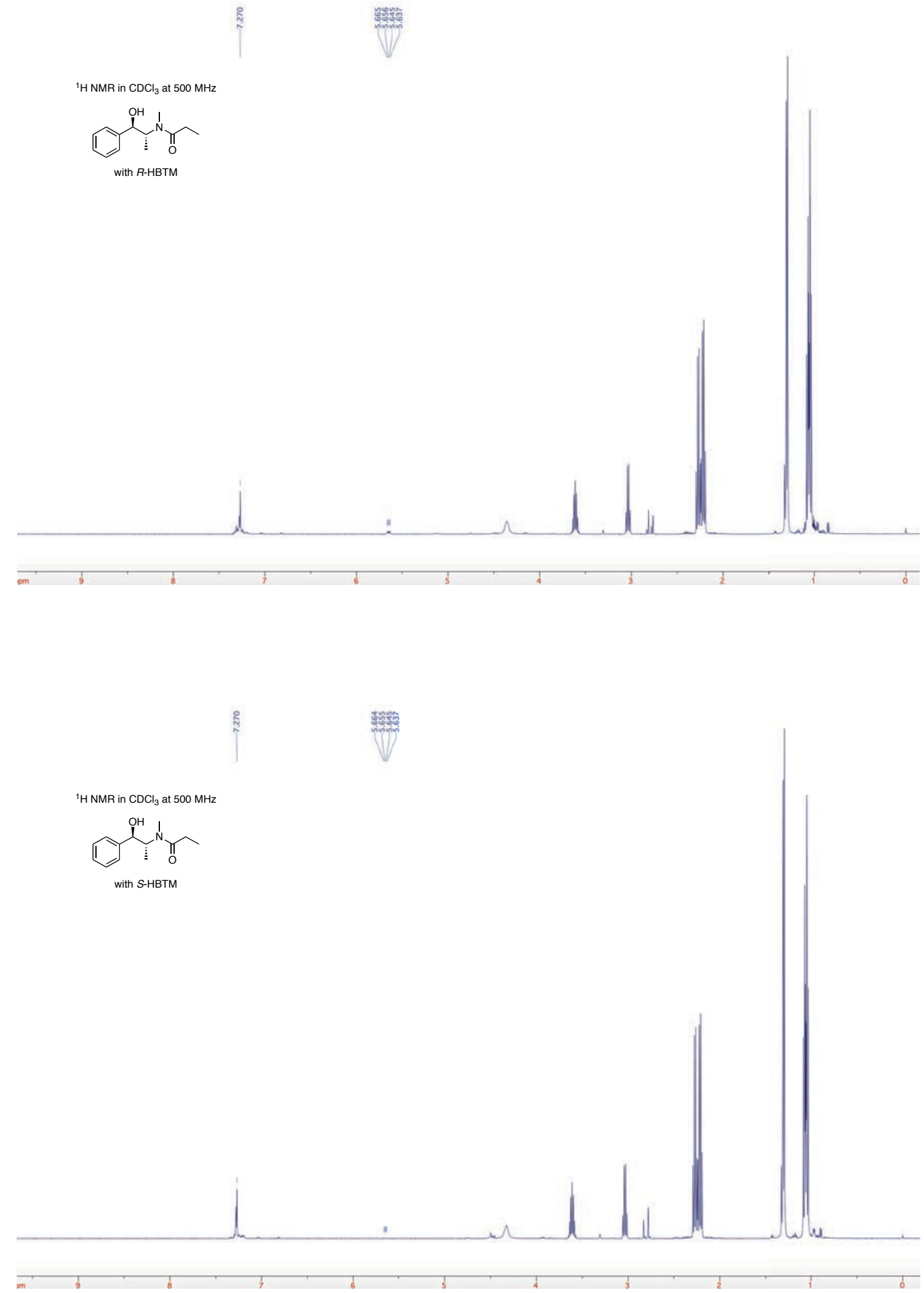
Table 6. Entry 5 - after vacuum removal of solvent and resolvation in $\mathrm{CDCl}_{3}$
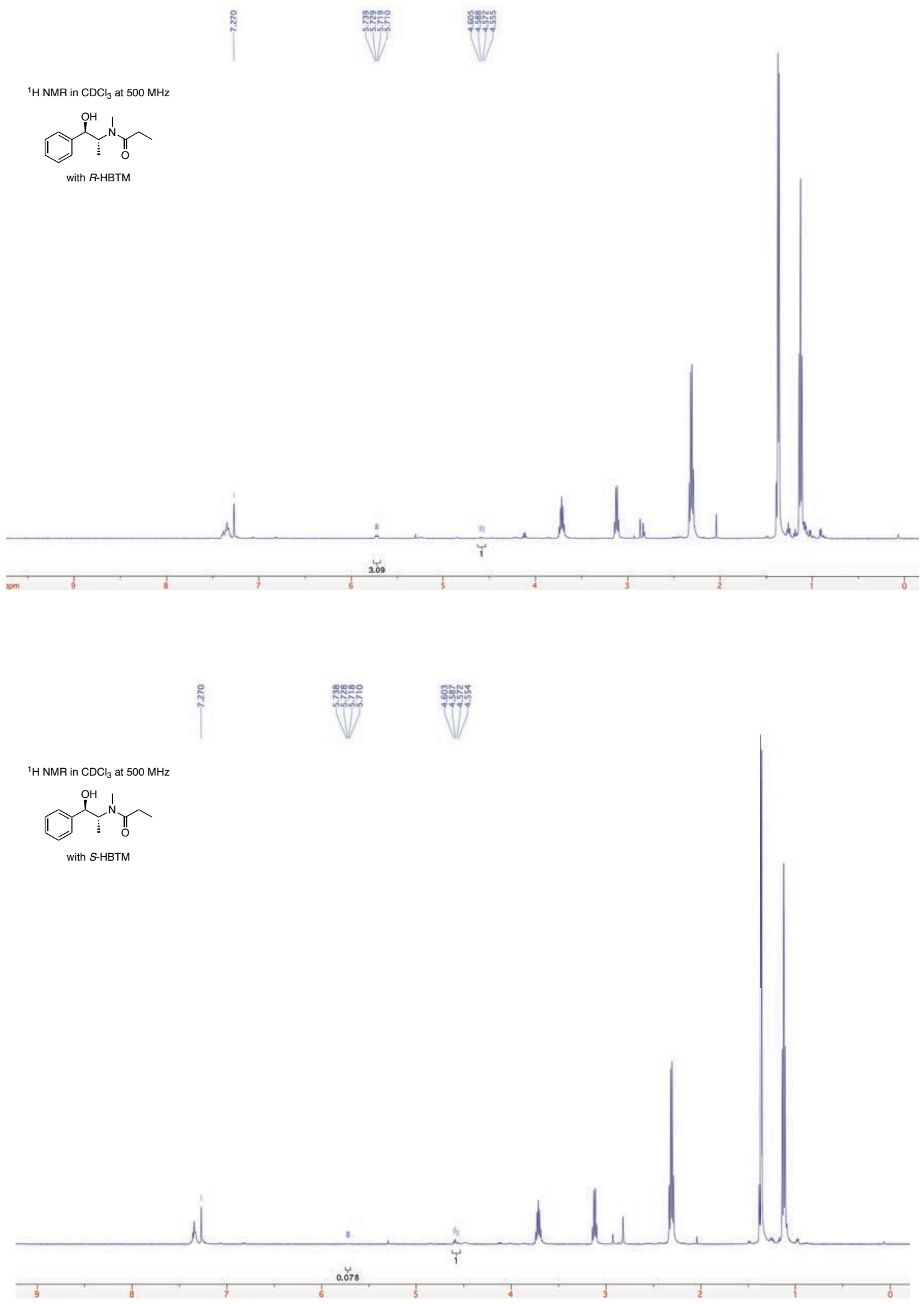
Table 6. Entry 6
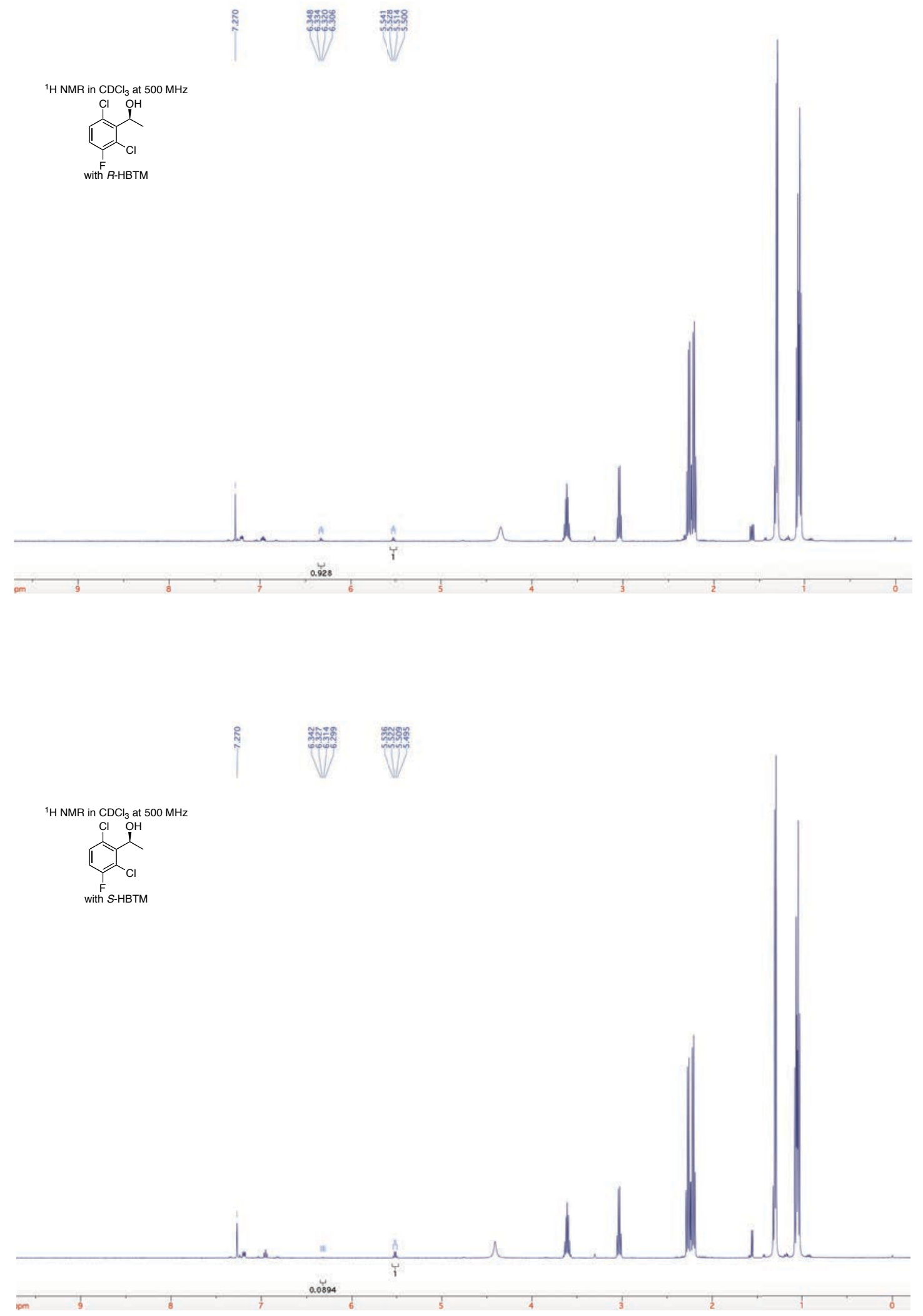
Table 6. Entry 7
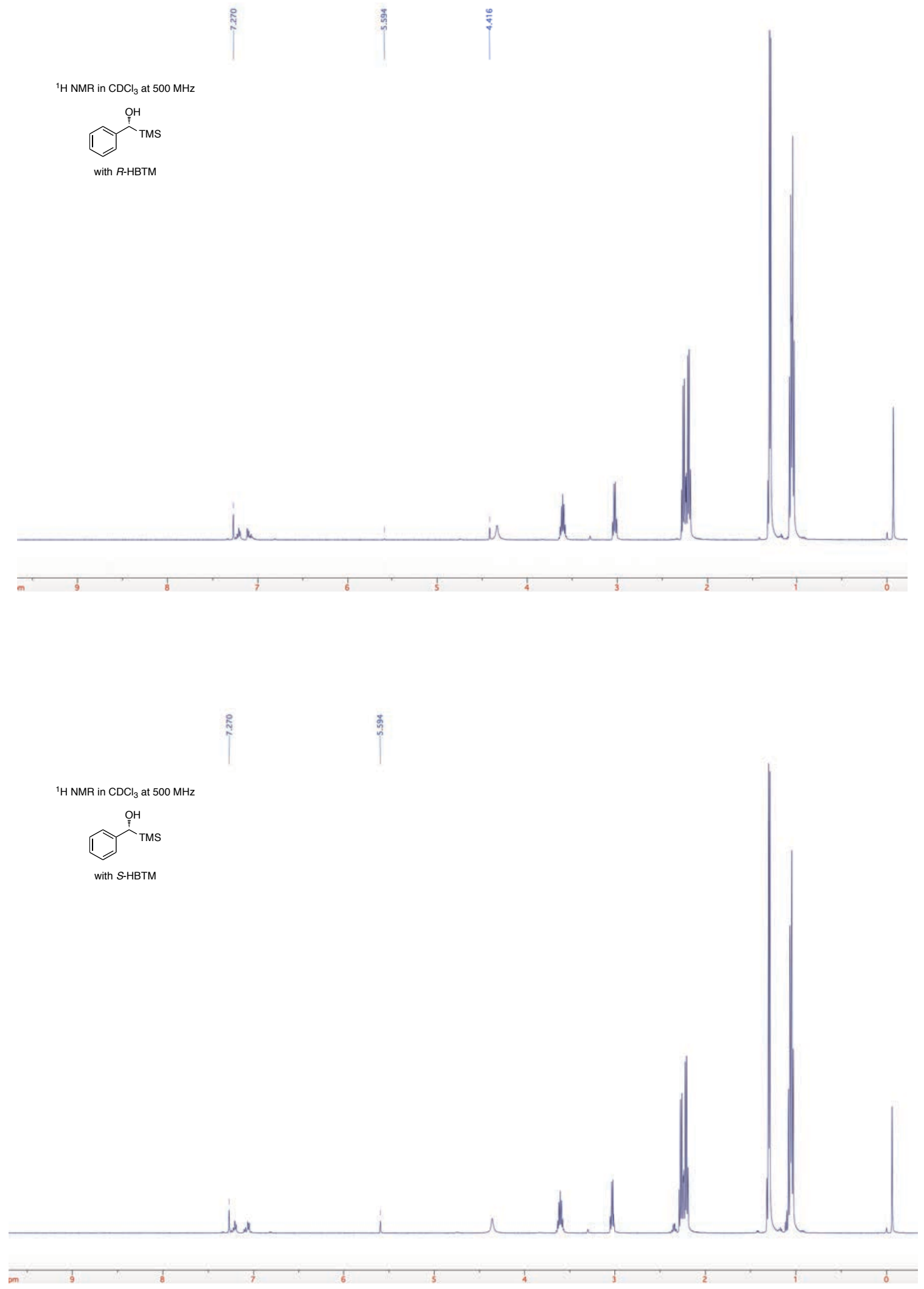
Table 6. Entry 7 - after vacuum removal of solvent and resolvation in $\mathrm{CDCl}_{3}$
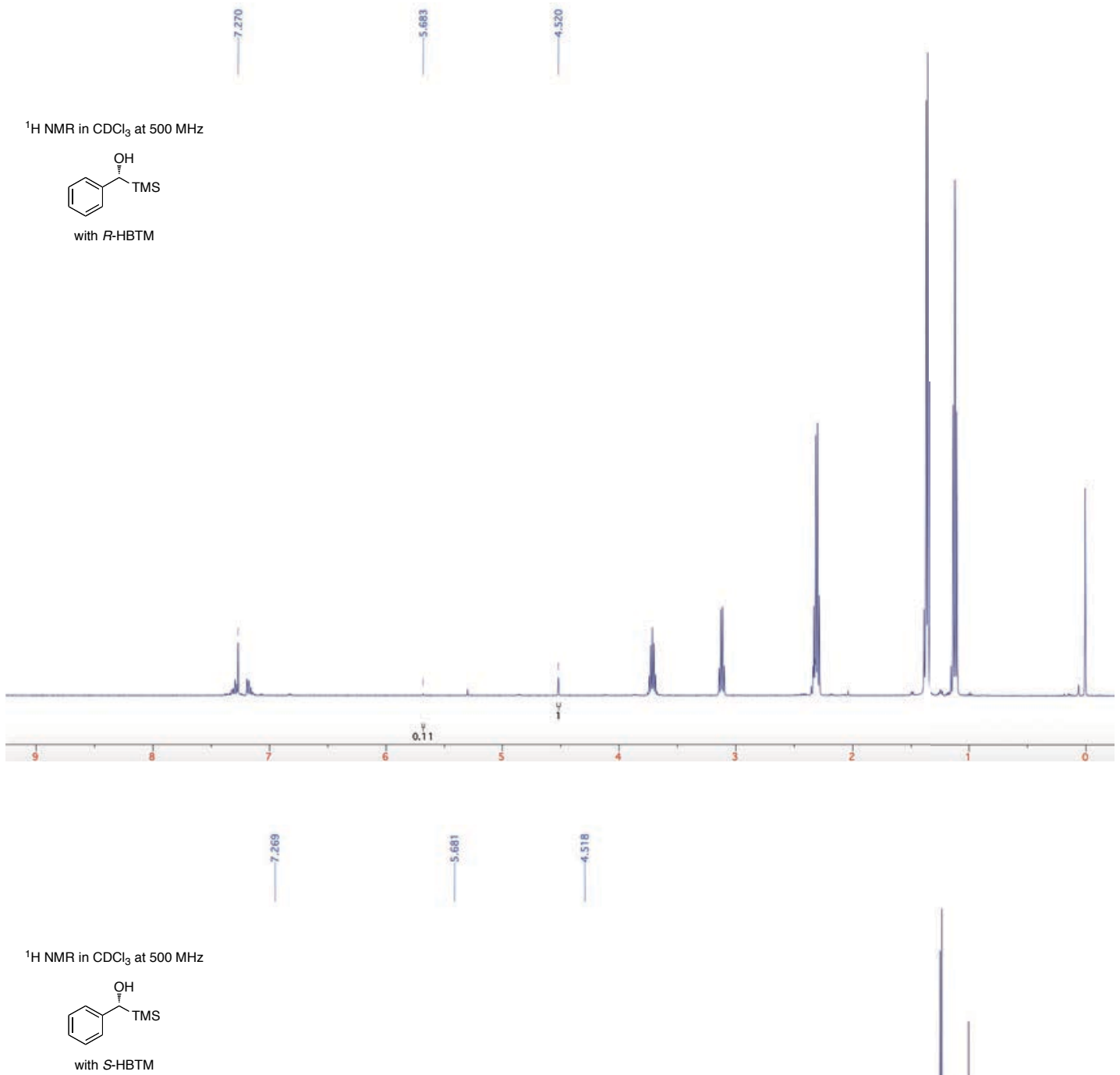

with S-HBTM




Table 6. Entry 8


Peaks are integrated, but not used for conversion in Table $7 ; R$-HBTM $81 \%, S$-HBTM $36 \%$. 
Table 6. Entry 8 - after vacuum removal of solvent and resolvation in $\mathrm{CDCl}_{3}$

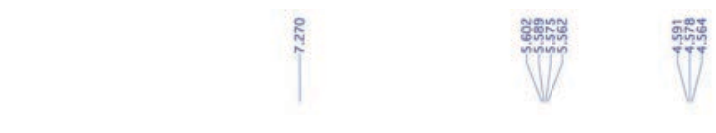

${ }^{1} \mathrm{H} \mathrm{NMR}$ in $\mathrm{CDCl}_{3}$ at $500 \mathrm{MHz}$


A peak from HBTM $(1 \mathrm{H})$ overlaps with the starting material peak $(1 \mathrm{H})$ at $4.57 \mathrm{ppm}$. The integrated starting material peak in the reaction mixture was calculated by subtracting the integrated catalyst peak $(1 \mathrm{H})$ at $6.77 \mathrm{ppm}$ before calculating percent conversion.

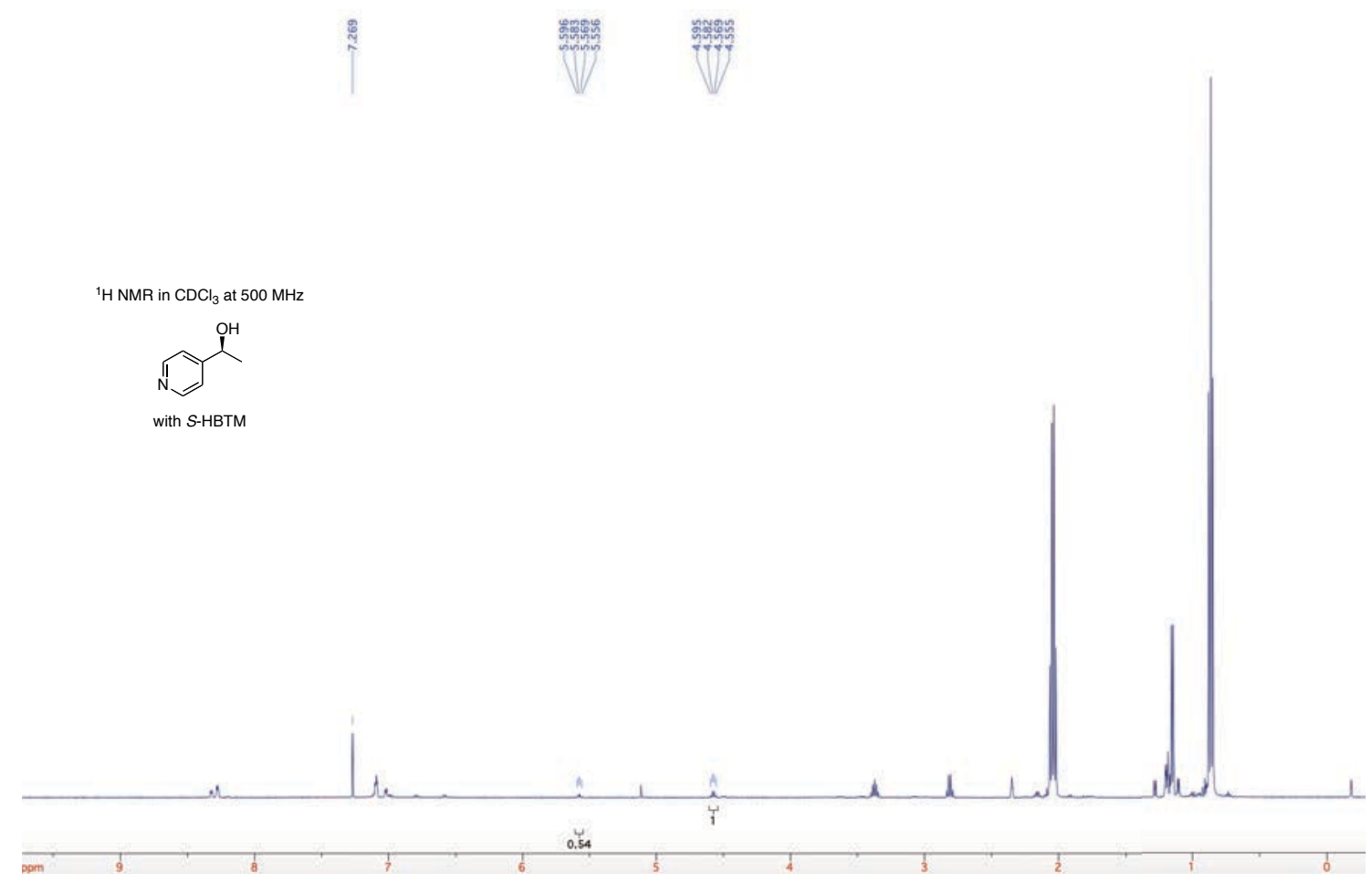


Table 6. Entry 9
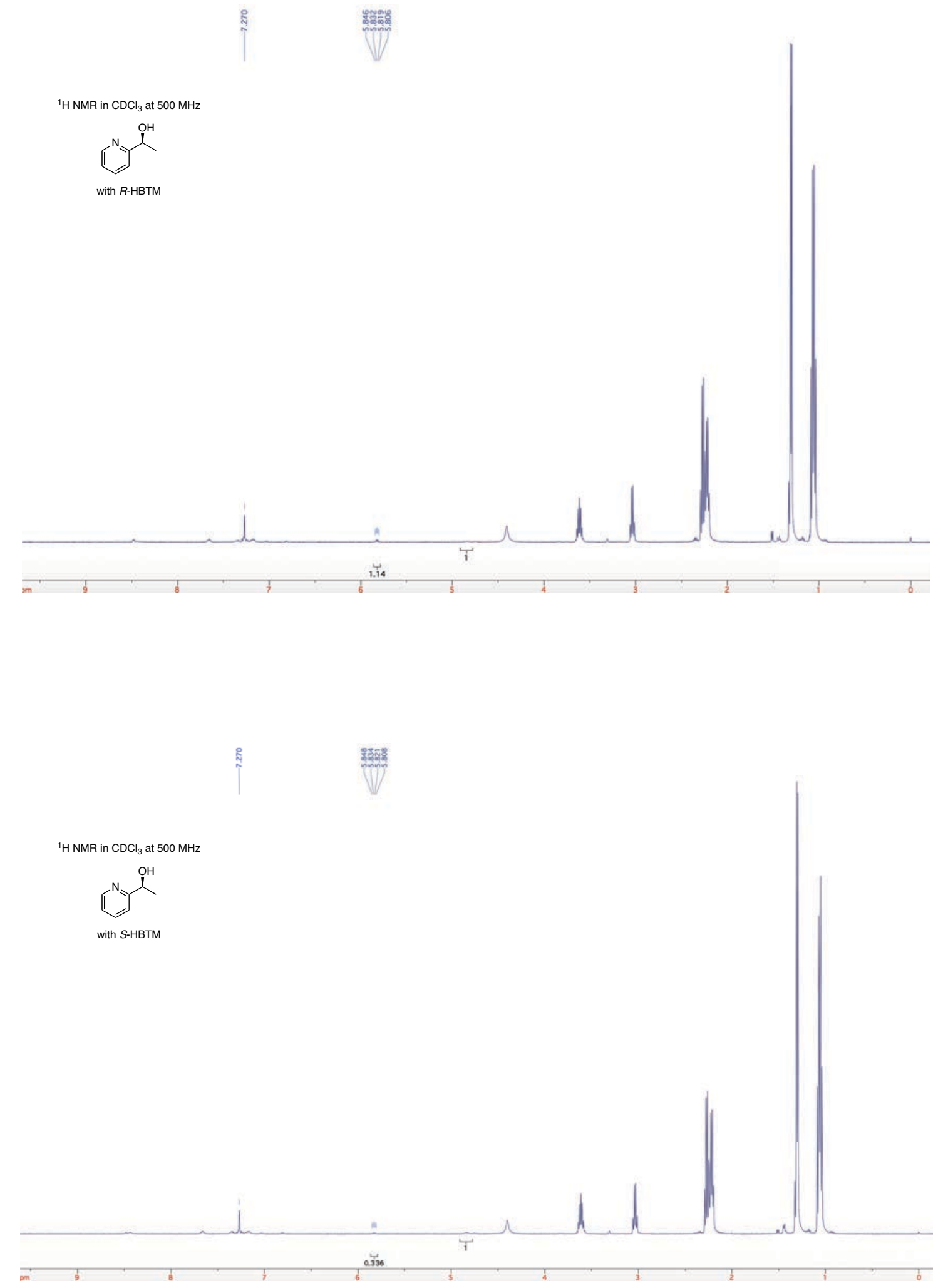
Table 6. Entry 10
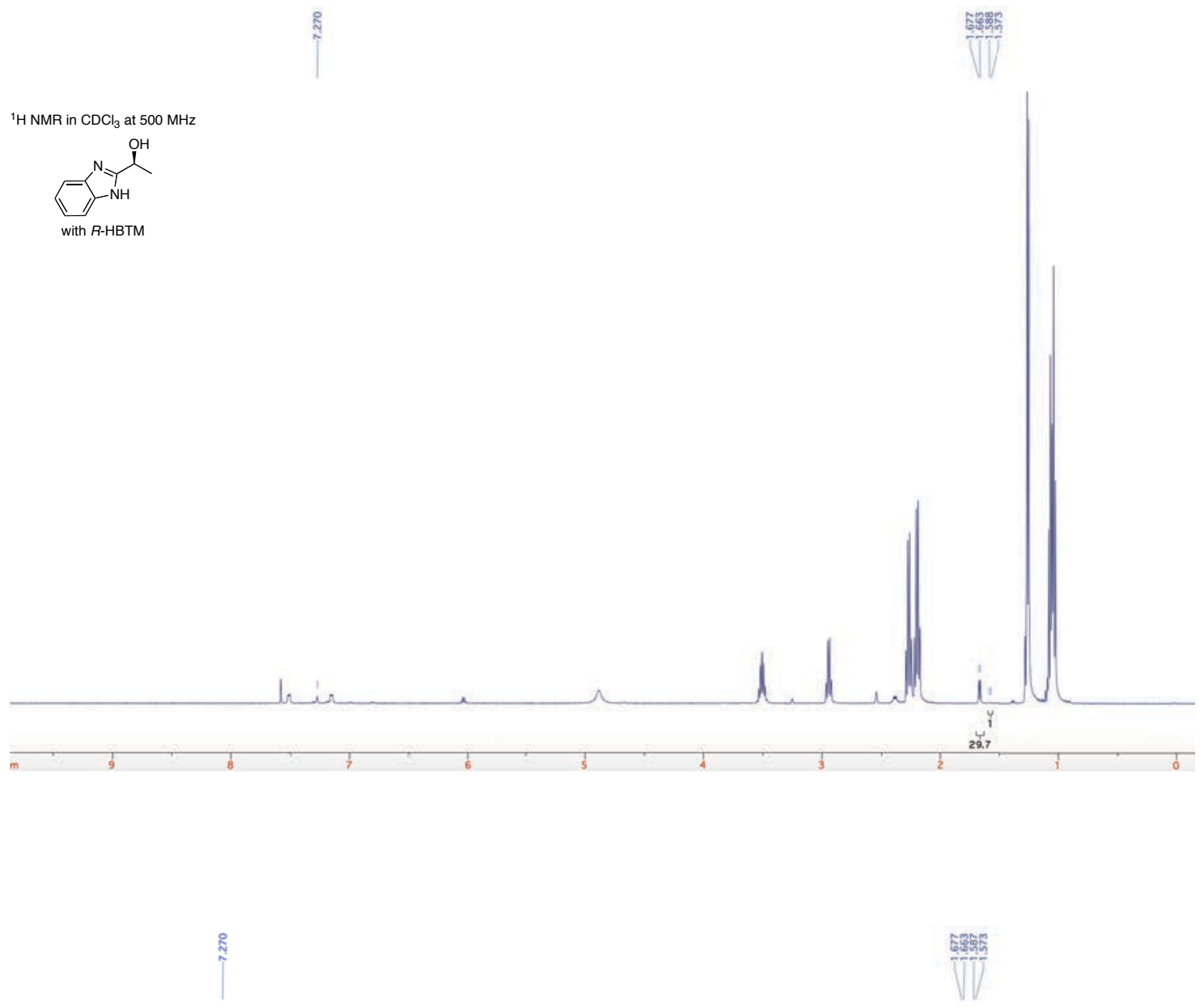

${ }^{1} \mathrm{H} \mathrm{NMR}$ in $\mathrm{CDCl}_{3}$ at $500 \mathrm{MHz}$

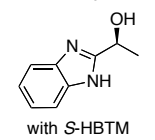

with S-HBTM

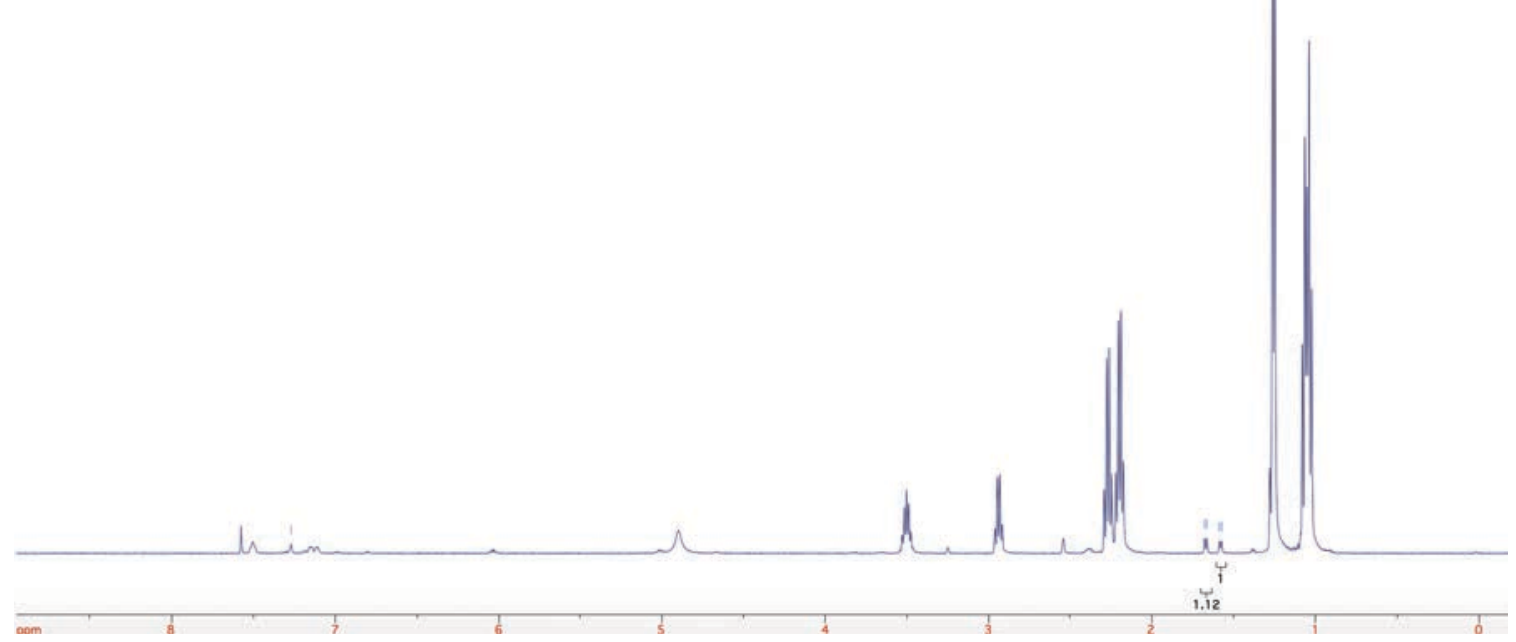


Table 6. Entry 11

Table 6. Entry 12
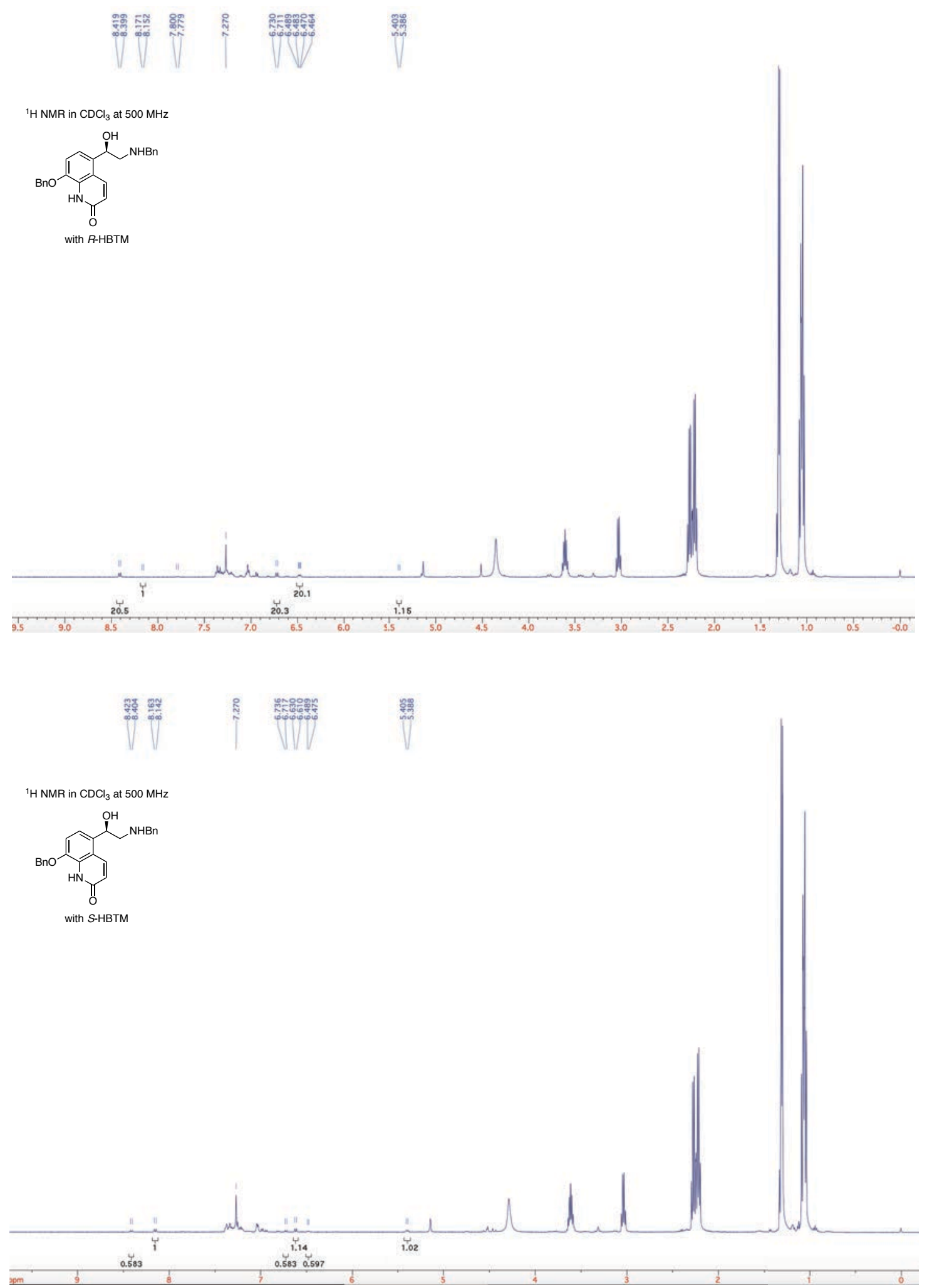

Peaks at 8.15 and $8.41 \mathrm{ppm}$ were used for calculation of reaction conversion. Other notable peaks are also highlighted in the reaction mixture between 5 and $7 \mathrm{ppm}$. 
Additional analysis for Table 6, Entry 12.<smiles>CCC(=O)NC[C@@H](OC(=O)CC)c1ccc(OCc2ccccc2)c2[nH]c(=O)ccc12</smiles>

HRMS (TOF MS ES, $\left.\mathrm{CH}_{2} \mathrm{Cl}_{2}\right) \mathrm{m} / \mathrm{z}$ calcd for $\mathrm{C}_{31} \mathrm{H}_{32} \mathrm{~N}_{2} \mathrm{O}_{5} \mathrm{Na}(\mathrm{M}+\mathrm{Na})^{+}$ 535.2209, found 535.2214.

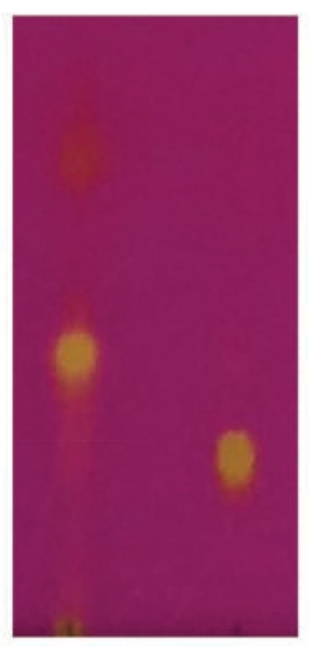<smiles>CCC(=O)NC[C@H](O)c1ccc(OCc2ccccc2)c2[nH]c(=O)ccc12</smiles>

HRMS (TOF MS ES, $\left.\mathrm{CH}_{2} \mathrm{Cl}_{2}\right) \mathrm{m} / \mathrm{z}$ calcd for $\mathrm{C}_{28} \mathrm{H}_{28} \mathrm{~N}_{2} \mathrm{O}_{4} \mathrm{Na}(\mathrm{M}+\mathrm{Na})^{+}$ 479.1947, found 479.1966.

TLC in 9:1 ethyl acetate/hexanes

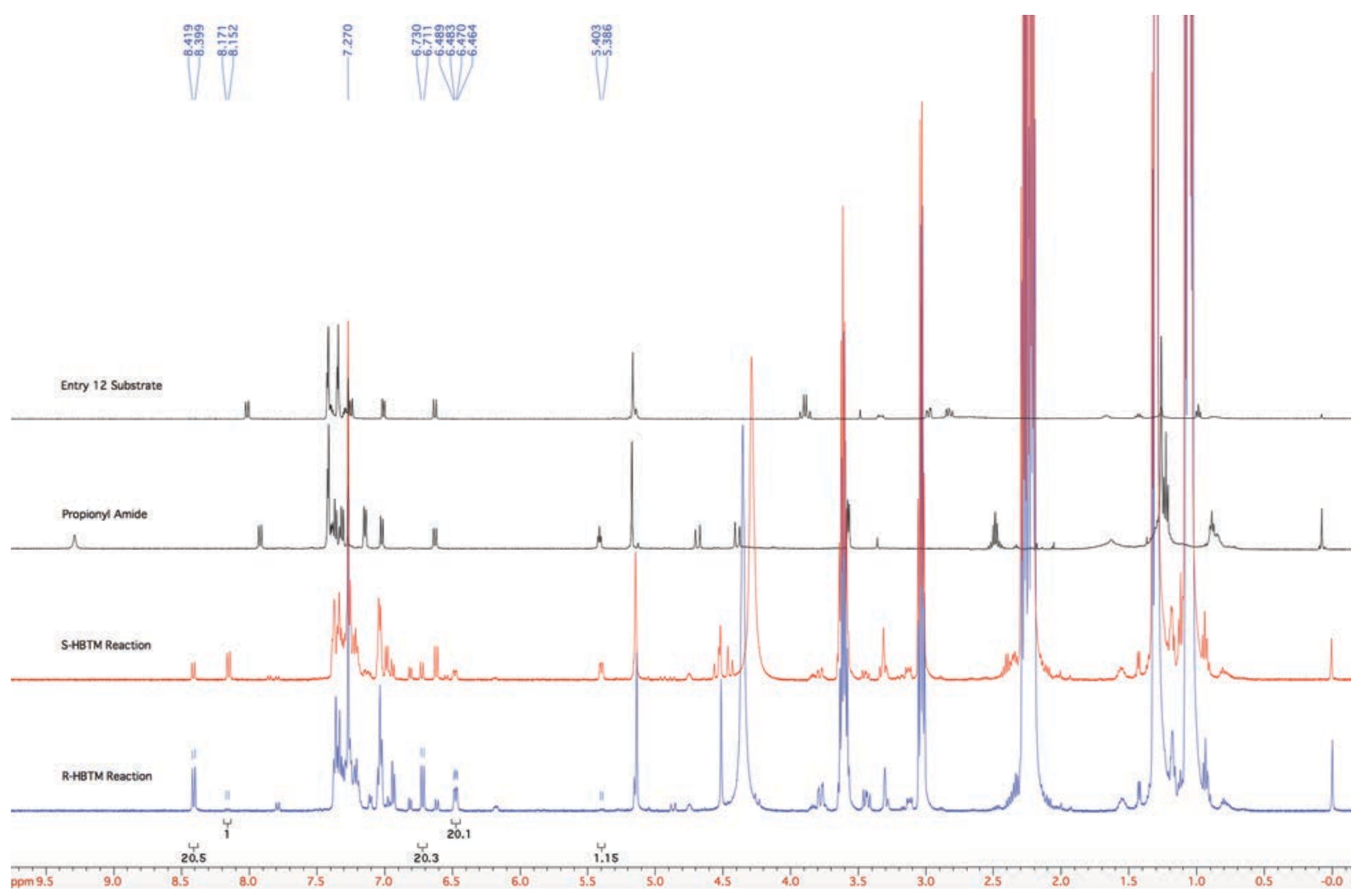




\section{Table 7. Entry 1}

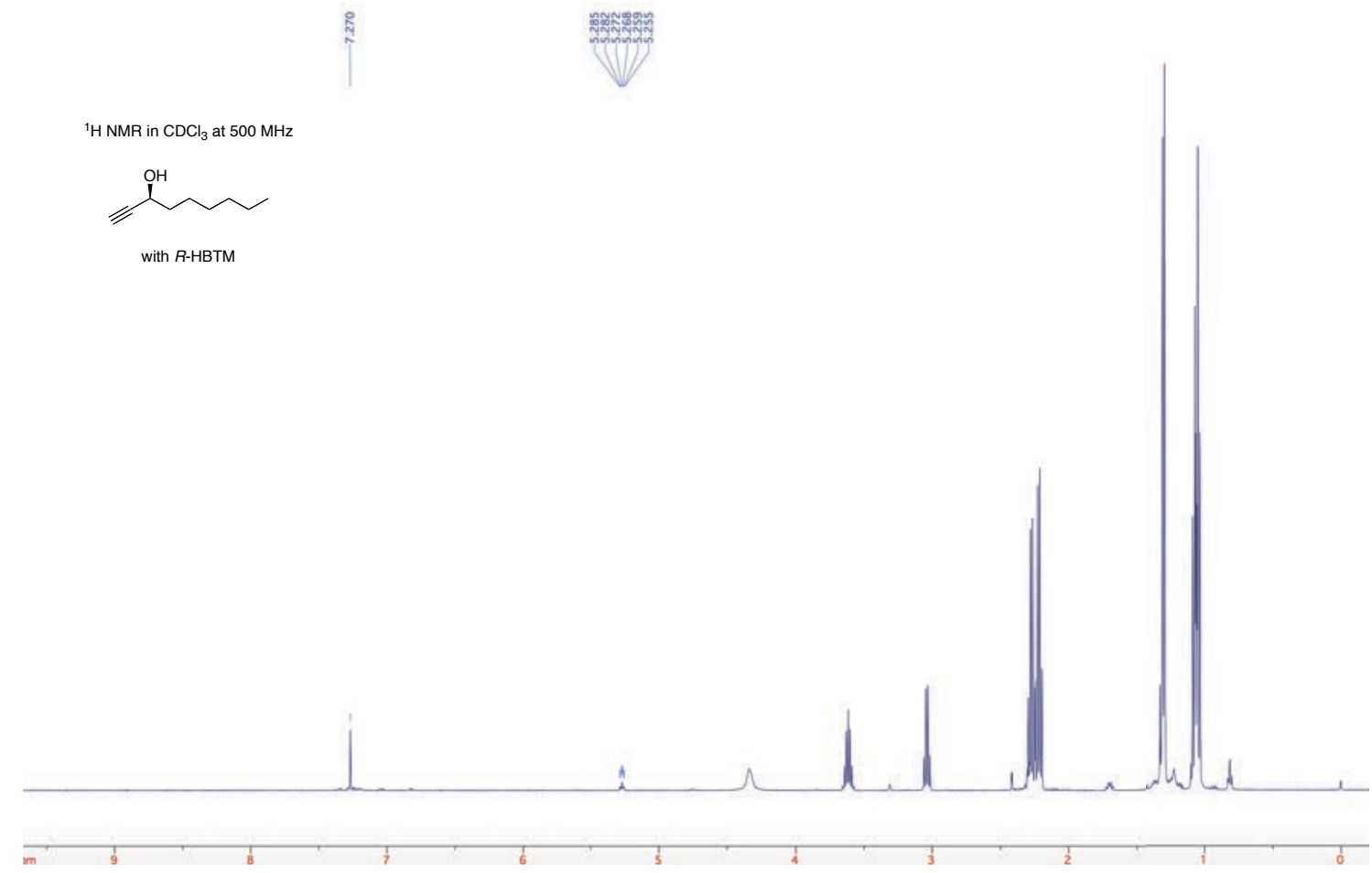

${ }^{1} \mathrm{H} \mathrm{NMR} \mathrm{in} \mathrm{CDCl}_{3}$ at $500 \mathrm{MHz}$

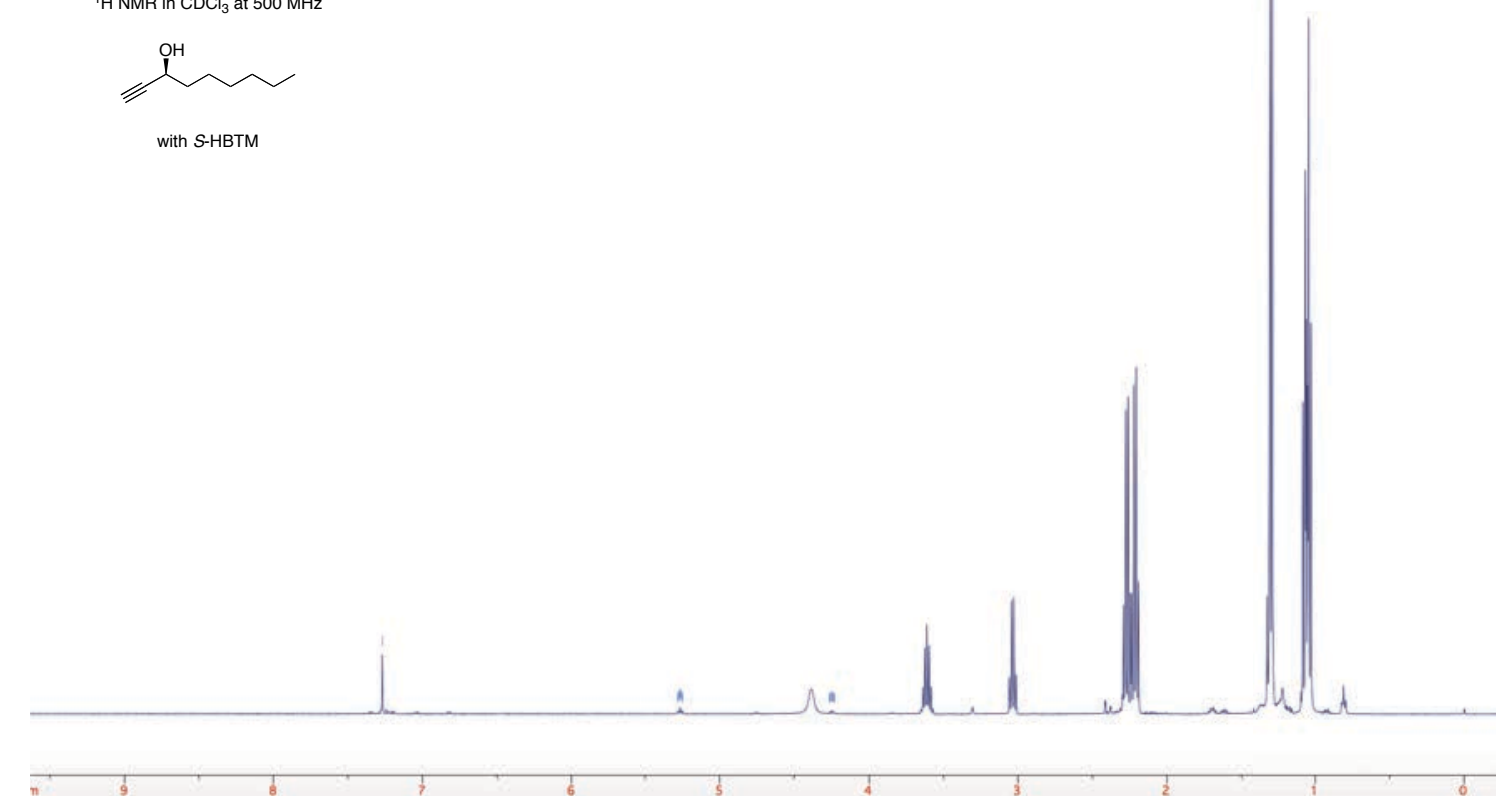

with S-HBTM




Table 7. Entry 1 - after vacuum removal of solvent and resolvation in $\mathrm{CDCl}_{3}$

Table 7. Entry 2
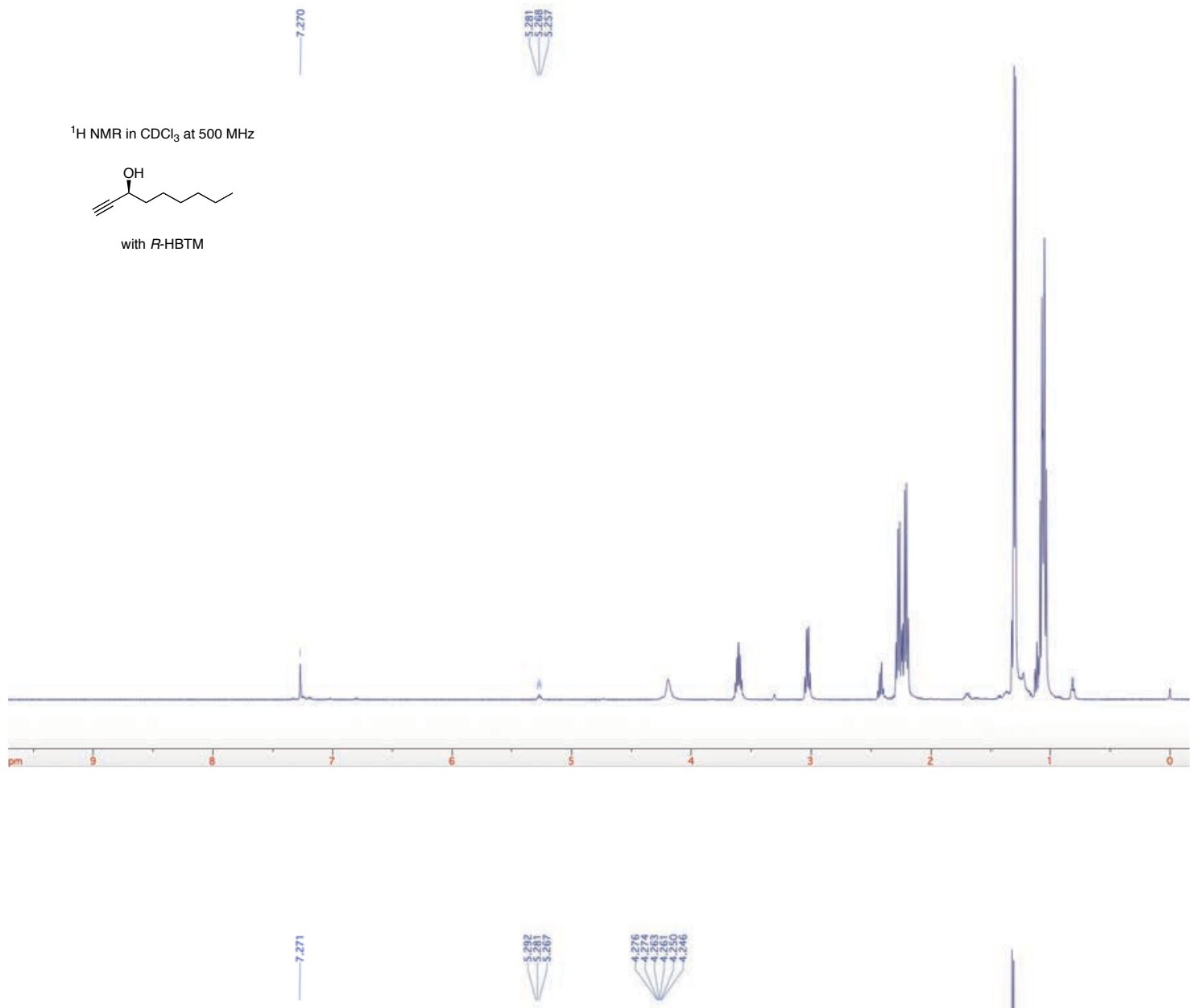

${ }^{1} \mathrm{H} \mathrm{NMR}$ in $\mathrm{CDCl}_{3}$ at $500 \mathrm{MHz}$

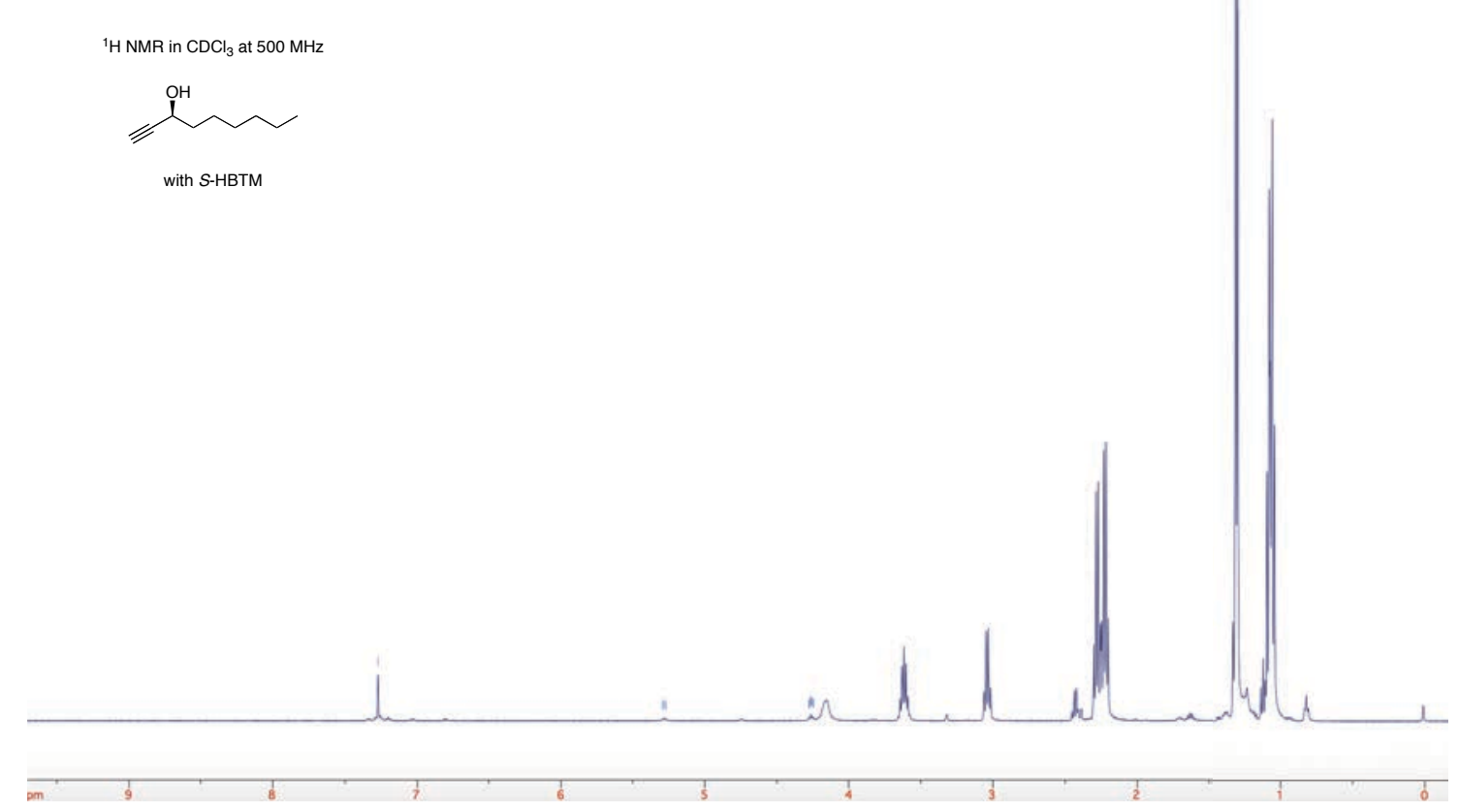

with S-HBTM 
Table 7. Entry 2 - after vacuum removal of solvent and resolvation in $\mathrm{CDCl}_{3}$



ก้

${ }^{1} \mathrm{H} \mathrm{NMR} \mathrm{in} \mathrm{CDCl}_{3}$ at $500 \mathrm{MHz}$

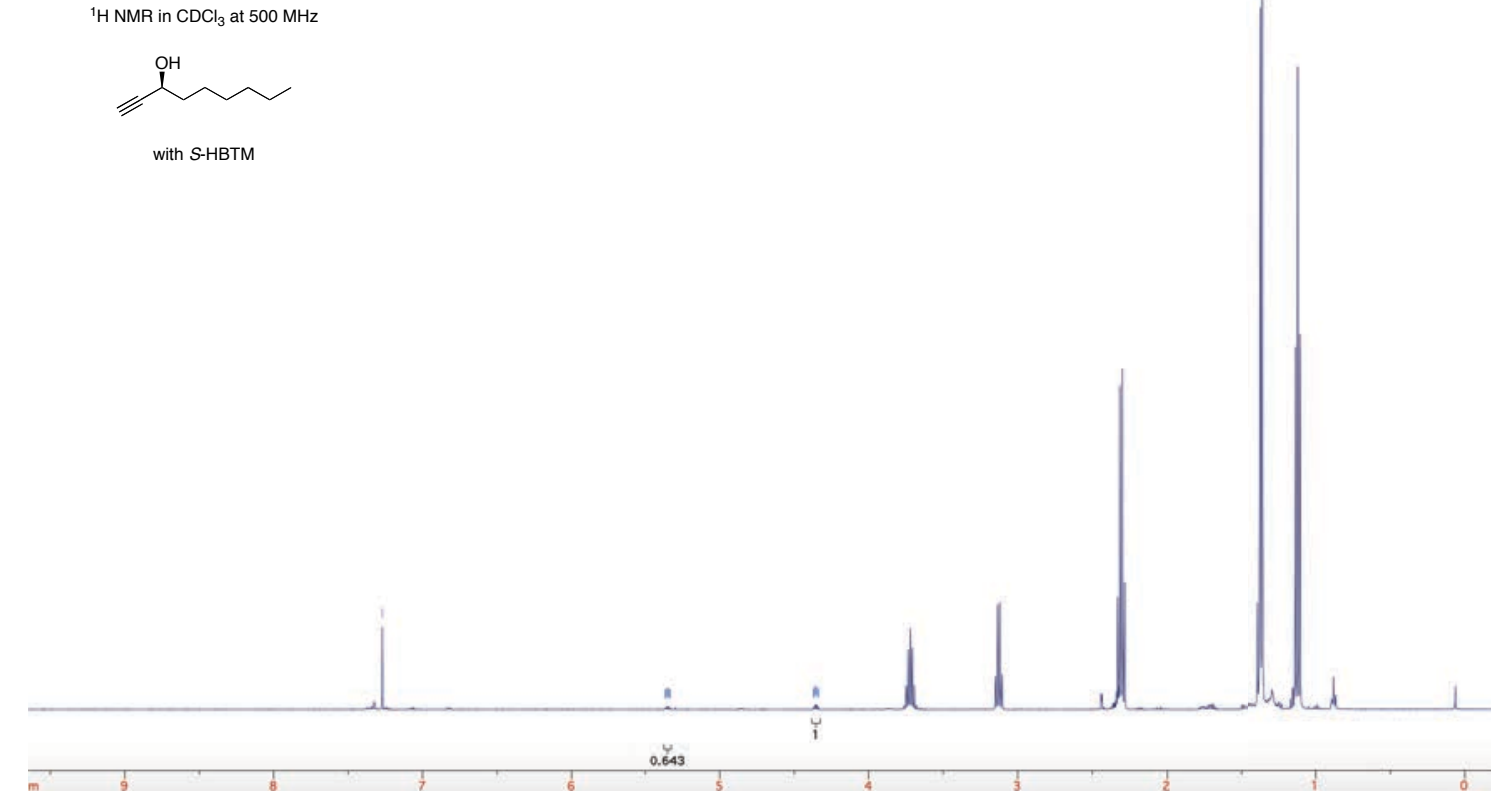

with S-HBTM 
Table 7. Entry 3
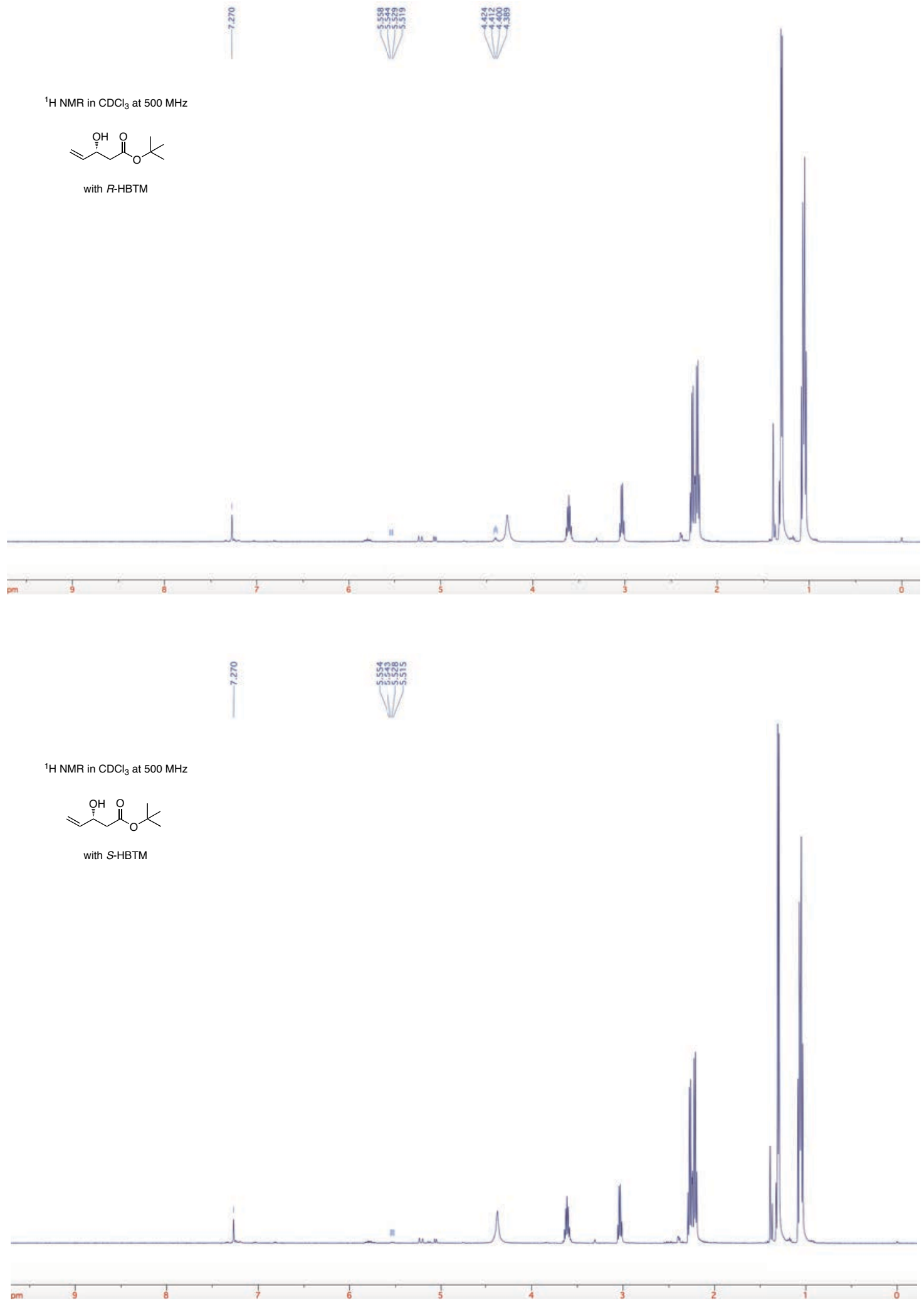
Table 7. Entry 3 - after vacuum removal of solvent and resolvation in $\mathrm{CDCl}_{3}$


${ }^{1} \mathrm{H} \mathrm{NMR}$ in $\mathrm{CDCl}_{3}$ at $500 \mathrm{MHz}$

$\overbrace{}^{\mathrm{OH}} \mathrm{O}^{\mathrm{O}}<$

with S-HBTM

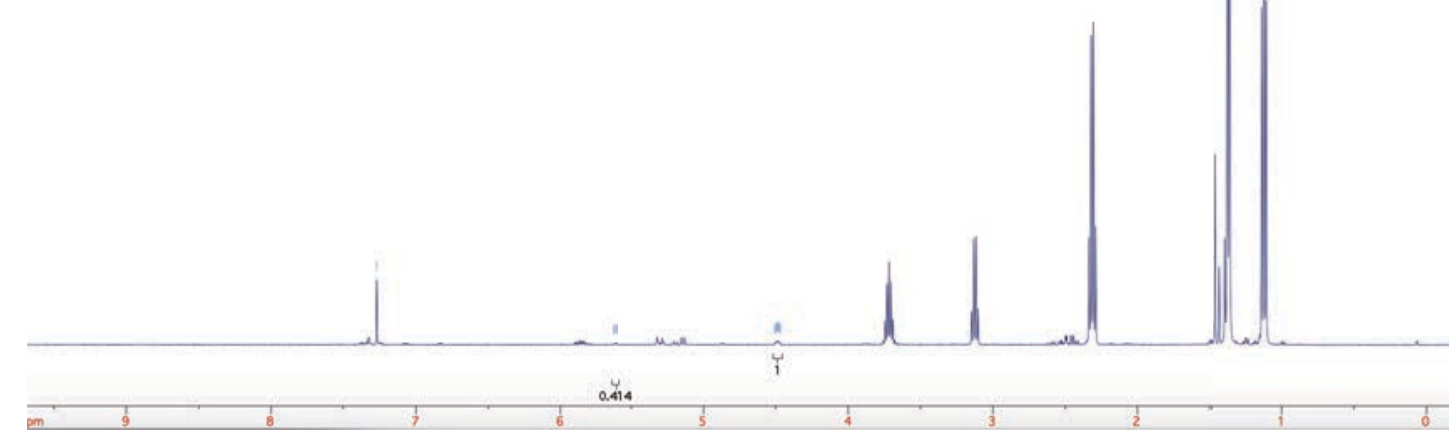


Table 7. Entry 4

Table 7. Entry 4 - after vacuum removal of solvent and resolvation in $\mathrm{CDCl}_{3}$
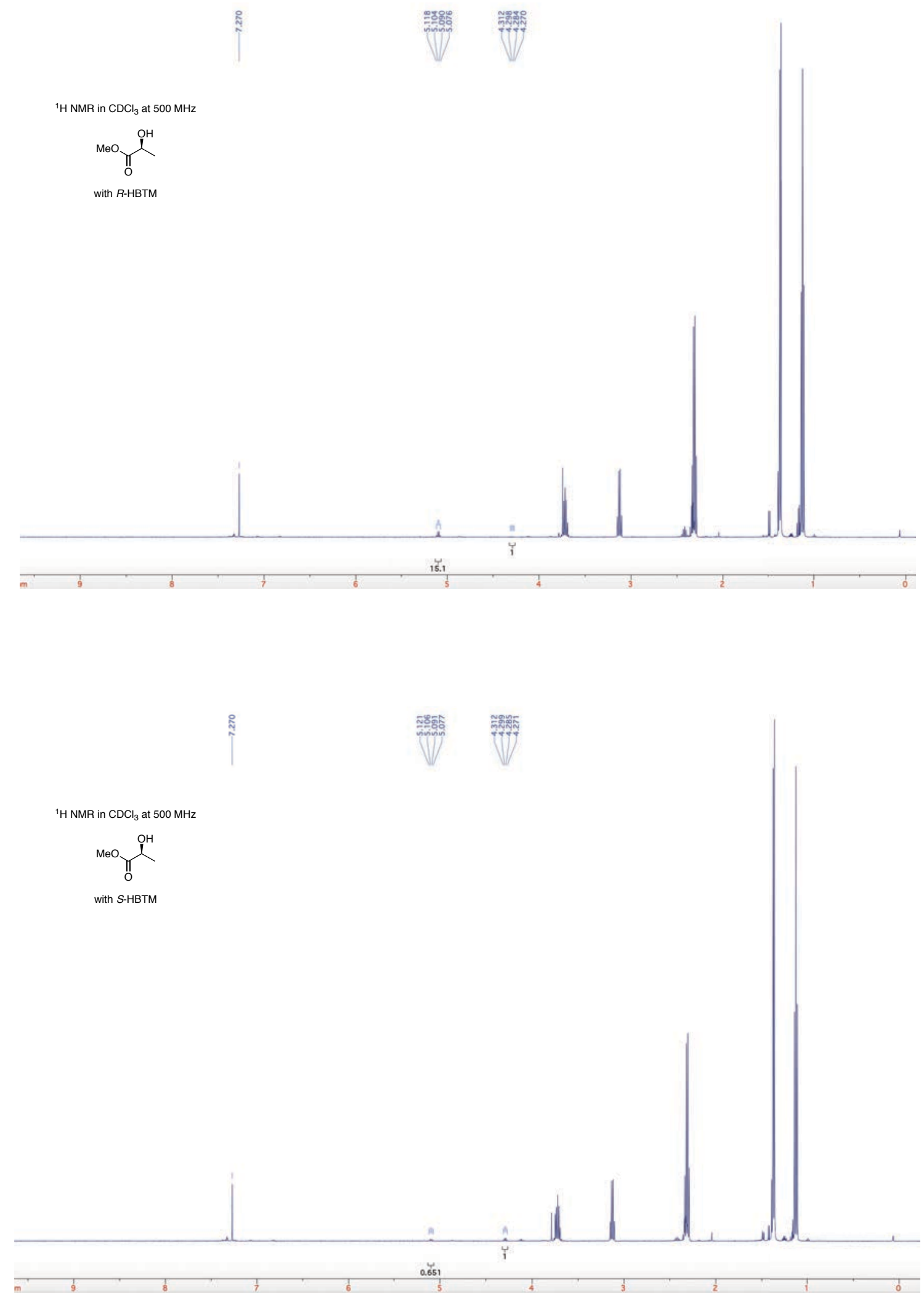


\section{Table 7. Entry 5}


${ }^{1} \mathrm{H} \mathrm{NMR} \mathrm{in} \mathrm{CDCl}_{3}$ at $500 \mathrm{MHz}$

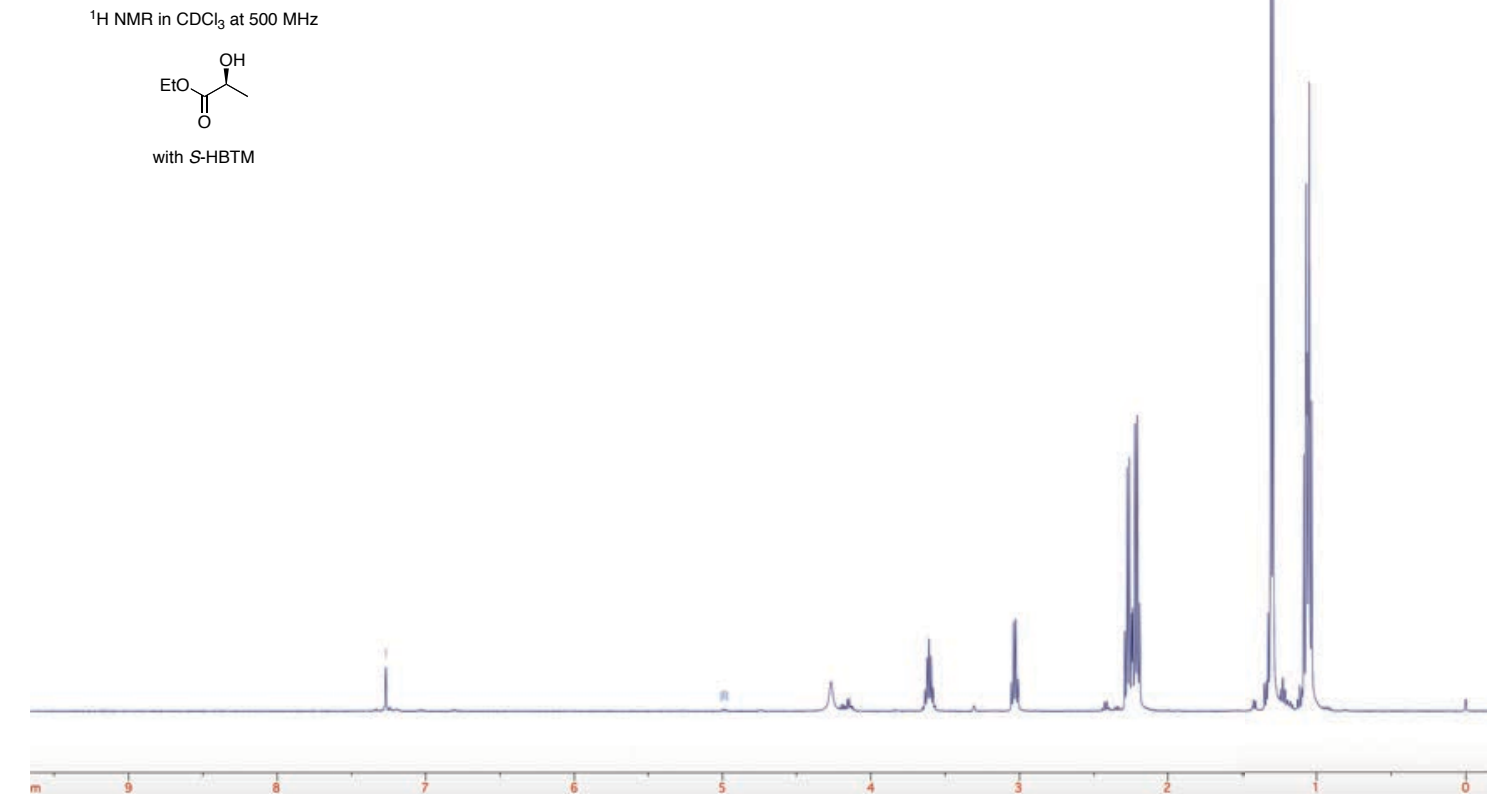

with S-HBTM 
Table 7. Entry 5 - after vacuum removal of solvent and resolvation in $\mathrm{CDCl}_{3}$




Table 7. Entry 6
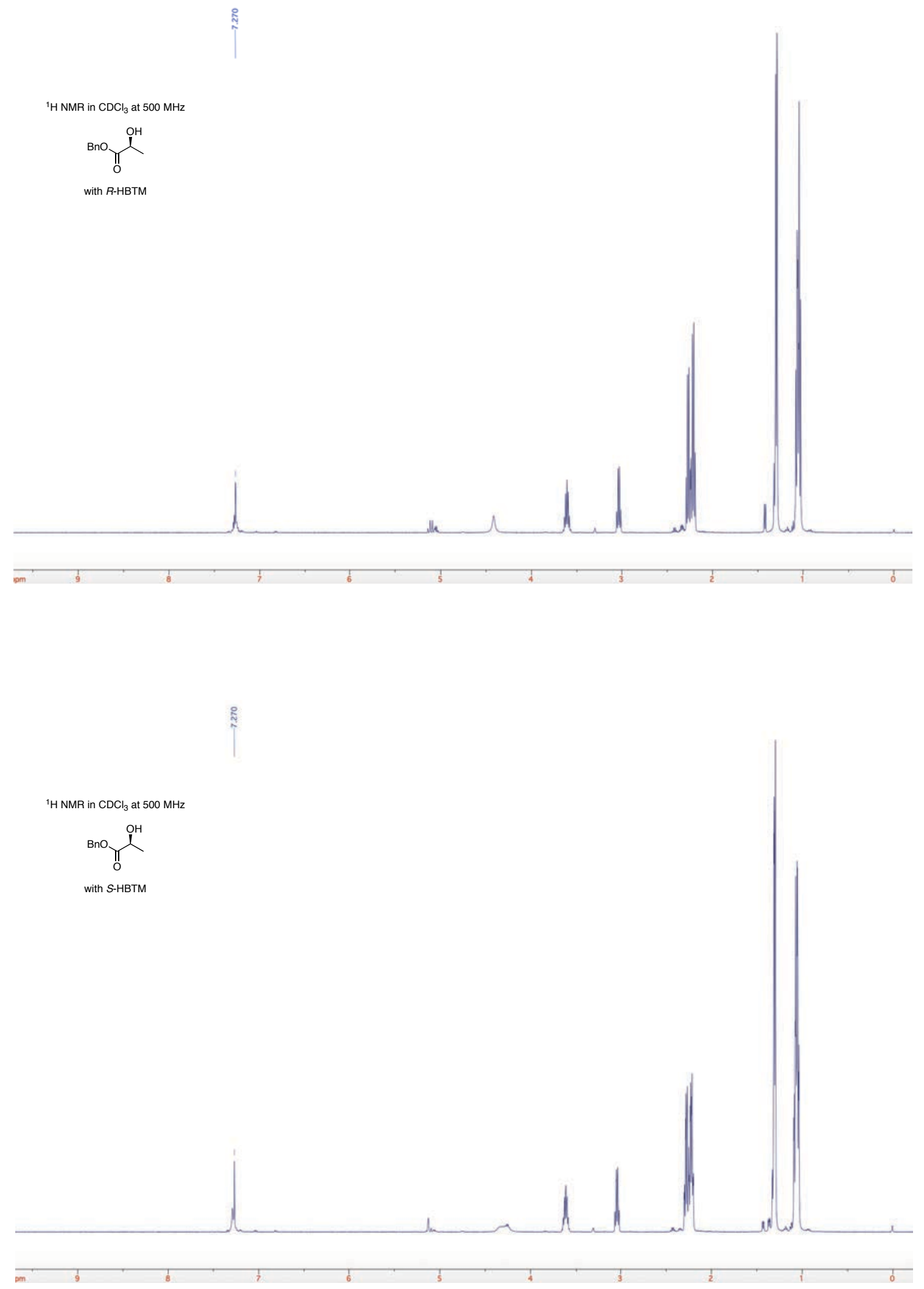
Table 7. Entry 6 - after vacuum removal of solvent and resolvation in $\mathrm{CDCl}_{3}$

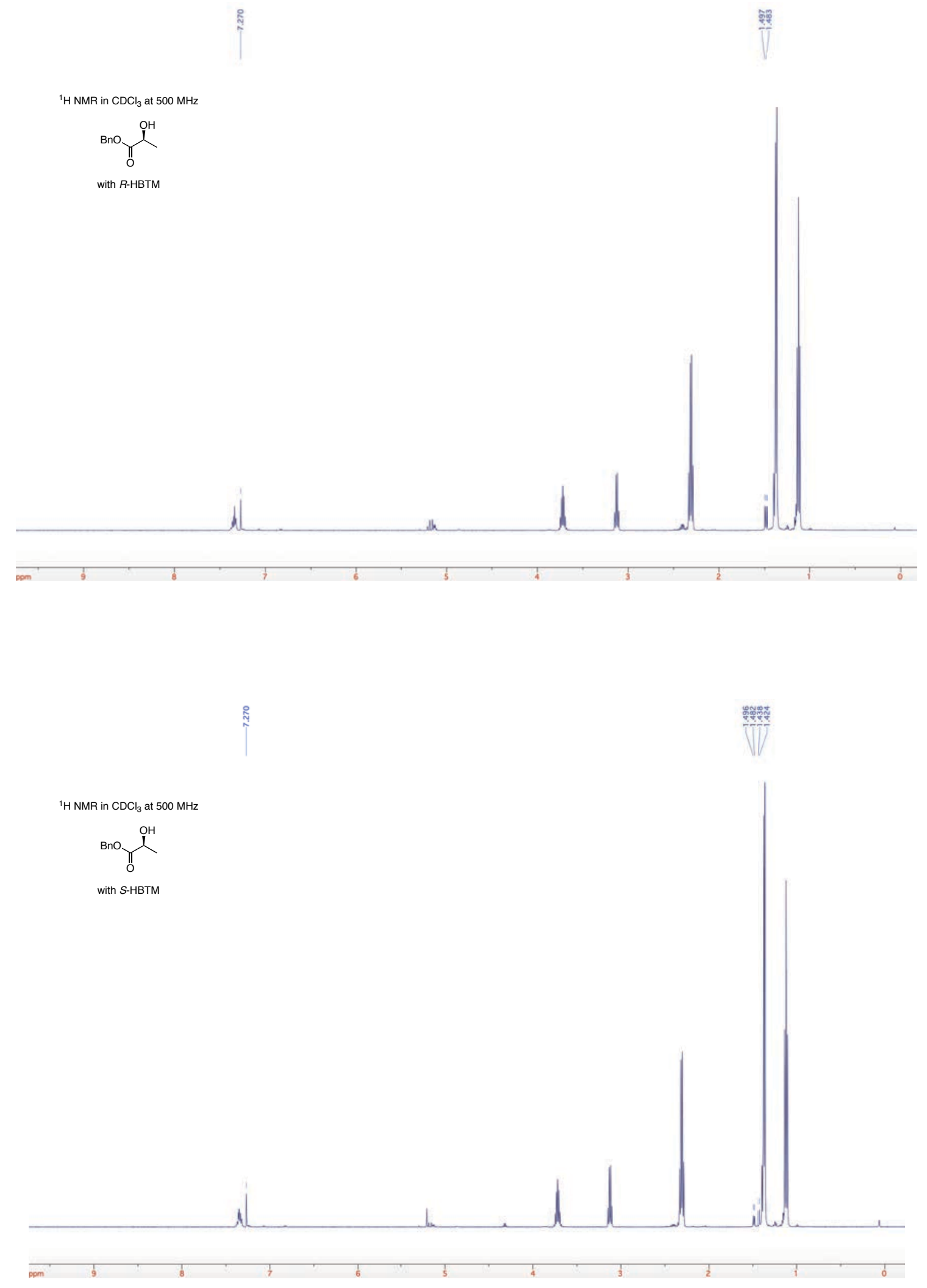


Table 7. Entry 6 - after vacuum removal of solvent, resolvation in $\mathrm{CDCl}_{3}$, and basic workup
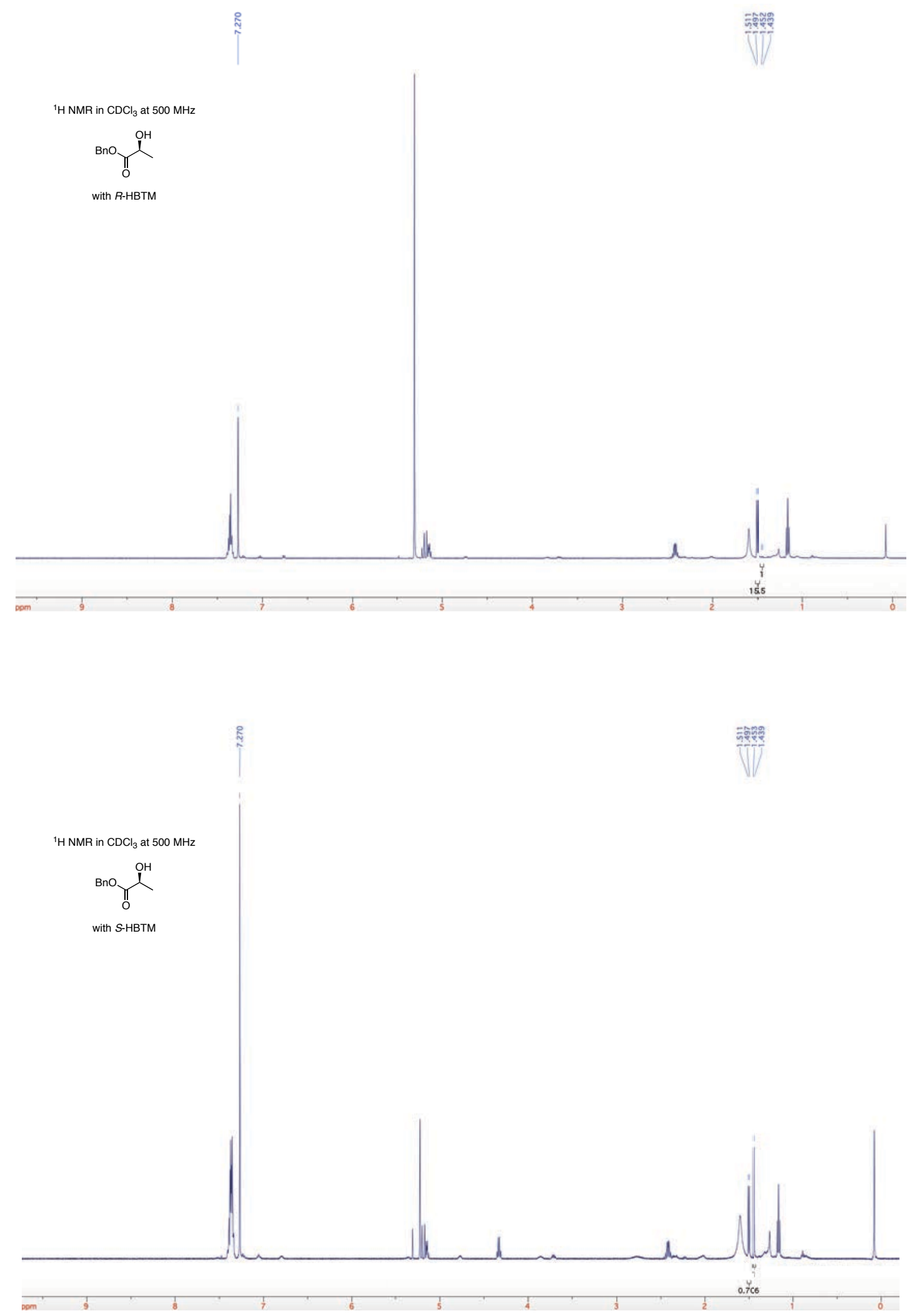
Table 7. Entry 7



${ }^{1} \mathrm{H} \mathrm{NMR}$ in $\mathrm{CDCl}_{3}$ at $500 \mathrm{MHz}$

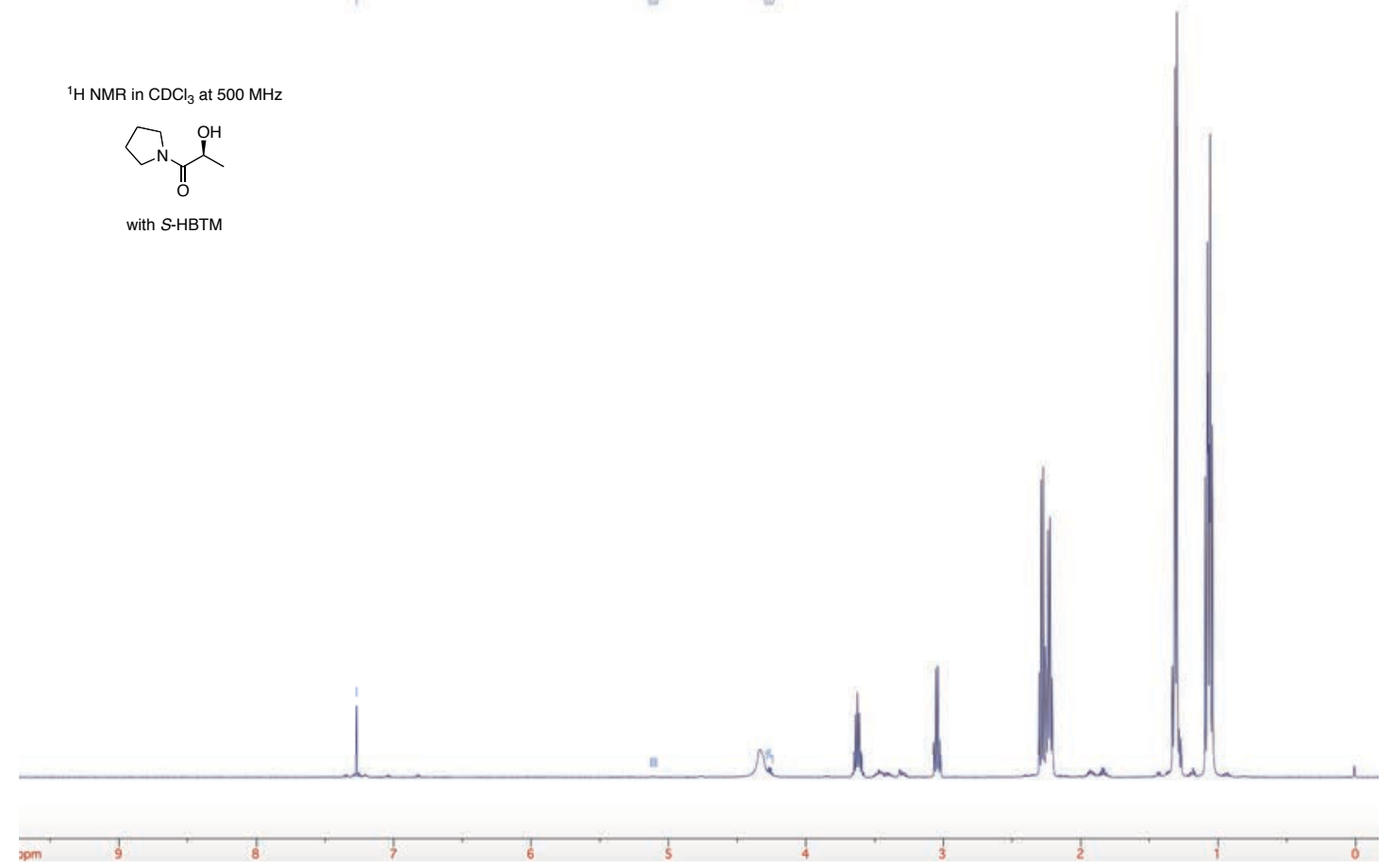

with S-HBTM 
Table 7. Entry 7 - after vacuum removal of solvent and resolvation in $\mathrm{CDCl}_{3}$

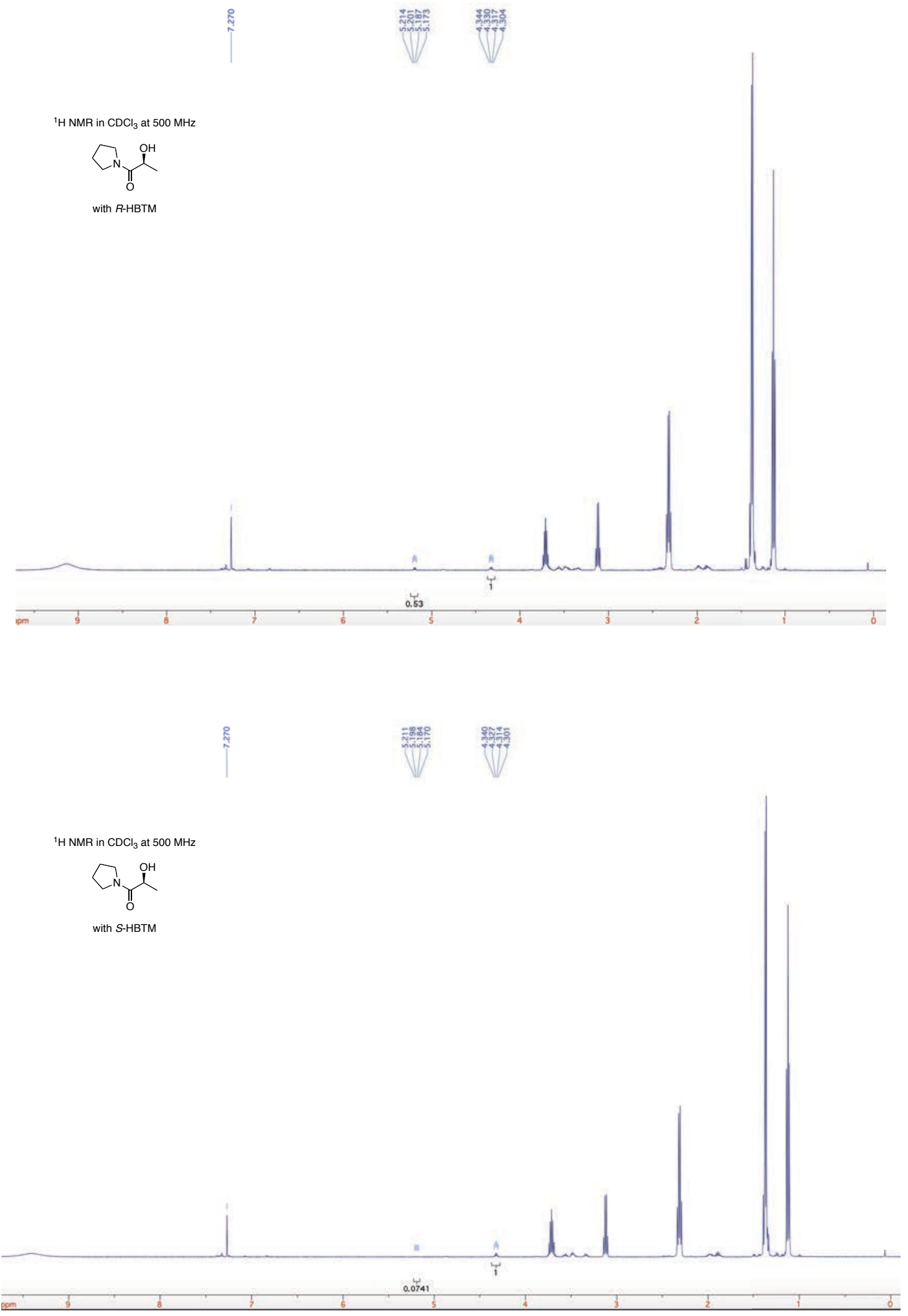




\section{Table 7. Entry 8}
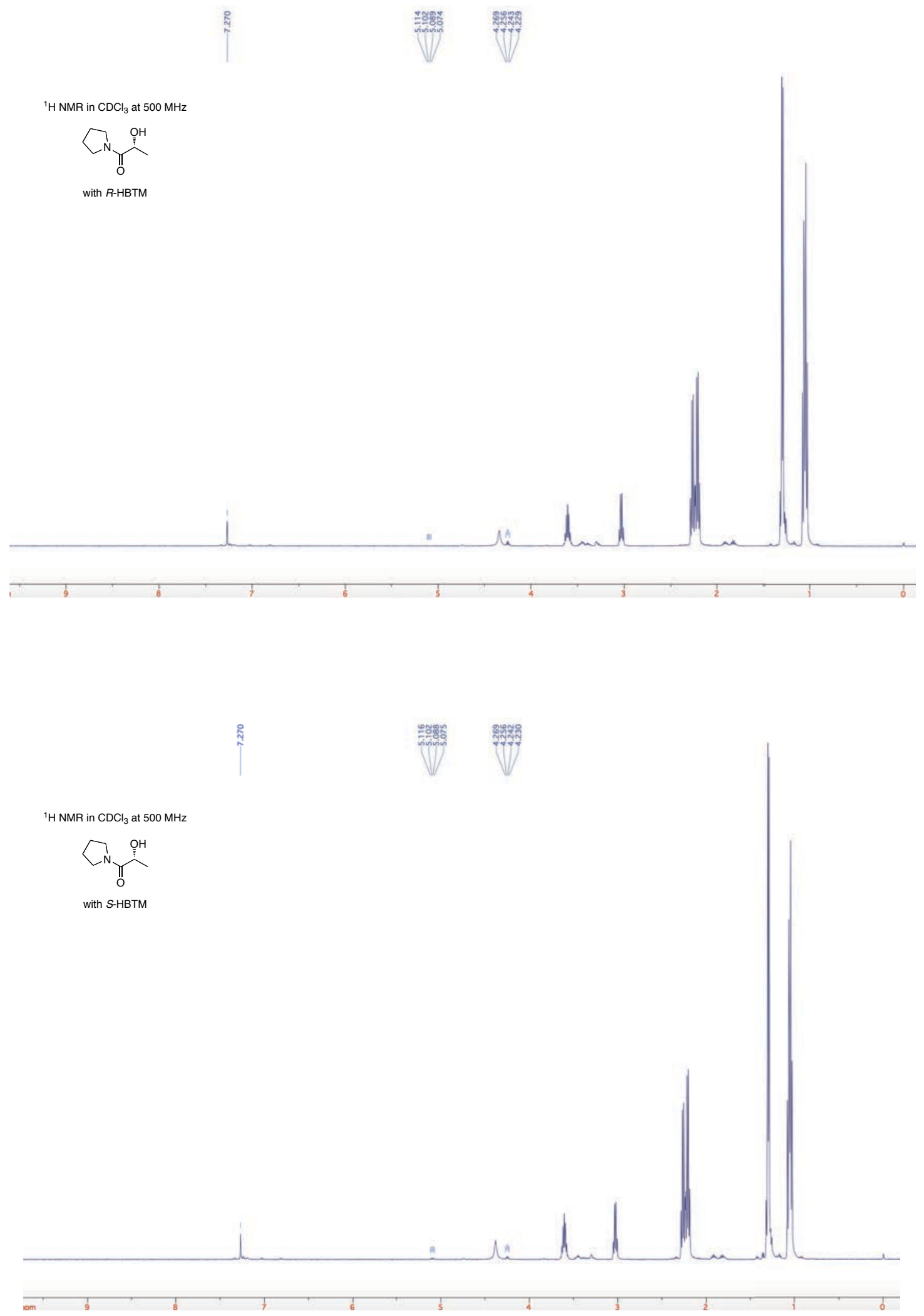
Table 7. Entry 8 - after vacuum removal of solvent and resolvation in $\mathrm{CDCl}_{3}$
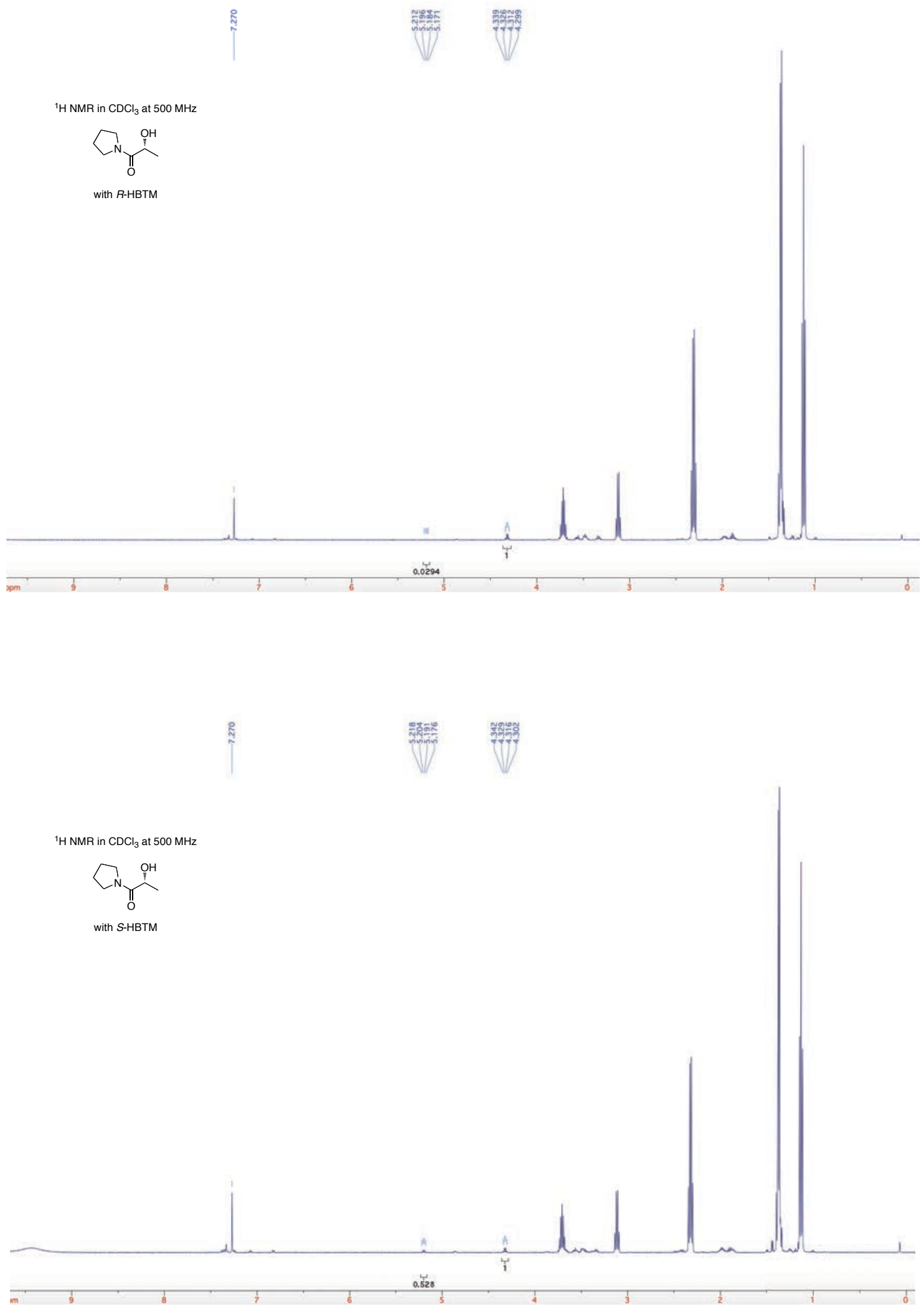


\section{Table 7. Entry 9}
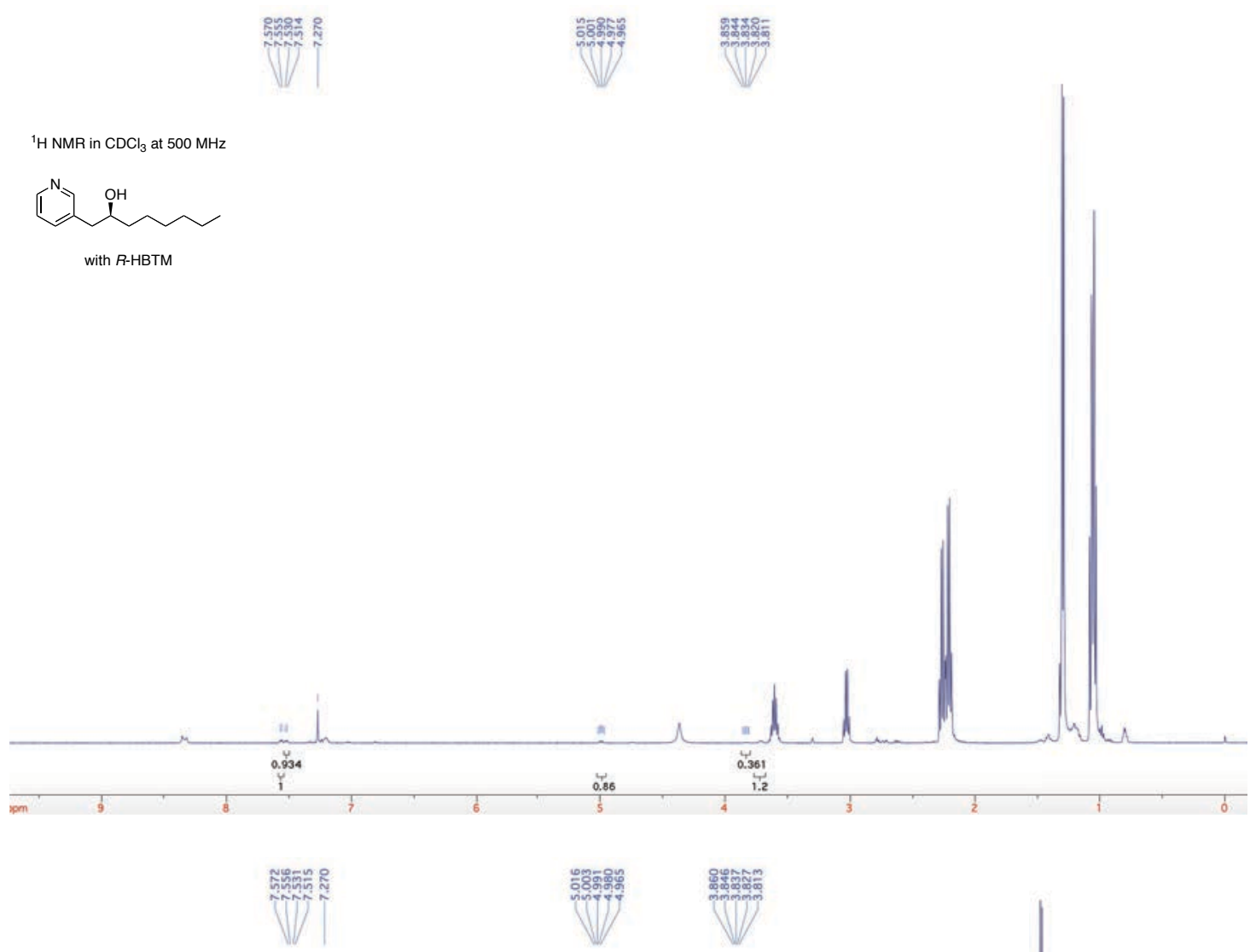

${ }^{1} \mathrm{H} \mathrm{NMR}$ in $\mathrm{CDCl}_{3}$ at $500 \mathrm{MHz}$



with S-HBTM

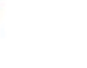


Table 7. Entry 10

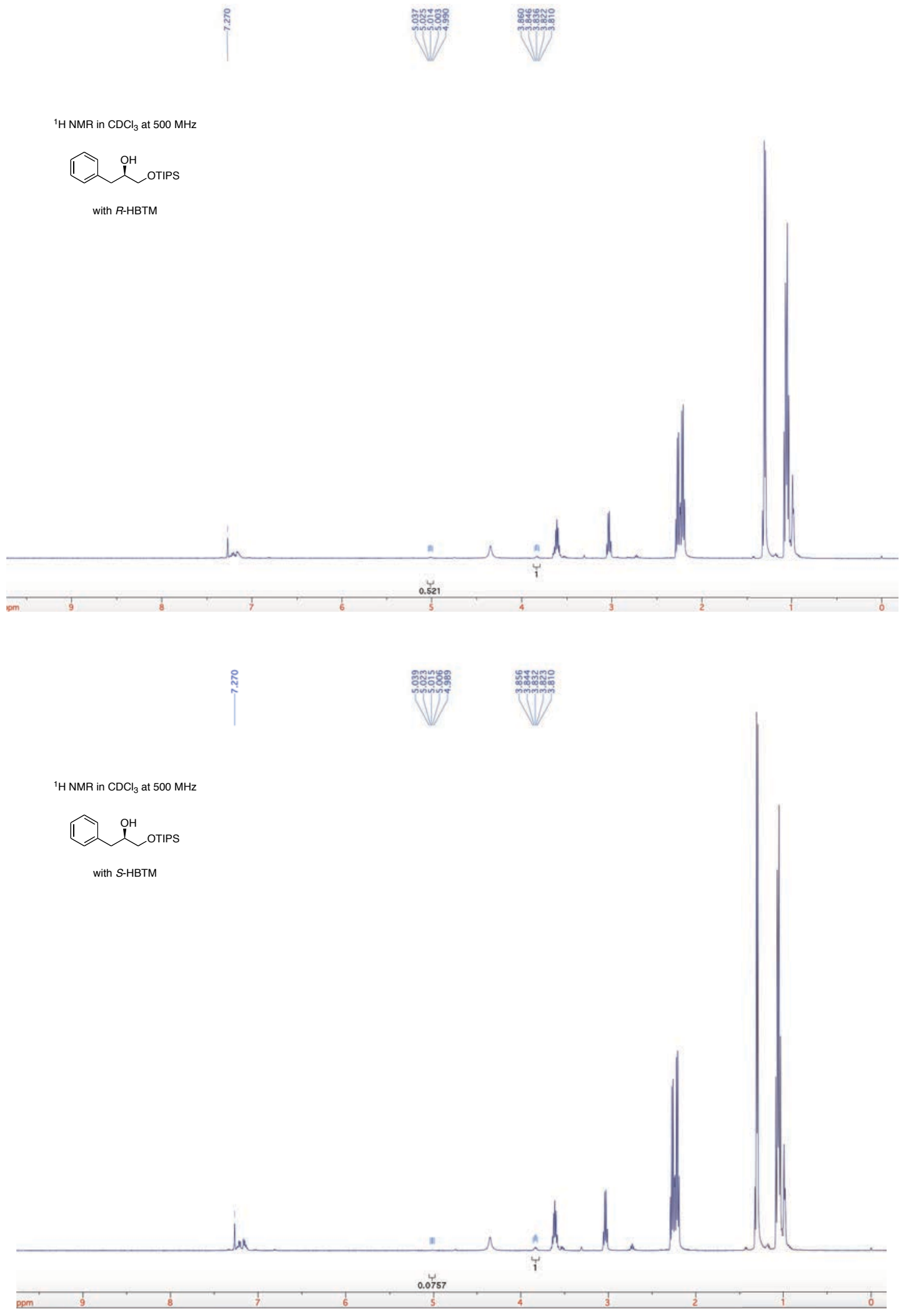


Table 7. Entry 11


${ }^{1} \mathrm{H} \mathrm{NMR}$ in $\mathrm{CDCl}_{3}$ at $500 \mathrm{MHz}$

${ }_{3} \mathrm{C}$

with S-HBTM




Table 7. Entry 12
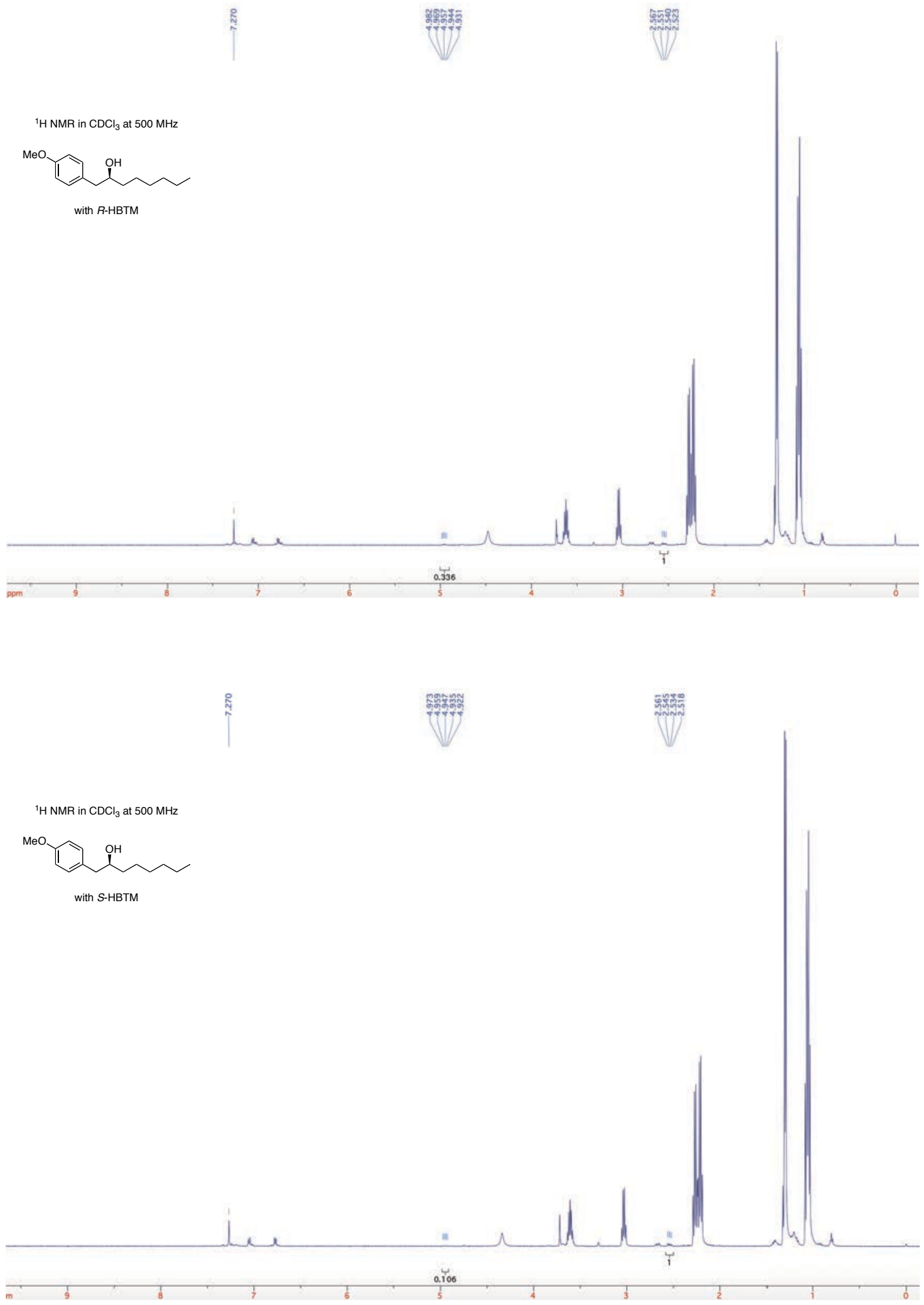


\section{${ }^{1}$ H NMR Spectra for Figure 9}

Figure 9. Plate 1




Figure 9. Plate 2


${ }^{1} \mathrm{H} \mathrm{NMR} \mathrm{in} \mathrm{CDCl}_{3}$ at $500 \mathrm{MHz}$



with S-HBTM
6 month old CEC kit

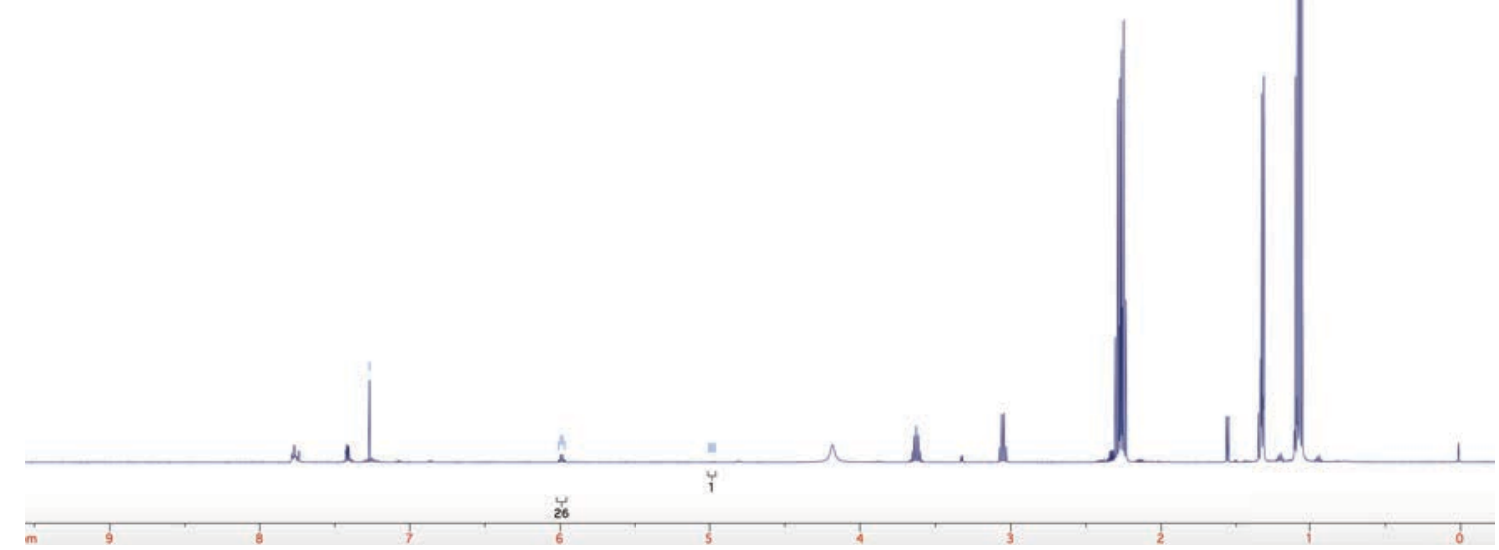




\section{Additional Manipulations of Microscale Systems and Data for Figure 10 \\ Figure 10 CEC Microscale Procedure, Purposeful Error, and Equivalents of Base Studies}

\section{Preparation of Solutions}

(R)-1-(naphthalen-2-yl)ethanol ((R)-5). To a $5 \mathrm{~mL}$ volumetric flask was added $(R)-1$ (naphthalen-2-yl)ethanol $(12.5 \mathrm{mg}, 0.0726 \mathrm{mmol})$. The flask was filled with toluene to the line and mixed, generating solution 1 of $(\boldsymbol{R})-5(0.0145 \mathrm{M})$. To a $2 \mathrm{~mL}$ volumetric flask was added solution 1 of $(\boldsymbol{R})-5(1.00 \mathrm{~mL})$. The flask was filled with toluene to the line and mixed, generating the solution 2 of $(\boldsymbol{R})-\mathbf{5}(0.00726 \mathrm{M})$. To a new $2 \mathrm{~mL}$ volumetric flask was added solution 2 of $(\boldsymbol{R})-5(1.00 \mathrm{~mL})$. The flask was filled with toluene to the line and mixed, generating the solution 3 of $(\boldsymbol{R})-5(0.00363 \mathrm{M})$. To a new $2 \mathrm{~mL}$ volumetric flask was added solution 3 of $(\boldsymbol{R})-5$ (1.00 $\mathrm{mL})$. The flask was filled with toluene to the line and mixed, generating the solution 4 of $(\boldsymbol{R})-\mathbf{5}$ $(0.00181 \mathrm{M})$. To a new $2 \mathrm{~mL}$ volumetric flask was added solution 4 of $(\boldsymbol{R})-5(1.00 \mathrm{~mL})$. The flask was filled with toluene to the line and mixed, generating the solution 5 of $(\boldsymbol{R})-5(0.000907$ $\mathrm{M})$.

$\boldsymbol{R}$-HBTM. To a $10 \mathrm{~mL}$ volumetric flask was added $R$-HBTM $(7.7 \mathrm{mg}, 0.029 \mathrm{mmol})$. The flask was filled with toluene to the line and mixed, generating the solution of $R$-HBTM $(0.0029 \mathrm{M})$.

$\boldsymbol{S}$-HBTM. To a $10 \mathrm{~mL}$ volumetric flask was added $S$-HBTM $(7.7 \mathrm{mg}, 0.029 \mathrm{mmol})$. The flask was filled with toluene to the line and mixed, generating the solution of $S$-HBTM $(0.0029 \mathrm{M})$.

Propionic anhydride $+\mathbf{N}, \mathbf{N}$-diisopropylethylamine. To a $10 \mathrm{~mL}$ volumetric flask was added propionic anhydride $(279 \mu \mathrm{L}, 2.18 \mathrm{mmol})$ and $N, N$-diisopropylethylamine $(75.9 \mu \mathrm{L}, 0.436$ mmol) via micropipette. The flask was filled with toluene to the line and mixed, generating solution 1 of propionic anhydride $(0.218 \mathrm{M})$ and $N, N$-diisopropylethylamine $(0.0436 \mathrm{M})$. To a 
new $10 \mathrm{~mL}$ volumetric flask was added propionic anhydride $(279 \mu \mathrm{L}, 2.18 \mathrm{mmol})$ and $N, N$ diisopropylethylamine $(50.6 \mu \mathrm{L}, 0.290 \mathrm{mmol})$ via micropipette. The flask was filled with toluene to the line and mixed, generating solution 2 of propionic anhydride $(0.218 \mathrm{M})$ and $N, N$ diisopropylethylamine $(0.0290 \mathrm{M})$. To a new $10 \mathrm{~mL}$ volumetric flask was added propionic anhydride $(279 \mu \mathrm{L}, 2.18 \mathrm{mmol})$ and $N, N$-diisopropylethylamine $(25.3 \mu \mathrm{L}, 0.145 \mathrm{mmol})$ via micropipette. The flask was filled with toluene to the line and mixed, generating solution 3 of propionic anhydride $(0.218 \mathrm{M})$ and $N, N$-diisopropylethylamine $(0.0145 \mathrm{M})$.

\section{CEC Method}

A $50 \mu \mathrm{L}$ syringe was used to draw up, in sequence, air $(5 \mu \mathrm{L}),(\boldsymbol{R})-5$ stock solution (varied $\mu \mathrm{L})$, air $(5 \mu \mathrm{L})$, HBTM stock solution (varied $\mu \mathrm{L})$, air $(5 \mu \mathrm{L})$, propionic anhydride and $N, N$ diisopropylethylamine stock solution (varied $\mu \mathrm{L}$ ), and air $(5 \mu \mathrm{L})$. The contents of the syringe were then mixed in a $500 \mu \mathrm{L}$ amber glass vial placed inside a 1 dram vial, initiating the reaction. The mixed reaction solution was drawn back into the microsyringe and allowed to sit for $1 \mathrm{~h}$. Then, the reaction solution in the microsyringe was ejected into methanol $(10 . \mu \mathrm{L})$. Specific solutions of (R)-5 and of propionic anhydride/ $N, N$-diisopropylethylamine used per entry, as well as specific volumes for all stock solutions, are outlined in each study utilizing these solutions below.

\section{Combinations for Figure 10:}

All entries used 10. $\mu \mathrm{L}$ of each stock solution used.

Entry 1: (R)-5 stock solution 2, the solution of each enantiomer of HBTM, solution 1 of propionic anhydride/ $N, N$-diisopropylethylamine 
Entry 2: $(\boldsymbol{R})$-5 stock solution 3, the solution of each enantiomer of HBTM, solution 1 of propionic anhydride/ $N, N$-diisopropylethylamine

Entry 3: (R)-5 stock solution 4, the solution of each enantiomer of HBTM, solution 1 of propionic anhydride/ $N, N$-diisopropylethylamine

Entry 4: (R)-5 stock solution 5, the solution of each enantiomer of HBTM, solution 1 of propionic anhydride/ $N, N$-diisopropylethylamine

\section{TLC Analysis}

To a TLC plate with 2 lanes was spotted the $R$-HBTM reaction $(4.0 \mu \mathrm{L})$, and the $S$-HBTM reaction $(4.0 \mu \mathrm{L})$ via micropipette. The plate was run $(30 \%$ ethyl acetate in hexanes), dried, stained (PMA), heated by oven $\left(160^{\circ} \mathrm{C}, \sim 1 \mathrm{~min}\right)$, and photographed.

\section{Purposeful Error in Microsyringe Volumes}

All entries display a clear qualitative assessment of the fast reaction as the $S$-HBTM reaction despite both positive and negative variations of $5 \mu \mathrm{L}$ from the standard volumes of carbinol solution 1, HBTM solutions, and anhydride/base solution 1 (Figure SI.8). This data supports the reliability of the $10 \mu \mathrm{L}$ measurement for each stock solution and displaces concern about a misguided conclusion based on minor differences in volume pulled from stock solutions. 

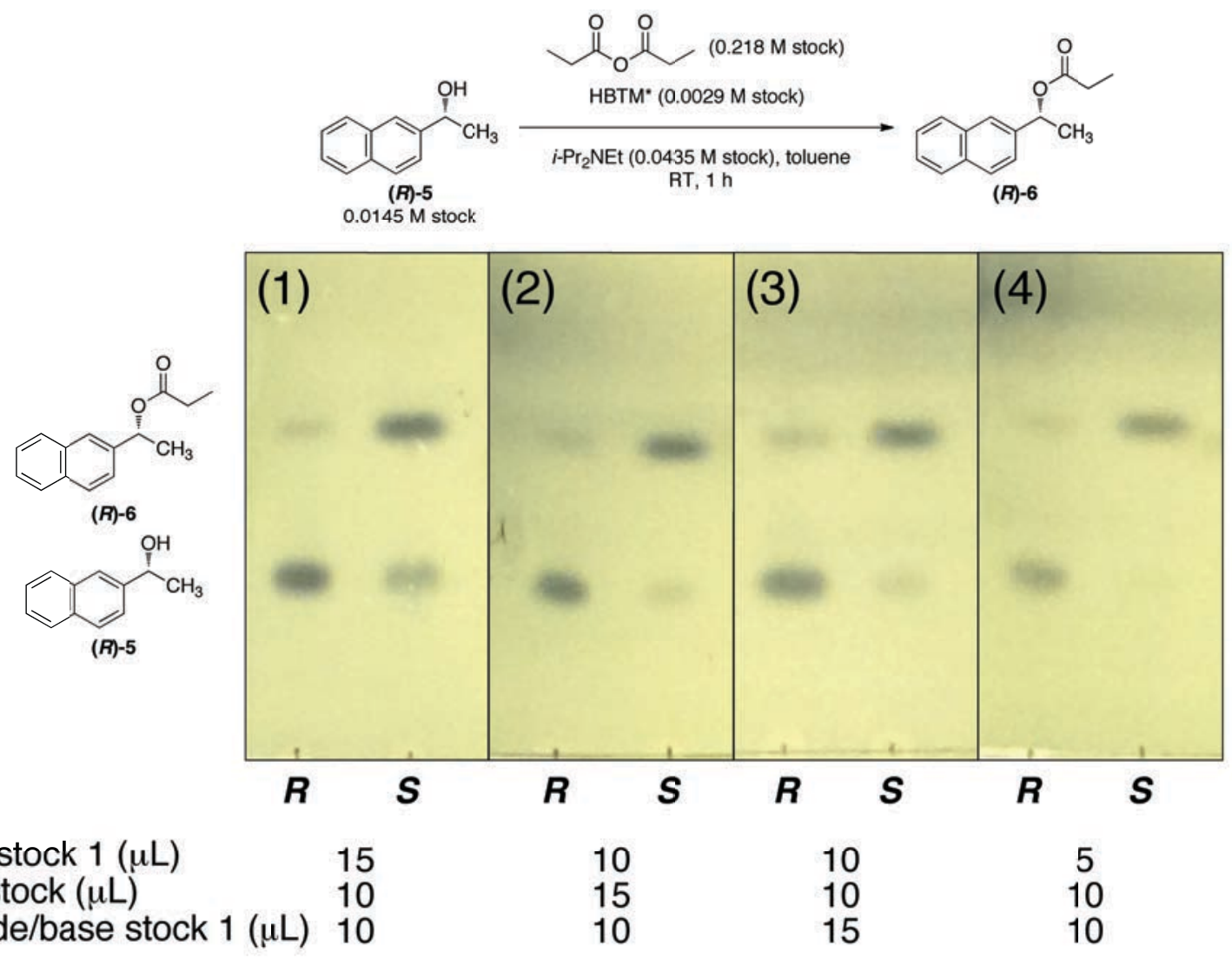

alcohol stock $1(\mu \mathrm{L})$

HBTM stock $(\mu \mathrm{L})$

10

10

(8)


alcohol stock $1(\mu \mathrm{L})$

HBTM stock $(\mu \mathrm{L})$

anhydride/base stock $1(\mu \mathrm{L}) \quad 10$

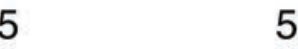

5
10

5

10

5
10

10

10

5

Figure SI.8. Variation of volume utilized from (R)-5 solution 1, HBTM solutions, and anhydride/base solution 1. The left lane of each TLC plate contains $R$-HBTM and the right lane contains $S$-HBTM. Plates were eluted in $30 \%$ ethyl acetate in hexanes. Visualization was achieved by staining with PMA stain 


\section{Studies on Effect of Base Equivalents}

All entries display clear qualitative assessment of the fast reaction as the $S$-HBTM reaction and no noticeable qualitative difference in reaction progress, providing supporting evidence that reaction progress is independent of base concentration (Figure SI.9). Based on this outcome, the equivalents of base was set at five relative to the standard carbinol concentration of $0.0145 \mathrm{M}$ for future experiments in order to assure an excess of base for a wider substrate scope.



Figure SI.9. Variation of equivalents of base utilized from anhydride/base solutions 1, 2 and 3. The left lane of each TLC plate contains $R$-HBTM and the right lane contains $S$-HBTM. Plates were eluted in $30 \%$ ethyl acetate in hexanes. Visualization was achieved by staining with PMA stain. 